IZA DP No. 8700

The Causal Effect of Unemployment Duration on Wages: Evidence from Unemployment Insurance Extensions

Johannes F. Schmieder

Till von Wachter

Stefan Bender

December 2014 


\title{
The Causal Effect of Unemployment Duration on Wages: Evidence from Unemployment Insurance Extensions
}

\author{
Johannes F. Schmieder \\ Boston University, \\ NBER and IZA \\ Till von Wachter \\ University of California, Los Angeles, \\ NBER, CEPR and IZA \\ Stefan Bender \\ Institute for Employment Research (IAB)
}

Discussion Paper No. 8700

December 2014

\author{
IZA \\ P.O. Box 7240 \\ 53072 Bonn \\ Germany \\ Phone: +49-228-3894-0 \\ Fax: +49-228-3894-180 \\ E-mail: iza@iza.org
}

Any opinions expressed here are those of the author(s) and not those of IZA. Research published in this series may include views on policy, but the institute itself takes no institutional policy positions. The IZA research network is committed to the IZA Guiding Principles of Research Integrity.

The Institute for the Study of Labor (IZA) in Bonn is a local and virtual international research center and a place of communication between science, politics and business. IZA is an independent nonprofit organization supported by Deutsche Post Foundation. The center is associated with the University of Bonn and offers a stimulating research environment through its international network, workshops and conferences, data service, project support, research visits and doctoral program. IZA engages in (i) original and internationally competitive research in all fields of labor economics, (ii) development of policy concepts, and (iii) dissemination of research results and concepts to the interested public.

IZA Discussion Papers often represent preliminary work and are circulated to encourage discussion. Citation of such a paper should account for its provisional character. A revised version may be available directly from the author. 


\section{ABSTRACT \\ The Causal Effect of Unemployment Duration on Wages: Evidence from Unemployment Insurance Extensions ${ }^{\star}$}

This paper estimates the causal effect of long-term unemployment on wages. Job search theory implies that if Unemployment Insurance (UI) extensions do not affect wages conditional on the month of unemployment exit, then reservation wages do not bind on average. Then, $\mathrm{UI}$ extensions affect mean wages only through unemployment durations and are valid instrumental variables (IV). Using a regression discontinuity design, we find that UI extensions in Germany reduced job searchers' reemployment wages on average, but did not affect wages conditional on unemployment duration. Resulting IV estimates imply substantial negative effects of unemployment duration on wages of $0.8 \%$ per month.

JEL Classification: J64, J65

Keywords: long-term unemployment, wage losses, unemployment insurance

Corresponding author:

Till von Wachter

Department of Economics

University of California Los Angeles

8283 Bunche Hall

MC 147703

Los Angeles, CA 90095

USA

E-mail: tvwachter@econ.ucla.edu

\footnotetext{
"We would like to thank David Card, Kyle Herkenhoff, Larry Katz, Pat Kline, Kevin Lang, Rafael Lalive, Claudia Olivetti, Daniele Paserman, Luigi Pistaferri, Robert Shimer, Fabien Postel-Vinay, Albert YungHsu Liu, as well as seminar participants at Boston University, the University of Chicago, Stanford, the ETH Zurich, Princeton University, Northwestern University, Northeastern University, Ohio State University, University of California Los Angeles, University of California Riverside, the Atlanta FRB, the Minnesota FRB, the NY FRB, the American Economic Association Meetings, the Society of Labor Economics, and the NBER Labor Studies meeting for helpful comments on this project. Johannes Schmieder gratefully acknowledges funding from the 2011 Scholars Program of the Department of Labor. All errors are our own.
} 


\section{Introduction}

At the peak of the Great Recession, long-term unemployment (unemployment spells lasting more than one year) in the United States rose to a historical 4.5 million individuals, and stands at about 2 million in mid-2014. In many European countries, long-term unemployment has been a persistent feature of labor markets since at least the early 1980s. There is an increasing concern among policy makers and academics about the costs of rising unemployment durations for individuals and families, as well as for the labor market and the economy as a whole (e.g., Bernanke 2012, Yellen 2014). ${ }^{1}$ However, there are few causal estimates of the effect of unemployment duration on wages, earnings, or other outcomes. ${ }^{2}$ This makes it not only difficult to assess the costs of long-term unemployment, but also difficult to choose policies at both the micro and the macro level. ${ }^{3}$ For example, if nonemployment durations decrease reemployment wages, extensions in unemployment insurance (UI) durations - the largest government program geared towards job losers in recessions - may hurt the prospects of job losers rather than helping them to obtain better job matches.

We use the term 'the causal effect of unemployment durations on job outcomes' to describe how rising unemployment durations harm the job prospects of unemployed workers. An individual who is unemployed longer may receive different job offers the longer the duration of unemployment, e.g., because of skill depreciation or stigma. Thus the worker will effectively face different labor demand solely due to the fact that she has been out of work longer. In addition the worker may accept different jobs the longer she is unemployed (she may have a declining reservation wage), effectively constituting a labor supply response. We define the 'causal effect of unemployment duration' as the change in reemployment wages that comes only

\footnotetext{
${ }^{1}$ It is widely thought that long unemployment durations can lower reemployment wages and other job outcomes of workers via depreciation of skills or because of stigma (e.g., Acemoglu 1995, Machin and Manning 1999). As a result, long-term unemployment can affect the aggregate labor market and economic recovery (e.g., Pissarides 1992, Ljungqvist and Sargent 2008, Ball 2009).

${ }^{2}$ We found essentially no studies estimating the effect of long-term unemployment on any outcome using quasi-experimental variation or within-spell variation from panels. This is reflected in Bernanke (2012) and Yellen (2014), who do not cite a single empirical study in support of the claim that unemployment duration is costly. As discussed below, several studies estimate the depreciation of human capital as one of several parameters in models of life-cycle earnings.

${ }^{3}$ Several papers show that the degree of skill depreciation affects the optimal policy mix at the micro level (e.g., Shimer and Werning 2006, Pavoni and Violante 2007, Pavoni 2009). Moreover, the speed and sources of wage loss with unemployment duration have important implications for the potential usefulness of both fiscal and monetary policy over the short and longer run.
} 
from the labor demand side, holding job acceptance decisions (labor supply) constant. This change in the wage offer distribution throughout the unemployment spell is an important parameter as it describes how quickly the job prospects of the unemployed are declining, independent of their own decisions. ${ }^{4}$

Existing estimates suggest that the cost of a widespread rise of unemployment duration could indeed be very large. ${ }^{5}$ However, these estimates potentially overstate the effect of unemployment duration on job outcomes for two reasons. A common concern is that workers with longer nonemployment durations also have other, potentially unobserved characteristics that make them hard to employ and lower their wages. Furthermore one would expect that any exogenous manipulation that affects nonemployment durations would also lead to changes in which jobs are accepted by the unemployed. As a result, even estimates free of selection generally recover a combination of effects arising from the individual's labor supply response (e.g., a change in reservation wages) and a decline in wage offers in response to longer unemployment durations (what we call the causal effect on wages) and are thus hard to interpret.

In this paper, we provide the first quasi-experimental estimates of the causal effect of unemployment duration on wage offers. These estimates are free of selection and of effects from changes in the reservation wage, and hence reflect true shifts in the wage offer distribution. We begin by laying out a conceptual framework based on the canonical partial-equilibrium model of job search in which both unemployment duration and reemployment wages are endogenous, which we augment with worker heterogeneity. A classic prediction from the model is that if workers value their outside option, a rise in potential UI durations leads to a decline in job search intensity and a rise in reservation wages. A key insight we exploit is that one can learn about the behavior of reservation wages from observed reemployment wages at different unemployment durations. In particular, we show that if the path of observed reemployment wages does not shift outward in response to a rise in UI durations, this implies that reservation

\footnotetext{
${ }^{4}$ The duration of unemployment is an endogenous variable, determined by individuals' search effort and job acceptance decisions as well as random arrivals of job offers. As in any instrumental variables setting, we identify the effect of the endogenous choice variable (unemploment duration) that results from exogenous variation. Below, we derive the mathematical formula for the treatment effect we obtain.

${ }^{5}$ Violante and Pavoni (2007) put consensus estimates from structural models (e.g., Keane and Wolpin 1997) and regression studies (e.g., Addison and Portugal 1989) at 16-23\% wage loss per year. For 3.2 million workers with unemployment spells longer than one year that implies a loss of over $\$ 30$ Billion at median earnings. This loss is understated since many individuals have unemployment spells longer than one year, and skill depreciation is usually specified linearly, implying losses for the many unemployment spells lasting below one year as well.
} 
wages do not bind, at least in the part of the wage offer distribution relevant for workers' employment decisions.

If the condition on reemployment wages is satisfied in the data, the only effect of nonemployment durations on wages must arise from a change in the wage-offer distribution over the duration of unemployment. We derive an expression of the resulting instrumental variables (IV) estimator, show that it obtains a local average treatment effect of unemployment duration on wages for individuals whose nonemployment duration responds to the UI extension, and derive an estimable expression of the corresponding weighting function. To gain further insights on the potential role of reservation wages, which are likely to affect the lower tail of accepted wages, we also extend our approach to estimate the average effect of nonemployment duration throughout the wage distribution. Based on the theory, we derive bounds for the causal effect of nonemployment duration on wages in case the condition on reemployment wages does not hold and instead reservation wages do seem to affect job prospects in response to UI extensions.

We implement our conceptual framework using quasi-experimental variation and data from Germany, which has several features that are ideal for our purposes. During the 1980s, UI durations for middle aged workers in Germany were a step function of exact age at benefit claiming, such that the causal effect of UI durations on job outcomes can be estimated using a regression discontinuity design. A key feature of the German environment is that we have access to the universe of social security records with information on day-to-day nonemployment spells, exact dates of birth, as well as a broad range of worker and job characteristics. The large samples and precisely measured unemployment and earnings information turn out to be crucial for estimating the effect of nonemployment durations on wages. ${ }^{6}$

We obtain three main findings. First, we find small but precisely estimated negative effects of UI extensions on wages, job duration, and other job outcomes of middle aged workers, such as the probability of full-time work and working in the same industry and occupation. Second,

\footnotetext{
${ }^{6}$ Similar data is currently not available for the United States, because administrative data do not measure exact unemployment and job durations, and samples from survey data are too small. During the period we study, the incidence of long unemployment spells and effect of UI extensions on unemployment duration in Germany were similar to comparable estimates for the United States (Schmieder, von Wachter, and Bender 2012a); the size and structure of wage losses of job losers were similar as in the United States (Schmieder, von Wachter, and Bender 2009); it is well known that the structure of earnings in the United States and Germany is similar as well.
} 
we show that the path of average reemployment wages at different nonemployment durations does not shift, implying that reservation wages do not bind in our setting. As a result, reservation wages do not contribute to declining wages over the nonemployment spell, and one can use UI extensions as valid manipulation of nonemployment durations. Third, we obtain IV estimates of the causal effect of nonemployment durations on wage offers. We find that for each additional month in nonemployment duration, average daily wages decline by a bit less than one percent. These results are robust to bounds resulting from small effects of reservation wages consistent with our wage data. If one extrapolates linearly over the course of six months, this effect can explain about a third of the average wage loss of unemployed workers. This effect fades after people have been on a job for a few years and is statistically indistinguishable from zero after five years. The wage decline can arise from multiple sources, including skill depreciation, stigma effects, or changes in job characteristics, something we address explicitly in our empirical analysis.

Our paper is related to several strands of literature. Foremost, it presents both a framework for obtaining causal estimates of the effect of nonemployment durations on wage offers, and a new set of causal estimates, neither of which is currently available in the literature. Existing estimates of wage effects are typically based on cross-sectional analyses of nonemployment durations and wages (e.g., Addison and Portugal 1989), or derived from structural models (e.g., Keane and Wolpin 1997). ${ }^{7}$ While our ordinary-least squares estimates are of similar magnitude as in the existing literature, our IV estimates are about two-thirds to a half of the basic correlation, suggesting a potential role of negative selection in standard estimates. In a recent paper, using an audit study Kroft, Lange, and Notowidigdo (2013) provided experimental evidence showing that there is a negative causal effect of nonemployment durations on call back rates for job interviews. Our paper extends these findings by studying the effect of unemployment on other key outcomes of the employment process, wages and job outcomes, which are harder to analyze in the context of an audit study because they inherently depend on the actual employment decision.

The parameter we estimate is important for policy. Our findings can be used to assess with more confidence the potential cost of rising unenmployment durations for middle aged

\footnotetext{
${ }^{7}$ In an exception, Edin and Gustavsson (2008) document a significant negative effect of nonemployment spells on direct measures of skills in Sweden. Estimates of the earnings losses of displaced workers have also been used to infer the correlation of nonemployment duration and wages (e.g., Neal 1995).
} 
workers. Since we show that our IV estimate puts weight on all workers exiting unemployment from one to 18 months, our results suggest that even shorter increases in unemployment duration may be costly. Our estimates can be used to calibrate models in macroeconomics or in public finance in which the causal effect of nonemployment plays an important role. In public finance, a growing theoretical literature shows how the optimal structure of labor market policies depends on the degree of wage decline with nonemployment. For example, Pavoni and Violante (2007) show that this parameter plays a key role when multiple labor market policies are chosen jointly. In macroeconomics, a series of papers by Ljungqvist and Sargent (2008) argues that skill depreciation in conjunction with generous UI benefits has led to rising unemployment rates in Europe in the 1980s. For the 2008 recession in the U.S., Katz, Kroft, Lange, and Notowidigdo (2013) argue that negative duration dependence may explain part of the lasting rise in long-term unemployment. In an extension of our main findings, we show that the effect of unemployment durations on wages appears to be larger in recessionary environments. Hence, a negative causal effect of nonemployment duration on wage offers may indeed be a reason for this duration dependence.

Our findings also relate to the literature examining the properties and effects of reservation wages. Most of the literature is based on survey evidence of reservation wages (e.g., Feldstein and Poterba 1984, Blau and Robins 1986, DellaVigna and Paserman 2005, Krueger and Mueller 2011, 2014). In contrast, here we show that it is possible to infer about the effect of and changes in reservation wages directly when quasi-experimental variation of workers' outside option is available. As in many other areas of economics, such a revealed-preference approach allows one to side step important measurement issues and hence provides an important complement to analyses of stated preferences. This is in a similar spirit as Hornstein, Violante, and Krueger (2011), who infer about reservation wages using data on worker flows, and who find, consistent with our results, that in a broad range of search models unemployed workers' must place a low value on their outside option. ${ }^{8}$ The best recent evidence on reser-

\footnotetext{
${ }^{8}$ Lalive, Landais, and Zweimueller (2013) replicate our approach of analyzing reemployment wage paths for Austria and find similar results. In contrast to our findings, and findings by both Card, Chetty, and Weber (2007a) and Lalive, Landais, and Zweimueller (2013) for Austria, Nekoei and Weber (2013) find a larger spike in wages at UI exhaustion that induces a slight positive overall effect of UI extensions on wages. This may be related to the fact that the UI extensions studied by Nekoei and Weber occur much earlier in the spell where individuals may be more responsive. Hagedorn, et al. (2013) show some estimates of the effects of UI extensions on wages of continuously employed individuals comparing neighboring counties in the US and find positive effects.
} 
vation wages comes from Krueger and Mueller (2014), who find that while reservation wages appear to influence employment decisions among UI recipients in New Jersey, reservation wages are unaffected by unemployment duration and UI exhaustion. Hence, as in our setting, changes in reservation wages are unlikely to be responsible for reductions in reemployment wages over the unemployment spell.

Our paper also adds to the literature estimating the effect of UI benefits on nonemployment durations and job outcomes. While a substantial body of research has documented the disincentive effect of UI benefits (for example, Moffitt 1985; Katz and Meyer 1990; Meyer 1990; Rothstein 2011, Kroft and Notowidigdo 2012, Schmieder, von Wachter, and Bender 2012a,b, Farber and Valletta 2013), a much smaller literature has found mixed results regarding the effects on wages and other job outcomes based on research designs using observational studies (e.g., Addison and Blackburn 2000). More recent studies by Lalive (2007), Card, Chetty and Weber (2007a), and Centeno and Novo (2009) used regression discontinuity designs to more clearly identify the effects and find negative impacts on wages. While these results are relatively imprecisely estimated and hence not statistically significantly different from zero, confidence intervals contain possible negative and positive values that are economically meaningful. ${ }^{9}$ In addition to providing more precise estimates, partly due to larger sample sizes, the conceptual framework in this paper also allows an empirical assessment of the sources behind the wage effects of UI extensions.

\section{Theory}

We use a discrete time, non-stationary search model (e.g. van den Berg 1990) to derive our main findings in three steps. First, we show how the effect of UI extensions on reemployment wages can be decomposed into changes in reservation wages and changes in the wage offer distribution over the nonemployment spell. ${ }^{10}$ Second, we use the model to show how the effect of UI extensions on the reemployment wage path (i.e., reemployment wages conditional

\footnotetext{
${ }^{9}$ Consistent with a negative effect of nonemployment durations, Black, Smith, Berger and Noel (2003) find positive effects on reemployment and quarterly earnings of UI recipients who are randomly assigned to (but not necessarily participate in) more intensive job search services. Meyer (1995) reports imprecisely estimated positive effects on earnings for UI recipients who receive a bonus upon faster reemployment. Degen and Lalive (2013) find negative earnings effects from a reduction in potential UI benefit durations in Switzerland in a difference-in-difference design.

${ }^{10}$ For an early insightful discussion of these issues, see Addison and Portugal (1989).
} 
on the time of exiting unemployment) can be used to infer about the response of reservation wages to UI extensions. Third, we show that if the reemployment wage path is unaffected, it is possible to identify the average change in the wage offer distribution over the nonemployment spell - and hence the causal effect of nonemployment durations on wages - using UI extensions as a source of exogenous variation.

\subsection{Setup of Model}

Workers become unemployed in period $t=0$, are risk neutral and maximize the present discounted value of income. In each period workers receive UI benefits $b_{t}$ and choose search intensity $\lambda_{t}$, which is normalized to be equal to the probability of receiving a job offer in that period. Without loss of generality we focus on the case of a two-tiered UI system, where UI benefits are at a constant level $b$ up to the maximum potential duration of receiving UI benefits $P$. After benefit exhaustion, individuals receive a second tier of payments indefinitely, so that $b_{t}=b$ for all $t \leq P$ and $b_{t}=\underline{b}$ for all $t>P$. The cost of job search $\psi\left(\lambda_{t}\right)$ is an increasing, convex and twice differentiable function.

Jobs offer a wage $w_{t}^{*}$ and wage offers are drawn from a distribution with cumulative distribution function $F\left(w^{*} ; \mu_{t}\right)$, which may vary with the duration of unemployment $t$, for example due to skill depreciation or stigma. To simplify the exposition we assume that the distribution can be summarized by its mean in period $t: \mu_{t}{ }^{11}$ In this case we can write $w_{t}^{*}=\mu_{t}+u_{t}$, where $E\left[u_{t} \mid t\right]=0$ such that $u_{t}$ reflect random draws from the wage offer distribution. If a job is accepted, the worker starts working at the beginning of the next period and stays at that job forever. Optimal search behavior of the worker is described by a search effort path $\lambda_{t}$ and a reservation wage path $\phi_{t}$, so that all wage offers $w_{t}^{*} \geq \phi_{t}$ are accepted. In the appendix we provide details on the value functions, the first order conditions, as well as the derivations for the following results.

\subsection{The Causal Effect of Unemployment Durations on Wages}

Since unemployment duration is a choice variable in the model, it is useful to explicitly define what we mean by its causal effect. Given our set up, the expected wage of an individual exiting

\footnotetext{
${ }^{11}$ This is easily generalizable to more flexible distribution functions characterized by a vector of parameters $\mu_{\mathrm{t}}$.
} 
unemployment in month $t$ is $w^{e}(t ; P)=\frac{\int_{\phi_{t}}^{\infty} w^{*} d F\left(w^{*} ; \mu_{t}\right)}{1-F\left(\phi_{t}\right)}$, which given the above assumptions can be written as: $w^{e}\left(\phi_{t}, \mu_{t}\right) \equiv w^{e}(t ; P)=\mu_{t}+E\left[u_{t} \mid u_{t} \geq \phi_{t}(P)-\mu_{t}\right]$. Note that the change in $w^{e}(t ; P)$ over time can be either due to changes in $\phi_{t}$ or due to changes in $\mu_{t}$. Using this notation, we define the slope of the reemployment wage path as the total (right) derivative of the reemployment wage with respect to unemployment duration: ${ }^{12}$

$$
\frac{d w^{e}(t ; P)}{d t}=\frac{\partial w^{e}\left(\phi_{t}, \mu_{t}\right)}{\partial \phi_{t}} \frac{\partial \phi_{t}}{\partial t}+\frac{\partial w^{e}\left(\phi_{t}, \mu_{t}\right)}{\partial \mu_{t}} \frac{\partial \mu_{t}}{\partial t}
$$

Based on this we can provide a precise definition of the causal effect of unemployment duration on wages as the part of the slope of the reemployment wage path that is due to changes in the wage offer distribution over time:

$$
\frac{\partial w^{e}\left(\phi_{t}, \mu_{t}\right)}{\partial \mu_{t}} \frac{\partial \mu_{t}}{\partial t}
$$

The causal effect of unemployment duration on wages is thus the change in expected reemployment wages that would result from exogenously increasing unemployment duration by one month while holding the reservation wage constant over time. Note that if the reservation wage is not binding at $t$, i.e., $F\left(\phi_{t}\right)=0$, then $w^{e}\left(\phi_{t}, \mu_{t}\right)=\mu_{t}$ and $\frac{\partial w^{e}\left(\phi_{t}, \mu_{t}\right)}{\partial \mu_{t}} \frac{\partial \mu_{t}}{\partial t}=\frac{\partial \mu_{t}}{\partial t}$, that is the causal effect of unemployment duration on the reemployment wage is simply the change in mean offered wages over time. We will argue below that this seems plausible in the light of our empirical results. Therefore, for simplicity, we will alternatively refer to $\frac{\partial w^{e}\left(\phi_{t}, \mu_{t}\right)}{\partial \mu_{t}} \frac{\partial \mu_{t}}{\partial t}$ in (2) as the causal effect of nonemployment durations on wages or as the change in the wage offer distribution in the rest of the paper.

Regressing $w$ on unemployment durations $t$ using OLS will not result in a meaningful parameter for two reasons: First, since the duration of unemployment $t$ itself is determined by the search intensity and reservation wage of an individual, both $t$ and $w$ are affected by

\footnotetext{
${ }^{12}$ Our model is a discrete model in time, but for the following the notation will be simpler if we can work with time derivatives. In the model only the values of $\phi_{t}, \mu_{t}$ and $w^{e}(t, P)$ at discrete values of time $\{0,1,2, \ldots\}$ are necessary to describe the relevant environment for an individual and the optimal search strategy. Without loss of generality we can therefore define the values of $\phi_{t}, \mu_{t}$ and $w^{e}(t, P)$ for the time values between these discrete values such that they are linear between the discrete points. For example for $0<t<1$ let $w^{e}(t, P)$ be defined as: $w(0)+[w(1)-w(0)] t$. This means that $\phi_{t}, \mu_{t}$ and $w^{e}(t, P)$ are piecewise linear, with kinks at the integer values. All time derivatives below are right derivatives so that by construction we have that: $\frac{d f(t)}{d t}=f(t+1)-f(t)$, where $f(t)$ is any function $\phi_{t}, \mu_{t}, w^{e}(t, P)$.
} 
individual characteristics (such as human capital) and the correlation between the error term of the wage equation and $t$ leads to the standard omitted variable bias in the estimate of the slope of the reemployment wage path $\frac{d w^{e}(t ; P)}{d t}$. Second, even if we could fully condition on individual heterogeneity, due to changes in reservation wages over the spell we would obtain an estimate of (1) but not of the causal effect of unemployment duration on wages as defined in $(2)$.

\subsection{The Effect of Increasing Potential UI Durations on Wages}

To simplify the exposition we will first analyze the model under the additional assumption that workers are homogeneous and that the expected reemployment wage is a linear function of unemployment duration: $w^{e}(t ; P)=\xi+\frac{d w^{e}(t ; P)}{d t} t$, where we assume that $\frac{d w^{e}(t ; P)}{d t}$ is a constant. Below we will show that our result generalizes to the nonlinear case with heterogenous workers.

The expected reemployment wage of an individual at the start of the nonemployment spell can be calculated by integrating the reemployment wage conditional on exiting unemployment at $t$ over the distribution of nonemployment durations. In particular, if $g(t)$ is the probability mass function of the nonemployment distribution, we have that $E\left[w^{e}(t ; P)\right]=$ $\sum_{0}^{\infty} w^{e}(t ; P) g(t)$. An extension in potential UI durations $P$ affects the expected reemployment wage through two components:

$$
\frac{d E\left[w^{e}(t ; P)\right]}{d P}=\sum_{t=0}^{\infty}\left[\frac{\partial w^{e}(t, P)}{\partial P} g(t)\right]+\sum_{0}^{\infty}\left[w^{e}(t, P) \frac{\partial g(t)}{\partial P}\right]
$$

The first term $E\left[\frac{\partial w^{e}(t, P)}{\partial P}\right]=\sum_{t=0}^{\infty}\left[\frac{\partial w^{e}(t, P)}{\partial P} g(t)\right]$ represents the average (weighted by the distribution of nonemployment durations) shift in the reemployment wage path that is caused by the benefit extension. The second term is due to the shift in the distribution of nonemployment durations along the reemployment wage path. Note that the expected nonemployment duration is $D=\sum_{t=0}^{\infty}[t g(t)]$ and the effect of extending UI benefits is: $\frac{d D}{d P}=\sum_{t=0}^{\infty}\left[t \frac{d g(t)}{d P}\right]$. Given our assumption of linearity for $w^{e}(t ; P)$, Equation $(3)$ can then be written as:

$$
\frac{d E\left[w^{e}(t ; P)\right]}{d P}=E\left[\frac{\partial w^{e}(t, P)}{\partial P}\right]+\frac{d w^{e}(t ; P)}{d t} \frac{d D}{d P}
$$

where $\frac{d D}{d P}$ is the marginal effect of an increase in $P$ on the expected non-employment duration 
$D$. This formula holds independently from our model and shows how in general the reemployment wage effect can be decomposed into shifts of the reemployment wage path and movement along the reemployment wage path due to increases in nonemployment durations.

While the decomposition in equation (4) is mechanical, results from the search model provide key insights into how changes in the outside option (in this case UI durations) affect wages. Combining equations (4) and (1) it follows that the reemployment wage effect can then be written as a combination of the reservation wage effect and the change in the wage offer distribution over time:

$$
\frac{d E\left[w^{e}(t ; P)\right]}{d P}=E\left[\frac{\partial w^{e}\left(\phi_{t}, \mu_{t}\right)}{\partial \phi_{t}} \frac{\partial \phi_{t}}{\partial P}\right]+\left[\frac{\partial w^{e}\left(\phi_{t}, \mu_{t}\right)}{\partial \phi_{t}} \frac{\partial \phi_{t}}{\partial t}+\frac{\partial w^{e}\left(\phi_{t}, \mu_{t}\right)}{\partial \mu_{t}} \frac{\partial \mu_{t}}{\partial t}\right] \frac{d D}{d P}
$$

where $E[$.$] again takes the expectation over nonemployment durations. The reservation wage$ response affects the reemployment wage in two ways: through a shift in the reservation wage and through movements along the reservation wage path. A key implication of equation (5) is

that in order to identify the causal effect of unemployment duration on wages $\left(\frac{\partial w^{e}\left(\phi_{t}, \mu_{t}\right)}{\partial \mu_{t}} \frac{\partial \mu_{t}}{\partial t}\right)$ it is necessary to isolate it from these two reservation wage effects. Direct estimates of the effect of UI extensions (or other changes in the outside options) capture all three components.

A final point of equation (5) is that the sign of the effect of extending UI benefits on the reemployment wage is ambiguous, reflecting the contrasting hypotheses about the effect of UI mentioned in the introduction: The first component - due to an upward shift in the reservation wage - will tend to increase the reemployment wage. The second component longer nonemployment durations leading to more job offers drawn from a different wage offer distribution with lower reservation wages - will tend to decrease the reemployment wage.

\subsection{Estimating the Causal Effect of Nonemployment Durations on Wages}

The search model has clear implications how reservation wages change with UI durations and over the nonemployment spell. Hence, to obtain an estimate of the effect of nonemployment durations on the wage offer distribution, we need to infer about the effect of reservation wages on reemployment wages conditional on exiting at time $t, \frac{\partial w^{e}\left(\phi_{t}, \mu_{t}\right)}{\partial \phi_{t}}$. If $\frac{\partial w^{e}\left(\phi_{t}, \mu_{t}\right)}{\partial \phi_{t}}=0$, i.e., if reservation wages do not bind, then we can estimate the causal effect of nonemployment duration on wages directly from equation (5). 
To learn about $\frac{\partial w^{e}\left(\phi_{t}, \mu_{t}\right)}{\partial \phi_{t}}$ we can exploit the fact that in a search model the response of the reemployment wage at any nonemployment duration to increases in UI duration (i.e., shifts in the reemployment wage path) is directly dependent on shifts in the reservation wage:

$$
\frac{\partial w^{e}(t, P)}{\partial P}=\frac{\partial w^{e}\left(\phi_{t}, \mu_{t}\right)}{\partial \phi_{t}} \frac{\partial \phi_{t}}{\partial P}=\frac{\partial w^{e}\left(\phi_{t}, \mu_{t}\right)}{\partial \phi_{t}} \frac{d V_{t}^{u}}{d P} \rho
$$

Rearranging this, one can see that the response in the path of reemployment wages to UI extensions can be used to infer about the effect of reservation wages on accepted wages: $\frac{\partial w^{e}\left(\phi_{t}, \mu_{t}\right)}{\partial \phi_{t}}=\frac{\partial w^{e}(t, P)}{\partial P} /\left(\frac{d V_{t}^{u}}{d P} \rho\right) \cdot{ }^{13}$ This holds as long as $\frac{d V_{t}^{u}}{d P}$ is not equal to 0, i.e. as long as the UI extension does in fact affect the value of the outside option. Yet, the valuation of the outside option is a key determinant of the hazard rate of exiting unemployment $\frac{d h_{t}}{d P} \cdot{ }^{14}$ This leads to a straightforward test for whether or not reservation wages affect reemployment wages. If the exit hazard is changing $\left(\frac{d h_{t}}{d P}<0\right)$ and there is no effect of UI durations on reemployment wages $\left(\frac{\partial w^{e}(t, P)}{\partial P}=0\right)$, then changes in the reservation wage do not affect reemployment wages.

Note that if reservation wages do not affect reemployment wages, then an increase in UI durations affects wages only through a rise in nonemployment durations and a corresponding decline in wage offers (the third term in equation 5). In this case, UI extensions satisfy all conditions of a valid instrumental variable. From equation (5), the causal effect of nonemployment durations on wages is simply the ratio between the effect of UI extensions on the average wage and the effect of UI extensions on nonemployment durations, which is the formula of the standard IV estimator. In other words, if the conditions on the reemployment hazard and the path of reemployment wages hold, then the change in the wage offer distribution can be estimated by regressing wages on nonemployment durations using UI extensions as an instrument.

Note that the result that the reemployment wage path does not shift in response to UI extensions does not necessarily imply that the reservation wage is not binding for the entire wage distribution. In the Web Appendix we show that all that is required for our empirical

\footnotetext{
${ }^{13}$ Note that we have implicitly assumed that there is no direct effect of UI extensions on the wage offer distribution itself, i.e., $\frac{\partial \mu_{t}}{\partial P}=0$. This would fail for example if firms set wages taking a worker's outside option into account, in which case $\frac{\partial \mu_{t}}{\partial P}>0$. However as long as wage offers respond weakly positive to the value of the outside option $\frac{\partial \mu_{t}}{\partial P} \geq 0$ our approach is robust: $\frac{\partial w^{e}(t, P)}{\partial P}=\frac{\partial w^{e}(t, P)}{\partial \phi_{t}} \frac{d V_{t}^{u}}{d P} \rho+\frac{\partial w^{e}(t, P)}{\partial \mu_{t}} \frac{\partial \mu_{t}}{\partial P}$. Since both terms on the right hand side are weakly positive, if $\frac{\partial w^{e}(t, P)}{\partial P}=0$ and $\frac{d V_{t}^{u}}{d P}$ this implies that $\frac{\partial \mu_{t}}{\partial P}=0$ and $\frac{\partial w^{e}(t ; P)}{\partial \phi_{t}}=0$. $14 \frac{d h_{t}}{d P}=-\frac{d V_{t+1}^{u}}{d P}\left[\frac{\left(1-F_{t}\left(\phi_{t}\right)\right)^{2}}{(1+\rho) \psi^{\prime \prime}\left(\lambda_{t}\right)}+\rho \lambda_{t} f\left(\phi_{t}\right)\right]$, where the part in the brackets is positive.
} 
strategy to hold is that for small changes reservation wages have no effect locally in the distribution. This can be the case if for example the wage offer distribution is bimodal, with a mode for very low wage jobs, and a mode for higher wage jobs, with little density in between. If the reservation wage lies in between two modes - as is likely to be realistic in our empirical application of middle aged workers with high labor force attachment - then reservation wages are binding, but small changes therein will not affect the mean of accepted wages. ${ }^{15}$

\subsection{Heterogeneity and Nonlinearity}

The results generalize to the case of heterogeneous workers and nonlinear changes in reemployment wage path. Allowing for heterogeneity in our context is important since it makes it clear that our estimates of the effect of UI extensions on the path of reemployment wages may be affected by dynamic selection. As we further discuss in Section 3.3, selection may entail either higher or lower ability individuals searching longer or responding more strongly to UI incentives. In the theory, heterogeneity is purposefully kept completely flexible. In our empirical analysis, we resolve the problem of dynamic selection using our quasi-experimental research design.

Heterogeneity is also important because in its presence our IV estimates will be a weighted average of the individual-specific treatment effects. Moreover, since skill depreciation is not necessarily linear throughout the nonemployment spell, the IV estimates will also be an average over different parts of the potentially nonlinear skill depreciation schedule. To be able to interpret the IV estimate, we derive an expression for the IV estimator and its weighting function.

Let subscripts $i$ denote heterogeneity in terms of the model parameters (such as the cost of job search, the wage offer distribution, preferences, etc.). In the Web Appendix we show that in the presence of heterogeneity and nonlinearity, the effect of UI extensions on average reemployment wages shown in equation (4) can be generalized to:

$$
\frac{d E\left[w_{i}^{e}\left(t_{i}, P\right)\right]}{d P}=E\left[\frac{\partial w_{i}^{e}(t, P)}{\partial P}\right]+\int_{0}^{\infty} E_{i}\left[\frac{\partial w_{i}^{e}(t)}{\partial t} \mid \frac{\partial S_{i}(t)}{\partial P}>0\right] \frac{\frac{\partial S(t)}{\partial P}}{\frac{d D}{d P}} d t \frac{d D}{d P}
$$

\footnotetext{
${ }^{15}$ One can show that if the wage distribution has a range in which workers do not receive wage offers and the reservation wage lies in that range, then our empirical strategy measures the causal effect of nonemployment duration over the effective wage offer distribution, i.e., the part of the distribution above the reservation wage.
} 
where $E_{i}[$.$] is the expectation taken over i$, and $E[$.$] denotes the expectation taken over$ both $i$ and $t$. Equation (7) shows that the basic intuition of equation (4) still holds even in the heterogeneous and nonlinear case. The average effect of extending UI benefits on wages can be decomposed into the shift of reemployment wages conditional on unemployment durations, which depends on the shift in reservation wages, and movement along the reemployment wage path, which depends on the change in reservation wages and wage offers with unemployment duration. The movement along the reemployment wage path can again be expressed as the product of the overall increase in nonemployent durations $\frac{d D}{d P}$ and what is now a weighted average of the individual slopes of the reemployment wage path $\frac{\partial w_{i}^{e}(t)}{\partial t}$. At each nonemployment duration $t$, the average is taken over the (possibly heterogeneous) slope of wages at that nonemployment duration of all individuals whose nonemployment durations are in fact responding to the UI extension. The average slopes at each month $t$ then receive a weight proportional to the overall change in the survivor function in that month.

As in the linear, homogenous case, if the reemployment wage path is not affected by changes in potential UI durations, then we can infer that the reservation wage does not affect reemployment wages. Thus, the second term in equation (7) would reduce to a weighted average of causal effects of nonemployment duration on wages for different individuals at different durations, $\frac{\partial w_{i}^{e}\left(\phi_{i t}, \mu_{i t}\right)}{\partial \mu_{i t}} \frac{\partial \mu_{i t}}{\partial t}$. In this case, we can derive an IV estimator of the causal effect of nonemployment durations on wages. The following proposition states the exact interpretation of this IV estimator for the case that potential UI durations $P$ take on discrete values (as it does in our empirical application):

Proposition 1. Suppose the reservation wage is not binding for all individuals for whom the duration of unemployment is responding to changes in UI durations. If potential UI durations $P$ take on exactly two values $\left(P, P^{\prime}\right)$, then the IV estimand, defined as the ratio of the difference in average wage at two values of the durations instrument, to the difference in average durations at the same two values of the durations instrument,

$$
\beta^{*}=\frac{E\left[w_{i}\left(t, P^{\prime}\right)\right]-E\left[w_{i}(t, P)\right]}{D\left(P^{\prime}\right)-D(P)}
$$


equals the following weighted average of the derivative of the wage function:

$$
\beta^{*}=\int_{0}^{\infty} E\left[\frac{\partial w_{i}^{e}\left(\phi_{i t}, \mu_{i t}\right)}{\partial \mu_{i t}} \frac{\partial \mu_{i t}}{\partial t} \mid t_{i}^{e}\left(P^{\prime}\right)>t>t_{i}^{e}(P)\right] \omega^{*}(t) d t
$$

where the weights

$$
\omega^{*}(t)=\frac{\operatorname{Pr}\left(t<t_{i}^{e}\left(P^{\prime}\right)\right)-\operatorname{Pr}\left(t<t_{i}^{e}(P)\right)}{\int_{0}^{\infty} \operatorname{Pr}\left(t<t_{i}^{e}\left(P^{\prime}\right)\right)-\operatorname{Pr}\left(t<t_{i}^{e}(P)\right) d t}=\frac{S\left(t ; P^{\prime}\right)-S(t ; P)}{D\left(P^{\prime}\right)-D(P)}
$$

are nonnegative and integrate to one.

Proposition 1 states that the IV estimator from a regression of wages on nonemployment durations using UI extensions as an instrument has an interpretation of a local average treatment effect of unemployment durations on wages. The weighting function $\omega^{*}(t)$ is proportional to the differences in survivor functions. The IV estimator puts more weight on those individuals whose nonemployment durations respond more strongly to the instrument (i.e., whose survival functions are shifting). This is akin to the standard result in linear models with heterogeneous parameters (Angrist, Imbens, and Rubin 1996), but is here derived for the general case in which wages may be a nonlinear function of nonemployment durations (Angrist, Graddy, and Imbens 2000). Hence, as in the more standard linear case, the weighting function can be estimated from the data. In the empirical section, we discuss the weighting function, discuss how the IV estimator is affected if the underlying conditions of Propositions 1 fail, and we present bounds for the case in which there are small shifts in the reservation wage path.

\subsection{Empirical Content of Model}

The main results do not depend on the particular model of wage setting. The contribution of the theory is to show that estimating whether the path of reemployment wages is affected by changes in the UI benefit path (or other factors affecting the value of nonemployment), provides a test for the importance of the outside option of unemployed workers in the wage determination process. If reemployment wages conditional on unemployment duration do not respond to changes in the outside option, then the decline of reemployment wages over the unemployment spell can not be due to a response to the the outside option throughout the unemployment spell. Instead, it must be due to a decline of the wage offer distribution over the 
nonemployment spell. For this to be meaningful, individuals must value the outside option, as implied by a change in hazard rates. The theory suggests a straightforward strategy for the empirical work. Another key insight is that using weak additional assumptions implied by the theory, one can estimate the effect of UI extensions on the path of reemployment wages even if the distribution of characteristics throughout the nonemployment spell changes. We will return to our empirical approach after briefly describing the institutional set up.

While we illustrated this insight in a model of wage posting, a symmetric intuition applies in wage bargaining models, where wages should in principle also be affected by the outside option of the unemployed worker. If they are not, then changes in the value of the outside option throughout the unemployment spell should also not have an effect on reemployment wages and thus cannot explain the observed decline in reemployment wages. A similar intuition would hold in a directed search model where workers choose to search for jobs in a segment of the labor market. In such a model wages are affected by the choice of the labor market and the reservation wage when searching in a market. If the wage conditional on unemployment duration does not respond to UI benefit changes, then the choice of which segment to search in is not responding to changes in the outside option and the outside option cannot explain the decline in wages over the unemployment spell.

\section{Institutions, Data and Empirical Methods}

\subsection{Institutional Background}

After working for at least 12 months in the previous three years, workers losing a job through no fault of their own in Germany are eligible for UI benefits that provide a fixed replacement rate of 63 percent for an individual without children. ${ }^{16}$ This paper focuses on the time period between 1987 and 1999, which is the longest period for which the UI system was stable, and during which the maximum duration of benefits was tied to the exact age of the start of benefit receipt and to prior labor force history. Between July 1987 and March 1999, the maximum potential UI duration for workers who were younger than 42 years old was 12 months. ${ }^{17}$ For

\footnotetext{
${ }^{16}$ For individuals with children the replacement rate is 68 percent. There is a cap on earnings insured, but it affects only a small number of recipients. Since they are derived based on net earnings, in Germany UI benefits are not taxed themselves, but can push total income into a higher income tax bracket.

${ }^{17}$ For a description of other cutoffs present in the system and recent reforms, see Schmieder, von Wachter, and Bender (2012a).
} 
workers age 42 to 43 maximum potential UI duration increased to 18 months and for workers age 44 to 48, the maximum duration further rose to 22 months. Workers with lower prior labor force attachment also experienced increases in potential UI durations at the 42 and 44 age cutoffs, albeit smaller. Our main identification strategy is to use the variation in potential UI durations at the age thresholds to analyze unemployment, wages, and the effect of nonemployment duration on wages. ${ }^{18}$

\subsection{Data}

For this paper we have obtained access to the universe of social security records in Germany from 1975 to 2008. The data covers day-to-day information on every instance of employment covered by social security and every receipt of unemployment insurance benefits, as well as corresponding wages and benefit levels. We observe several demographic characteristics, namely gender, education, birth date, nationality, place of residence and work, as well as detailed job characteristics, such as average daily wage, occupation, industry, and characteristics of the employer. ${ }^{19}$

For our analysis sample, we extracted all unemployment insurance spells where the claimant was between age 40 and age 46 on the claim date. We consider unemployment spells starting any time between July 1987 and April 1999. For each UI spell we created variables about the previous work history (such as job tenure, labor market experience, wage, industry and occupation at the previous job), the duration of UI benefit receipt in days, the UI benefit level, and information about the next job held after non-employment.

Since we do not directly observe whether individuals are unemployed we follow the previous literature and, in addition to duration of UI benefit receipt, we use length of non-employment as a measure for unemployment durations (e.g., Card, Chetty, and Weber 2007b). The duration of non-employment is measured as the time between the start of receiving UI benefits

\footnotetext{
${ }^{18}$ In Germany individuals who exhaust regular UI benefits are eligible for means tested unemployment assistance benefits (UA), which do not have a limited duration. The nominal replacement rate is $53 \%$, but UA payments are reduced substantially by spousal earnings and other sources of income, which may explain why only about $50 \%$ of UI exhaustees take up UA benefits. In Schmieder, von Wachter and Bender (2012a) we provide an in-depth assessment of the role of UA.

${ }^{19}$ Individual workers can be followed using a unique person identifier. Since about 80 percent of all jobs are within the social security system (the main exceptions are self-employed, students, and government employees) this situation results in nearly complete work histories for most individuals. Each employment record also has a unique establishment identifier that can be used to merge establishment characteristics to individual observations.
} 
and the date of the next registered period of employment. Our analysis period assures that we can follow individuals for at least 9 years after the start of the UI spell.

We calculate each individual's potential UI duration at the beginning of the UI spell, using information about the law together with information on exact birth dates and work histories. This method yields exact measures for workers who have been employed for a long continuous time and hence are eligible for the maximum potential benefit durations for their age groups. However, the calculation is not as clear cut for workers with intermittent periods of unemployment because of complex carry-forward provisions in the law. We thus define our core analysis sample to be all unemployment spells of workers who have been employed for at least 36 months (44 months at the age 44 cutoff) of the last seven years and who did not receive unemployment insurance benefits during that time period. ${ }^{20}$ In Schmieder et. al. (2012a), we show that the characteristics of this sample are comparable with those of UI recipients of similar age in the United States. In addition, in our sensitivity analysis we also consider results when we use all workers affected by the two age cutoffs, irrespective of prior labor force history. While for these we cannot obtain the marginal effect of an additional month of UI extension, we show that we can obtain consistent IV estimates of the effect of nonemployment duration under the same conditions as in our main sample.

\subsection{Estimation}

The institutional structure and data allow us to estimate the causal effect of UI durations on wages. In addition, it allows us to verify the conditions on the path of reemployment wages described in Section 2 even in the presence of dynamic selection. As a result, it can be used to obtain estimates of the causal effect of nonemployment duration on wages. Our empirical strategy follows three consecutive steps.

Estimating the Causal Effect of UI Durations on Employment and Wages. The institutional structure and data allow us to estimate the causal effect of large extensions in UI benefit durations on non-employment duration, reemployment wages and other outcomes for workers with previously stable employment using a regression discontinuity design. We follow

\footnotetext{
${ }^{20}$ Individuals who have quit their jobs voluntarily are subject to a 12 weeks waiting period. To focus on individuals who lost their job involuntarily and minimize selection concerns due to quitting we restrict our sample to individuals who claimed UI benefits within 12 weeks after their job ended.
} 
common practice and first show smoothed figures to visually examine discontinuities at the eligibility thresholds (e.g., Lee and Lemieux 2010). To obtain estimates for the main causal effects, we follow standard regression discontinuity methodology and estimate variants of the following regression model:

$$
y_{i}=\beta+\gamma \times \Delta P \times D_{a_{i} \geq a^{*}}+f\left(a_{i}\right)+\epsilon_{i},
$$

where $y_{i}$ is an outcome variable, such as non-employment duration (D) or reemployment wages $(w)$, of an individual $i$ of age $a_{i} . D_{a_{i} \geq a^{*}}$ is a dummy variable that indicates that an individual is above the age threshold $a^{*}$. In the notation from Section 2, we obtain estimates for $\frac{d D}{d P}$ and $\frac{d E[w]}{d P}$.

For our main estimates, we focus on the period from July 1987 - March 1999, and we use the sharp threshold at age 42 . We estimate equation (8) locally around the two cutoffs and specify $f\left(a_{i}\right)$ as a linear function while allowing different slopes on both sides of the cutoff. We use a relatively small bandwidth of two years on each side of the cutoff, and summarize our extensive sensitivity analysis below. In order to obtain additional power we also estimate a pooled regression model, where we take the estimation samples for the age 42 and the age 44 cutoffs together. ${ }^{21}$ For this procedure we normalize the age for all individuals within two years of the age 42 (44) threshold to the age relative to age 42 (44) (i.e. the rescaled age variable is set to 0 for someone who is exactly age 42 (44) at the time of claiming UI). We estimate the following model on the pooled sample: $y_{i}=\beta+\gamma \times \overline{\Delta P} \times D_{a_{i} \geq a^{*}}+f\left(a_{i}\right)+\epsilon_{i}$, where $a_{i}$ is the normalized age variable and $\overline{\Delta P}$ is the average change in potential UI durations at the age threshold. With this specification $\hat{\gamma}$ is a direct estimate of the rescaled marginal effect, forcing it to be equal at the two cutoffs. We always present regression discontinuity robust standard errors based on Calonico et al. (forthcoming). ${ }^{22}$

Estimating the Shift in the Path of Reemployment Wages and Hazards. The main goal of the paper is to estimate the causal effect of nonemployment durations on wages. As

\footnotetext{
${ }^{21}$ We also estimated all results at the age 44 cutoff separately. The point estimates are very similar but lack precision.

${ }^{22}$ Optimal bandwidth computations (as in Imbens and Kalyanaraman, 2012, and Calonico et al., forthcoming) are computationally quite demanding due to the large number of observations, especially when we calculate dynamic effects. We therefore keep the bandwidth at 2 years, but report optimal bandwidth estimates for the main results in our robustness checks.
} 
derived in Section 2, the first step in obtaining such an estimate is to assess whether the path of reemployment wages and the reemployment hazard shift in response to the UI extensions. While estimating the shift is in principle straightforward, a key issue is the potential presence of selective exit throughout the nonemployment spells, which we will refer to as dynamic selection. It is commonly believed that less productive workers are more likely to have longer nonemployment durations. In addition, low skilled workers may be more credit constrained, and hence respond more strongly to UI extensions.

In the absence of selection, we could directly estimate the average shift in the reemployment wage path and test whether it is equal to zero. Let $\delta=E\left[\frac{\partial w_{i}^{e}(t, P)}{\partial P}\right]$ be the average shift in the reemployment wage path. To obtain an estimate of $\delta$, one would estimate the following regression on the sample above and below the respective age cutoffs

$$
w_{i}^{*}=\delta P_{i}+\sum_{t=1}^{T} \theta_{t}+f\left(a_{i}\right)+\epsilon_{i}
$$

where $w_{i}^{*}$ is the observed reemployment wage, $\theta_{t}$ are time dummies for the duration of nonemployment, and $f\left(a_{i}\right)$ is a polynomial in age. Yet, although $\operatorname{cov}(P, \epsilon)=0$ from the RD assumptions, the resulting estimate for $\delta$ from this regression is inconsistent because nonemployment durations may be correlated with unobserved productivity (i.e., $\operatorname{cov}(t, \epsilon) \neq 0)$. However, under the standard assumption that $\operatorname{cov}(t, \epsilon) \leq 0$, we show in the Web Appendix that the estimated OLS coefficient $\hat{\delta}$ is an upper bound for the true $\delta$. The assumption that less able individuals tend to have longer nonemployment durations is supported by two findings. Our analysis of an unusually rich set of observable determinants of potential wages of individuals exiting at different durations confirms that there is a moderate amount of negative selection over the nonemployment spell. ${ }^{23}$ There, we also find that the distribution of observable characteristics does not respond to UI extension, speaking against a strong role of dynamic selection in our case. Our contrast of the IV and OLS estimators of the effect of nonemployment on wages in Section 5 also supports the assumption that selection over the nonemployment spell is negative. ${ }^{24}$

\footnotetext{
${ }^{23}$ We can go significantly beyond the typical variables used in canonical human capital earnings functions (age, gender, education) and include prior job tenure, prior industry and occupational tenure, prior wages, as well as occupation and industry.

${ }^{24}$ Note that a long literature has presented estimates of the effect of UI durations on reemployment hazards without specifically addressing this selection issue.
} 
Obtaining an upper bound estimate of $\delta$ is sufficient for our purposes, because from the theory we know that the reservation wage has to rise or stay constant and hence that $\frac{\partial w^{e}(t, P)}{\partial P} \geq 0$ for all $t$. Since $\delta$ is a weighted average of the effect of UI extensions at all nonemployment durations (with positive weights), if $\delta \approx 0$ then it must be that $\frac{\partial w^{e}(t, P)}{\partial P}=0$ at all nonemployment durations t. In other words, if we find that the estimated $\hat{\delta}$ is close to zero, given that $\hat{\delta}$ is an upper bound of the true $\delta$, we can conclude that the entire reemployment wage path and hence reservation wages have not shifted. Below, we will also use the confidence interval for the estimate $\hat{\delta}$ to derive bounds for our causal estimates for small shifts in reservation wages.

Estimating the Causal Effect of Nonemployment Durations on Wages. If the hazard rate declines $\left(\frac{d h_{t}}{d P}<0\right)$ and there is no change in reemployment wages $\left(E\left[\frac{\partial w_{i}^{e}(t, P)}{\partial P}\right]=0\right)$ then the relevant conditions for Proposition 1 hold, and the effect of UI durations on reemployment wages are driven solely by higher nonemployment durations. The final step then is to directly estimate the causal effect of nonemployment duration on wage offers using potential UI durations as instrumental variables for nonemployment durations. By the results in Section 2.3, the resulting IV estimator obtains the average effect of nonemployment duration on wages for all individuals responding to the UI extension, irrespective of elapsed nonemployment duration. Below, we will calculate the weighting function of the IV estimator over the nonemployment spell. As explained in Section 3.2, we also extend our IV strategy and use the age cutoff itself as instrument for nonemployment duration for the broader sample of workers for whom we cannot calculate potential UI durations.

\subsection{Validity of RD Design}

A key aspect in all three steps of our empirical strategy is the validity of the RD design. The regression discontinuity method only yields consistent results if factors apart from the treatment variable do not vary discontinuously at the threshold. In our setting, both UI claimants and their employers face potential incentives to manipulate the age of claiming. We have examined this issue at length in our related paper (Schmieder, von Wachter, and Bender 2012a) and its Web Appendix, and conclude that sorting around the threshold is not a concern in this case. We only summarize the main findings here and refer the interested reader to our precursor paper for a more detailed discussion of manipulation, including potential reasons 
for its absence.

A standard test for sorting around the threshold is to investigate whether the density of observations shifts or spikes near the threshold (McCrary 2008). Figure 1 (a) shows the number of unemployment spells in two-week age intervals around the cutoff. There is a small shift in observations from two weeks before to two weeks after the age cutoffs, that affects only about 200 individuals relative to about 500,000 observations in the sample close to the age cutoff. Further investigation showed that this increase is not driven by individuals who postpone their claim, but that, if at all, the incidence of separations rises slightly at the eligibility age. To investigate the nature of sorting further we investigated whether predetermined characteristics vary discontinuously at the threshold. Figure 1 (b) shows the pre-unemployment log wage in 2 month bins around the thresholds and shows no discernible discontinuity. We investigated many other baseline characteristics and found that only the fraction of UI recipients who are female is estimated to increase statistically significantly by about 0.8 percentage points. All other variables show essentially no (economically or statistically) meaningful difference at the threshold. ${ }^{25}$ In smaller datasets, such minor discontinuities and density shifts would almost certainly not be detectable. While these findings point to a small violation of the RD identification assumptions, these should have a relatively small impact on the overall results. In fact, neither trimming observations close to the eligibility thresholds nor directly controlling for observable characteristics affects our results. To ensure that our results are not affected by sorting around the threshold and by particular implementation choices of the RD estimator, we performed multiple robustness checks summarized in the sensitivity section (Section 6).

\section{The Average Effect of UI extensions on Job Quality}

\subsection{The Effects of UI extensions on Nonemployment Durations}

We begin by replicating our findings on the effect of UI extensions on UI duration and nonemployment duration from our previous paper (Schmieder, von Wachter, and Bender 2012a), which we will later use to calculate IV estimates of the effect of nonemployment duration on wages. Increases in potential UI durations have a very clear effect on nonemployment dura-

\footnotetext{
${ }^{25}$ There is a tiny difference in the years of education variable at the first threshold of about 0.03 years (or 10 days) of education.
} 
tions and hence substantially change behavior of unemployed individuals. Showing averages by two-months age windows, Figure 2 (a) shows that increasing potential UI durations at the two age thresholds leads to substantial increases in UI durations. This effect is partly mechanical, since individuals who would have exhausted their benefits at 12 months or 18 months are now covered for up to 6 more months, and partly behavioral, since individuals may reduce their search effort and thus stay unemployed longer. The purely behavioral effect of an increase in potential UI durations is demonstrated in Figure 2 (b), which shows the effect on nonemployment durations.

In Table 1, columns (1) and (2) confirm the visual impression. The effects on actual UI duration and nonemployment duration are very precisely estimated. The table also shows the marginal effect of an increase in potential UI durations by 1 month, i.e. the estimated RD coefficient rescaled by the increase in potential UI durations. For one additional month of potential UI benefits unemployed individuals receive about 0.3 months of additional benefits and remain unemployed for about 0.15 months longer. These marginal effects are similar to findings from previous research including Moffitt (1985), Katz and Meyer (1990), Meyer (1990) Card, Chetty, and Weber. (2007a), or Lalive (2007), although much more precisely estimated.

Finally, as further discussed in von Wachter, Bender, and Schmieder (2012b), column (3) of 1 shows that the probability of ever again working in a social security liable job decreases by about $0.5(0.1)$ percentage points per additional month of potential UI benefits at the age 42 threshold (pooled). In the sensitivity section, we will assess whether this small effect could imply a potential bias from sample selection in our main wage estimates.

\subsection{The Effect of UI Extensions on Reemployment Wages}

As discussed in the theory section, longer nonemployment durations in response to higher potential UI durations could either raise wages as individuals have more time to search for a better job, or lower wages if the negative effect from longer nonemployment durations dominates. Figure 3 (a) shows the effect on the log wage at the first job after the period of unemployment. There appears to be a small decline by about 0.01 log points in the post-unemployment wage at the age 42 threshold. At the age 44 threshold, the lines (fitted quadratic polynomials) also seem to indicate a small drop in the post-unemployment wage. Figure 3 (b) shows the 
difference in the pre-unemployment log wage and the post-unemployment log wage. This difference is a way to remove an individual fixed effect and hence can be viewed as a way to both control for possible selection into employment and to obtain more precise estimates by controlling for predetermined characteristics. The figure shows that the average wage loss for the unemployed in our sample is substantial, ranging from $13 \%$ to $16 \%$. While the gain in precision is modest, Figure 3 (b) indicates that selection along the previous wage has little impact on the results, and again clearly points to a negative effect of a rise in potential UI durations on post-unemployment wages.

The corresponding regression estimates in Table 1 columns (4) and (5) show that increases in potential UI durations lead to precisely estimated negative effects on post-unemployment wages. Panel A shows that the post-unemployment wage is about 0.8 percent lower in both levels and first differences when potential UI durations increase by six months. Panel B shows the results from pooling both cutoffs and reveals similar estimates with a small gain in statistical precision. The estimate from the pooled model implies that an increase in potential UI durations by one month decreases post-unemployment wages by about 0.1 percent. Below we show that these small effects of UI extensions on wages can imply substantial negative effects of nonemployment durations on wages.

Although the effect on the initial wage obtained after reemployment shown in Table 1 is small, the losses can add up to more substantial effects if individuals remain in lower paying jobs for a long period of time. Table 2 shows the effect on the log wage one, three, and five years after the start of the new employment spell. The estimates decline from one to five years start of employment, consistent with the result in Table 2 that there is a small positive (yet insignificant) effect of potential UI durations on wage growth. Yet, although the longerterm effects are not estimated precisely, the point estimates after 5 years are suggestive of potentially substantial cumulated wage losses. We will return to the implications for the total wage loss and individual behavior in the conclusion.

Other papers that have estimated the wage effect of increases in potential UI durations have found similar point estimates, although generally with less precision than we do. For example Card, Chetty and Weber (2007a) found a negative point estimate of UI durations on wages, quite comparable when rescaled to a marginal effect. Similarly, van Ours and Vodopivec (2008) and Centeno and Novo (2009) find negative effects of similar magnitude of 
UI extensions. As further discussed in Section 5, an additional value added with respect to these papers is that we provide a framework and dynamic results that allow us to separate the wage offer and the reservation wage effect.

\subsection{The Effect of UI Extensions on Other Job Outcomes}

In this section we show that individuals do not simply accept lower wages in return for other desirable job characteristics - i.e., jobs tend to be worse among all the dimensions we can measure here. Columns (1) to (4) of Panel B of Table 2 show the effect of increases in potential UI durations on a number of job-related outcome variables. The first outcome is the completed job tenure at the post-unemployment job, which is often used as an indicator of the quality of the job match. Column (1) of Panel B shows that there is a small decrease in the duration of the post-unemployment job of about 0.0081 years in Panel A, which is a decline of about $1 \%$ relative to mean post-unemployment job tenure (it is statistically significant at a $10 \%$ level for the full sample, see the Web Appendix). This confirms findings in Table 1 that higher potential UI durations reduce job stability even beyond the initial spell. Hence, it does not appear individuals with longer UI durations trade lower wages for more stable jobs or jobs that appear to represent better matches.

We analyzed several additional indicators of job quality. Longer potential UI durations decrease the probability of finding a full time job, but although precisely estimated the effect is less than $1 \%$ relative to the mean of $89 \%$ (column (2) of Panel B). ${ }^{26}$ An important finding of the literature on displaced workers is that those switching to another industry or occupation experience much larger declines in earnings (e.g., Neal 1995, Addison and Portugal 1989). Hence, one would expect that longer UI durations may help individuals to find jobs in their previous line of work. Columns (3) and (4) of Panel B of Table 2 show that this is not the case. Longer potential UI durations increase the probability of switching to a different industry and a different occupation by about 0.12 to 0.18 percentage points, respectively.

Overall, all measures of job quality available in our data either point to negative effects of longer potential UI durations or no effect. Hence, at least based on this limited set of job characteristics, it does not appear that workers with longer UI durations accept lower wages

\footnotetext{
${ }^{26}$ We also analyzed changes in firm size as proxy for employer quality, as well as the probability of a rise in commuting, and found no significant change.
} 
in return to better job outcomes along other dimensions. The analysis of other job outcomes also provides insights into the potential channels underlying the reduction in wages and the role of nonemployment durations, which we further discuss below.

\section{The Causal Effect of Nonemployment Durations on Reemployment Wages}

\subsection{Selection Throughout the Nonemployment Spell}

A key step in estimating the causal effect of nonemployment duration on wages is to assess the response in hazard rates and reemployment wages throughout the nonemployment spell. Although we will directly control for selection below, to assess the potential for dynamic selection we begin with a descriptive analysis of the evolution of observable characteristics throughout the nonemployment spell. As summary measures Figure 4 shows the mean of preunemployment wages (a) and the mean of predicted reemployment wages (b) (based on a broad range of pre-determined characteristics discussed in Section 3.3) by month of nonemployment duration. Vertical bars indicate that the point estimates at time $t$ are statistically significant at the 5 percent level. As expected, there is some correlation between pre-determined characteristics and nonemployment duration, though the gradient is not very strong. For example, mean pre-unemployment wages fall by about $5 \%$ and mean predicted wages fall by about $7 \%$ in the first year of nonemployment duration. More importantly for our analysis, in both of these figures the pre-unemployment wage paths and the predicted reemployment wage path are essentially unaffected by changes in potential UI durations. While there are a few statistically significant point estimates in each figure (and in the figures of single characteristics not shown here), given that each figure is created from 24 separate point estimates, it is expected that about one to two of the estimates are statistically significant on the 5 percent level purely because of sampling variation. ${ }^{27}$ Overall, these figures therefore support the notion that the distribution of observable characteristics over the nonemployment spell is essentially uncorrelated with potential UI durations, suggesting that it is unlikely that potential UI durations

\footnotetext{
${ }^{27}$ The one exception appears to be the spikes at the exhaustion point for fraction female. Individuals who are exiting from unemployment at the exhaustion points are significantly more likely to be female. This is consistent with larger labor supply effects of UI benefits for women. The fact that the spikes in fraction women cancel each other out, seems to indicate that some women are simply waiting until their benefits expire before going back to work. To address this aspect, we show in the sensitivity section that our results hold within gender groups.
} 
exert a strong effect on the distribution of unobservable characteristics.

\subsection{Estimates of the Shift of Reemployment Hazards and Wages}

Figure 5 shows estimates of the shift in the hazard rate at the age 42 discontinuity. We clearly see that the hazard rate shifts downward in response to increasing $P$ for all nonemployment durations $t$ smaller than the maximum potential UI duration $P$. This is statistically significant for nearly all point estimates, even in the first period $(t=0)$, so individuals are clearly forward looking and responding to the increase in $P$ a long time before they are running out of benefits. A similar pattern has been observed in many other studies of the effect of UI extensions on nonemployment duration (e.g., Card, Chetty, and Weber 2007b).

Figure 6 Panel (a) shows the effect of changes in $P$ on the reemployment wage conditional on $t$. On average, wages decline by about 25 percent within the first year. However, we do not observe a change in the path of reemployment wages over the nonemployment spell in response to rising UI durations. In the notation of the model of Section 2, it appears that indeed $\frac{\partial w_{i}^{e}(t, P)}{\partial P}=0$ for all nonemployment durations $t<P$. In the Web Appendix we show an almost unchanged pattern when we control for individual heterogeneity by plotting the difference in post and pre unemployment log wage. Extending UI benefits does not appear to shift the reemployment wage path upwards.

The only statistically significant changes in the reemployment wages are at the exhaustion points for the two groups, when reemployment wages go down relative to the other group. It is noteworthy that the two downward spikes are of very similar magnitude and essentially cancel each other out. These differences are reduced when we look at women and men separately, indicating that the negative wage spikes are partly driven by more women exhausting UI benefits.

The descriptive evidence in Section 5.1 suggests it is unlikely that these findings are overturned by a change in the distribution of worker characteristics over the nonemplyoment spell. As outlined in Section 3.3, relying on our RD assumptions, we can estimate an upper bound of the mean shift in the reemployment wage path even in the presence of selection. Table 3 presents these upper bound estimates of the average shift in the reemployment wage path, $E\left[\frac{\partial w_{i}^{e}(t, P)}{\partial P}\right]$, obtained from implementing equation (9). Column (1) of Table 3 shows the results controlling for a linear effect of nonemployment duration. This yields an estimate for $\delta$ 
for the 12 to 18 month discontinuity very close to zero (point estimate $-0.016 \%$ with a standard error of $0.048 \%$ ). If we control more flexibly for the nonemployment duration effect (Columns 2 to 3 ), the point estimate is even closer to 0 . Given that the estimates in Table 3 are very close to zero, and that theory excludes cases for which $\frac{\partial w_{i}^{e}(t, P)}{\partial P}<0$, this confirms the visual impression of Figure 6 that $\frac{\partial w_{i}^{e}(t, P)}{\partial P}=0$ for all nonemployment durations $t<P$. This shows that the value of the outside option, in this case the potential UI duration, does not affect reservation wages sufficiently to affect the mean reemployment wage (below, we discuss effects on lower quantiles of the reemployment wage distribution). This implies that the effect of UI durations on wages found in Section 4 arises due to a rise in nonemployment durations.

These results imply that reservation wages do not appear to bind sufficiently in our sample to affect mean reemployment wages. This is consistent with related findings in the literature. For example, DellaVigna and Paserman (2005) calibrate a model similar to ours and find that very few wage offers fall below the reservation wage. Our results are also consistent with structural estimates in van den Berg (1990) who found that most job offers are indeed accepted and that unemployed workers do not seem to reject many jobs based on wages. Similarly, Hornstein, Krusell, and Violante (2011) show that in broad classes of search models, the value of non market time - and hence the reservation wage - has to be low to be able to reconcile why despite high wage dispersion, and hence a high option value of searching, workers in practice accept jobs quickly. Following our approach, Lalive, Landais, and Zweimueller (2013) also find that the path of reemployment wages does not respond to increases in UI durations in Austria.

In contrast, Krueger and Mueller (2014) find that jobs with wages above the self-reported reservation wage are more likely to be accepted, although a substantial fraction of jobs paying below the reservation wage are accepted as well. However, they also find that reservation wages do not change significantly throughout the nonemployment spell within individuals, nor do they respond to UI exhaustion. Hence, in our notation these results imply $\frac{\partial w_{i}^{e}(t, P)}{\partial \phi_{i t}}>0$ but $\frac{\partial \phi_{i t}}{\partial P}=\frac{\partial \phi_{i t}}{\partial t}=0$. In this case the first two terms in equation (5) are still equal to zero and the IV estimator discussed next recovers the causal effect of unemployment duration on wages. 


\subsection{Estimates of the Causal Effect of Nonemployment Durations on Wages}

The results on the hazard and reemployment wage path imply that reservation wages do not bind. As a result, the observed decline in reemployment wages is entirely due to the decline in the wage offer distribution (equation 1), and the effect of UI durations on wages is only due to a rise in nonemployment durations (equation 5). Proposition 1 then allows us to obtain a valid estimate of the average decline in the reemployment wage path. In the final step of our empirical analysis, we thus estimate the slope of the reemployment wage path using UI durations as instrumental variables for nonemployment durations: $\pi=\frac{\frac{d E[w]}{d P}}{\frac{d D}{d P}}$.

Table 4 shows 2SLS results for the effect of nonemployment durations on reemployment wages using extensions in potential UI durations as an instrument. The table first shows the first stage regression (i.e., the effect of UI extension on nonemployment durations), which easily passes weak instrument concerns. The second column shows the 'reduced form' of the IV estimator, which correspond to the baseline estimates of the effect of potential UI durations on wages of Section 4.2. Column (3) reports the resulting 2SLS estimate of nonemployment durations on wages. We find that $\pi=-0.78 \%$, which is precisely estimated. Thus, our main finding is that an additional month of nonemployment lowers average wage offers of middle aged workers by about 0.8 percent.

To better understand the nature of our IV estimator, recall that Proposition 1 states that in the presence of heterogeneity and nonlinearity in the slope of the reemployment wage function, the IV estimator obtains the local average treatment effect of wage declines for individuals whose nonemployment durations are most affected by the instrument. As such, it is weighted towards the treatment effects of compliers to the UI extensions that underlie our regression discontinuity (RD) estimates. As seen from the survival functions in Panel (b) of Figure 5 the compliers come from the entire range of nonemployment durations, with the largest weight being between 12 and 18 months. Hence, the IV estimator estimates an average of the effect of nonemployment duration on wages over a broad spell of nonemployment durations. In contrast to the IV estimator, the implicit weighting function of the OLS estimator puts more weight on long durations where there are fewer individuals but for whom the gradient is flatter. As a result the, OLS estimator for the full sample (column 3 of Table 4) is similar to the IV estimate. To obtain a better comparison, we reestimated the OLS estimator excluding 
individuals with spells longer than 18 months that would typically receive little weight in surveys with much smaller sample sizes. The resulting estimate corresponds more closely to what is shown in Figure 6, and is approximately double the IV estimate.

To gauge the magnitude of our estimates, our point estimates imply a loss in daily wages of $4.8 \%(9.6 \%)$ for 6 (12) additional months of nonemployment duration. Based on Figure 6, this represents about $40 \%$ of the average wage loss at 6 and 12 months, respectively. Thus, the causal effect of nonemployment spells explain a substantial fraction of the average wage loss at job loss. Since the causal effect we estimate here is likely due to multiple channels - including skill depreciation, discouragement, or stigma - it is not clear what magnitude to expect. While it is hard to compare our estimate with previous findings based on nonexperimental estimates, the findings fall in the same broad range. Estimates based on the correlation of nonemployment duration of displaced workers with reemployment wages suggest effects bigger than our IV estimate, and similar to our censored OLS estimate (e.g., Addison and Portugal 1989), but as explained above may be affected by selection. ${ }^{28}$ Estimates of the rate of depreciation of human capital during unemployment based on structural models show results of similar order of magnitude as our findings (e.g., Keane and Wolpin 1997).

\subsection{Analysis of Wage Distribution and Bounding}

The finding in Table 3 and Figure 6 (a) provide strong evidence that UI extensions do not affect reemployment wages through changes in reservation wages. Even with large extensions that clearly affect the hazard rate and a large administrative dataset the implied effect of changes in the reservation wage on the mean reemployment wage is a precisely estimated zero. To investigate whether our focus on the mean (even though this is the correct measure in our model) masks small effects of the reservation wage at the bottom of the wage distribution (where one might expect the largest effect), we used our large sample sizes to analyze the full distribution of wages. The percentiles of the wage distribution by nonemployment duration for those above and below the 12 month cut off point are shown in Figure 6 (b) (as before those RD estimates that are significant are shown with vertical bars). The figure clearly shows the evolution of the wage distribution with nonemployment duration as it shifts downwards

\footnotetext{
${ }^{28}$ Absent quasi-experimental evidence or detailed worker characteristics, Addison and Portugal (1989) address selection using a Heckman correction term.
} 
and fans out. If a response in reservation wages to UI extensions mattered, one should see the effect mostly at the bottom of the wage distribution. Figure 6 (b) indeed shows that there appears to be a significant rise in the lower quantiles of the wage distribution in response to UI extensions. However, the rise at the first cutoff and appears to be offset by a decline at the second cutoff. As in case of mean wages in Figure 6 (a), this crossing of the reemployment wage path can only be explained by dynamic selection and suggests the pattern may be due to a selective shifting from one exhaustion point to the next. To directly assess this possibility, we applied the same procedure as with the mean in Section 5.2 to the cumulative density function $(\mathrm{CDF})$ of reemployment wages for the entire sample. Columns 3 to 5 of Table 3 show estimates of the mean shift of selected points of the CDF in response to UI extensions. ${ }^{29}$ These estimates suggests that the effect of UI extensions on the CDF of wages for the entire sample is very close to zero. Recall that the effect on the entire CDF is a weighted average of the effect of the CDF at each nonemployment duration. Hence, since the theory suggests that reservation wages (and hence the $\mathrm{CDF}$ ) should rise, the finding of a zero response implies that the effect of UI extensions on the CDF at each nonemployment duration must be zero. This provides direct evidence that the pattern in Figure 6 (b) are likely to be due to selection. ${ }^{30}$

The interpretation of our IV estimates as causal effect of nonemployment duration on wages relies on our empirical result that $\frac{\partial w_{i}^{e}(t, P)}{\partial P}$ is approximately zero, which is difficult to establish empirically with certainty. It is however straightforward to derive bounds for the effect of nonemployment durations on wage offers for the case that there are small shifts in the reemployment wage path, $\frac{\partial w_{i}^{e}(t, P)}{\partial P}$. In the Web Appendix, we show that for the homogeneous and linear case for small shifts $\delta$ in the reemployment wage path the IV estimate obtains

$$
\frac{\frac{d E\left[w^{e}(t ; P)\right]}{d P}}{\frac{d D}{d P}}=\delta \frac{1}{\frac{d D}{d P}}+\delta \frac{\frac{d V_{t}^{u}}{d t}}{\frac{d V_{t}^{u}}{d P}}+\frac{\partial w^{e}(t ; P)}{\partial \mu_{t}} \frac{\partial \mu_{t}}{\partial t}
$$

Comparing this expression to equation (5), it is clear that the first term measures the

\footnotetext{
${ }^{29}$ These estimates use the identical specification as in equation (10) in Section 3.2 with using a dummy for being above the respective wage cutoff as a dependent variable. The CDFs at each nonemployment duration are shown in the Web Appendix, and contain the same results as the percentiles in Figure6 (b).

${ }^{30}$ Note that we cannot do the same exercise fo the percentile figures, because there is no direct linear correspondence between the percentiles of the wage distribution in the full sample and at each nonemployment duration. However, since there is a direct correspondence of the CDF at each nonemployment duration with the percentiles, the results in Table 3 are informative about the percentiles as well.
} 
direct effect of reservation wages on the reemployment wage path (akin to a direct effect of an instrument on the outcome). The second term captures a bias that arises from the fact that if reservation wages matter, longer nonemployment durations also induce wage changes due to changes in reservation wages. ${ }^{31}$

Given that we can estimate $\delta, \frac{d E[w]}{d P}$ and $\frac{d D}{d P}$, to obtain bounds for the causal effect $\pi \equiv$ $\frac{\partial w^{e}(t ; P)}{\partial \mu_{t}} \frac{\partial \mu_{t}}{\partial t}$ we have to say something about the ratio $\frac{d V_{t}^{u}}{d t} / \frac{d V_{t}^{u}}{d P}$, which is negative since $\frac{d V_{t}^{u}}{d t}<0$. Since $\frac{1}{\frac{d D}{d P}} \approx 7$, only for a very strong decline in the value function $\frac{d V_{t}^{u}}{d t} / \frac{d V_{t}^{u}}{d P}<-7$ would the IV estimate be biased downward. To get a sense for $\frac{d V_{t}^{u}}{d t} / \frac{d V_{t}^{u}}{d P}$, notice that if everything were stationary except for the benefits expiring at time $P$, then $\frac{d V_{t}^{u}}{d t}=-\frac{d V_{t}^{u}}{d P}$ for $t<P$, since reducing benefits by one month has the same effect on the value function as moving forward one more month (in unemployment). In practice it is probably true that $\frac{d V_{t}^{u}}{d t}<-\frac{d V_{t}^{u}}{d P}$, that is the value function declines faster than what one would expect simply from moving one month closer to the exhaustion date. This would be because skills are depreciating, people run out of savings, the cost of job search may increase (or job search becomes less effective), etc. On the other other hand these additional sources of non-stationarity are probably of similar or lesser importance for the value function as the finite duration of UI benefits. If so, then a plausible, very conservative range for $\frac{\frac{d V_{t}^{u}}{d t}}{\frac{d V_{t}^{u}}{d P}}$ would be -1 to around -4 (if, say, UI accounts for only one fourth of the non-stationarity).

In Table 5, we calculate the implied $\pi$ given various values of $\frac{d V_{t}^{u}}{d t} / \frac{d V_{t}^{u}}{d P}$ and $\delta$. Essentially as long as $\delta$ is close to the estimated range in Table 3 (which is always clearly less then $0.1 \%$ ) or $\frac{d V_{t}^{u}}{d t} / \frac{d V_{t}^{u}}{d P}$ is not too high (between -1 and -8) we get values for the change in the slope of the wage offer distribution that are quite close to the IV estimate or even smaller. For example for the upper bound of the confidence interval for the pooled estimate in Column (3) of Table 3, $\hat{\delta}=0.095 \%$, the range of slopes for the wage offer distribution is between $-1.4 \%$ (actually even smaller than the IV estimate) to $-0.7 \%$, just slightly larger than the IV estimate of $-0.78 \%$ decline in mean wage offers per month. ${ }^{32}$

\footnotetext{
${ }^{31}$ Recall from equation 6 that $\frac{d E[w \mid t]}{d P}$ is determined by the change in the reservation wage in response to a rise in potential UI durations times the effect of reservation wages on actual wages. The intuition of the various terms is hard to see from the final equation, but clear from the derivation in the Web Appendix, to which we defer the interested reader.

${ }^{32}$ Another source of potential bias in the IV estimator arises if $\frac{d h_{t}}{d P}=0$, which in our sample occurs for nonemployment durations greater than two years, when benefit durations are exhausted on both sides of the age threshold. In that case, even though $\frac{\partial w_{i}^{e}(t, P)}{\partial P}=0$, for $t>24$ it may be that reservation wages affect accepted wages (i.e., the second term in equation (5) is not zero). Given our results imply no response in
} 


\subsection{Discussion of Potential Channels Underlying IV Estimates}

As discussed in the theory section, the interpretation of our estimate as the causal effect of nonemployment duration is independent of the particular economic model of job search we used, and holds for a broad range of how wages and outside options are determined. Hence, independently of the particular underlying model or source of the effect, the parameter can be used to gauge the costs of uneployment duration and for assessing the optimal policy mix in response to nonemployment. However, for some applications it would be helpful to know more about the channels underlying the effect we find. Several channels have been suggested in the literature. Using longitudinal data on explicit skill measures from Sweden, Edison and Gustavsson (2008) report that one year of unemployment duration reduces skills by an equivalent of 0.7 years of schooling, pointing to the potential of skill decline. Kroft, Lange, and Notowidigdo (forthcoming) find that employers discriminate against the long-term unemployed, even holding information on education and career progression constant. Similarly, there is some evidence that the unemployed become increasingly unhappy throughout the nonemployment spell (e.g., Krueger and Mueller 2011).

Our analysis is not geared to uncover the channels underlying the causal effects we find. Nevertheless, our RD analysis reported in Section 4.3 provides some tentative findings about some potential channels. To assess the potential impact of these effects on reemployment wages, we included these outcomes as additional explanatory variables in our main RD estimates (not shown). Controlling for an indicator capturing industry and occupation changes leads to a slight drop in the effect of UI extensions on reemployment wages of 20-25\%. Controlling for a part-time indicator and completed tenure at the new job leads to a bit larger decline of 30-40\%. Including proxies for employer quality made no difference. Overall, while such regressions have to be interpreted with caution, they imply some prima facie evidence of role of industry and occupation changes, which have been associated with losses in (industry or occupation) specific skills in the literature. Similarly, the rise in part-time employment and the reduction in completed job tenure could reflect a decline in job quality. Clearly, some of these outcomes could reflect several mechanisms, hence we do not stress any particular interpretation here.

reservation wages for $t<24$, and given the findings in the literature on the role of reservation wages, we find it safe to assume that the reservation wage effect at $t>24$ is likely to be small and this source of bias minor. 
We have also analyzed differences in the effect of UI extensions on reemployment wages over the business cycle. On the one hand, if there is statistical discrimination and employers correctly update their priors, the rise in expected mean quality of job applicants during recessions should lead to lower stigma of nonemployment duration. On the other hand, it is plausible that the effect of nonemployment duration on wage offers is stronger in recessions. For example, there is ample evidence of both a decline in job quality and of a reduction of wages within jobs in recessions, which could hurt in particular workers with longer unemployment spells. When we compare our findings in periods with high and with low unemployment rates, the results are very robust in recessions, but imprecise and ambiguous in expansions (not shown). ${ }^{33}$ Hence, this does not point towards an explanation based on stigma.

Overall, we do not find prima facie evidence in favor of a stigma effect and find some suggestive evidence for skill depreciation. However, our results would also be consistent with stigma, skill depreciation, and factors such as worker discouragement jointly determining the causal effect of nonemployment durations on wages.

\section{Summary of Robustness Analysis}

\subsection{Robustness of Regression Discontinuity Estimates}

Our main results are all based on a two-year bandwidth around the age thresholds with linear age controls. Focusing on the model pooling both thresholds, Table 6 shows the sensitivity of our results when we allow for more flexibility in the estimation, focusing on five outcome variables. Columns (2) and (3) show the estimated effects when the bandwidth is reduced to 1 year and 0.5 years. While the sample size drops dramatically and the standard errors increase correspondingly, the point estimates all become larger in absolute terms, pointing to worse match outcomes than in the baseline estimates. This pattern is very similar when we control for age with quadratic or cubic polynomials on both sides of the cutoff (columns 3 and 4 ), where the point estimates are similar to the linear specification with 0.5 years of bandwidth. Using the Calonico et al. (forthcoming) optimal bandwidth algorithm - column (5) - we obtain optimal bandwidths between 0.6 to 0.7 and again slightly more negative wage

\footnotetext{
${ }^{33}$ The ideal test would hold the distribution of job types constant (comparable to what is done in audit studies), but is not feasible in our quasi-experimental setting because of small sample sizes and endogeneity problems.
} 
effecs.

In section 3, we reported that we found a slight increase in density just to right of the two age thresholds. Furthermore, we found a small increase in the fraction of female UI recipients at the threshold. Here, we provide several methods to investigate whether this increase will affect our results. Column (6) of Table 6 shows the results from estimating the marginal effect of potential benefit durations on employment outcomes using our RD design pooling both thresholds, when we exclude all observations within one month of the age threshold. Overall, while excluding the observations close to the cutoff reduces statistical power somewhat, it does not affect our overall conclusions. Column (7) of Table 6 shows how the estimates change when we control for a rich set of observables, including year, state, and industry fixed effects, as well as human capital and experience measures. The effects on nonemployment durations, the post-unemployment wage, and the duration of the post-unemployment job are slightly reduced but still clearly imply negative match effects. Column (8) of Table 6 shows another method robustness check to limit the effect of selective waiting before claiming UI, where we limit the sample to individuals who claim UI within two weeks of losing their job. These effects are quite similar to our baseline results.

\subsection{Robustness of Estimated Effects on Wages}

We implemented numerous robustness checks regarding our findings on wages as well. Here, we report results addressing the aspects of selective return to employment, differences in effects across groups, and changes in unemployment rates throughout the nonemployment spell.

In Section 4, we have shown that increases in UI extensions lead to precisely estimated declines in the incidence of employment (Table 1). While these effects were very small relative to the mean (less than 1\%), we investigated the potential effect of such selection on our estimates of the effect of UI durations on wages by analyzing differences in the quantiles of the distribution of outcomes on the two sides of the age cutoffs (shown in the Web Appendix). This standard procedure yields consistent estimates if selection depends monotonously on a single index of underlying characteristics. The results suggest that the decline in median wages is larger than the mean effect, suggesting that if at all our main findings underestimate

the effect of UI extensions on wages. Moreover, the lower percentiles of the wage distribution decline more strongly than the upper percentiles, , implying that the majority of wage declines 
in response to UI extensions occurr in the lower part of the distribution.

The concern of selective participation also arises when studying reemployment wages at each point in the nonemployment spell. As long as selection into employment for the full sample is not an issue, our procedure for controlling for dynamic selection in Table 3 also controls for the effects of selective participation when estimating the effect of UI extensions on the shift in the reemployment wage path.

In Section 5, we had said that part of the effect on reemployment wages at the exhaustion points month 12 and month 18 are likely to be due to a change in sample composition. In particular, there is a rise in the fraction of women to the right of the RD cutoffs, and a rise in the fraction of women exiting at the exhaustion points. To address this point, we have replicated our main RD analysis and our analysis of reemployment wages by gender. While women's nonemployment durations clearly respond more strongly to UI extensions (Schmieder, von Wachter, and Bender 2012a), there is no precisely estimated difference in the effect on reemployment wages by gender. As a result, the implied IV estimate of the effect of nonemployment durations on wages is somewhat smaller for women, and approximately the same for men. Hence, our main findings are robust for the small degree of selection of women into nonemployment and UI exhaustion we find.

Another potential concern is that our main analysis focuses on workers with comparatively high labor force attachment for whom nonemployment spells might be particularly costly. As discussed in Section 3, we can replicate our IV strategy for any worker eligible for UI. For this broader sample, Table 4 shows we obtain a somewhat larger estimate of $-1.2 \%$ for the age 42 cutoff, and $-1.5 \%$ when we pool both cutoffs, where only the latter is statistically significant from our main sample. ${ }^{34}$ Thus, our findings are not driven by the particular sample we use, and hold for a broad sample of middle aged workers in Germany. We also considered the effect of UI durations and nonemployment durations on wages for other subgroups, but statistical precision was low and hence did not pursue this further. ${ }^{35}$

\footnotetext{
${ }^{34}$ The difference in the size of the IV estimate is mainly driven by a smaller effect of UI extensions on nonemployment durations, which is to be expected since the average rise of potential UI durations is smaller for this group. The corresponding estimates are shown in the Web Appendix.

${ }^{35}$ For example, while lower educated workers had substantially larger responses in employment duration, the effect of UI durations on wage changes appeared only slightly larger for the lower educated, implying a smaller (but not precisely estimated) causal effect of nonemployment durations on wages.
} 


\section{Conclusion}

The effect of unemployment durations on job outcomes has important implications for policy at the micro and macro level. Using an IV strategy based on quasi-experimental extensions in UI benefits we find that for middle aged workers each additional month of nonemployment duration leads to a statistically significant and substantial reduction in wage offers of $0.8 \%$. We show that this estimate identifies a weighted average of the slope of the wage offer distribution for individuals whose nonemployment durations are affected by the UI extensions. Given that UI durations lead to a decline in reemployment probabilities throughout the nonemployment spell, it is relevant for a broad group of unemployed workers. In our setting, over six to twelve months this can explain about a third of wage losses from unemployment. These estimates are smaller than existing estimates with non-experimental controls for selection.

Our IV strategy is based on the key insight that the response of reemployment wages to UI extensions throughout the nonemployment spell is informative about the role of reservation wages even if the degree of selection is arbitrarily affected by UI durations. Our finding that the path of reemployment wages over nonemployment duration does not shift in response to UI extensions implies that reservation wages do not bind. Hence, the UI extensions only affect wages through a rise in unemployment durations and hence can be used as an instrument for non-employment durations. We also analyzed the response of different points in the wage distribution to UI extensions. While we do observe some small shifts in the lower quantiles estimates in response to UI extensions, these changes appear to be due to selection. In a bounding exercise, we show that our main results are robust to small and realistic effects of reservation wages. The framework we develop here for the analysis of the causal effects of nonemployment durations on wages and other job outcomes will be useful for other studies that analyze the effects of exogenous changes in wokers outside options on worker outcomes.

Our findings can be used to help quantify the earnings losses from long unemployment spells for workers, a key policy concern especially during recessions. They also affect the optimal policy mix in response to long-term unemployment and suggest that both at the micro- and macro-level policies should be front loaded to avoid the substatial cost associated with long-term unemployment. The results are also potentially informative about the effects of prolonged nonemployment spells on the aggregate economy. Our findings suggest that these 
can lead to persistent and substantial declines in wages that appear to be larger in recessions. In so far as workers may be receiving worse job matches or have lower productivity, this could imply a significant cost to society going beyond the direct cost of unemployment itself. However, by construction our regression discontinuity analysis is partial equilibrium in nature, and a full evaluation of the implications of causal effects of nonemployment we document here would require specifying the source of the losses and a macroeconomic model.

While we find unemployment duration has potentially large effects on wages, the small underlying effect of UI extensions on wages may not substantially affect the welfare consequences of UI extensions. If individuals get all the surplus from higher match quality, then they will have internalized the effect of their search behavior on match quality, and the effects of potential UI durations on match quality can be ignored from a social welfare perspective. This situation is different, if workers do not reap all the benefits of better matches - for example, because the surplus is shared with the employer or because the government receives taxes. Even in the latter case, the small direct effects of UI extensions on wages we find are unlikely to imply a substantial rise in costs of UI extensions. ${ }^{36}$

Our results are also related to the value of leisure. Rational individuals incur the costs of additional wage reductions above and beyond foregone earnings during nonemployment in favor of additional leisure. A back-of-the-envelope calculation suggests that the present discounted value of the cost from lower wages due to higher nonemployment durations is about half a month of average earnings per additional month of nonemployment duration. This may indeed be rational, in so far fixed costs of working or fixed costs of leaving a job put a wedge between the value of leisure and foregone earnings. Yet, it also could be that individuals do not fully foresee the wage penalty they incur. Without additional information and estimating structural parameters we cannot say more here.

Last but not least, by the nature of our regression discontinuity design and institutional framework, our estimates are based on middle age workers with stable labor force attachment. While this is the core constituency of unemployment insurance in Germany, the United States and other countries, it does not speak to the potential effects of UI durations and nonemployment durations for a broader population. Studies with data and research designs

\footnotetext{
${ }^{36}$ This is essentially an application of the envelope theorem. See Chetty (2008) and Schmieder, von Wachter, and Bender (2012a) for details. Nekoei and Weber (2013) show that foregone tax revenues from lower earnings can also play a role.
} 
encompassing broader groups of workers will help to obtain additional information on how the effects we measure here differ in the population, what the likely effect on the macroeconomy is, and what the underlying channels may be. Similarly, while we showed in our precursor paper that the characteristics of our sample is comparable to similarly aged UI recipients in the United States and that the effect of UI durations on employment are comparable (Schmieder, von Wachter, and Bender 2012a), one has to be careful in generalizing from our results based on Germany.

\section{References}

Acemoglu, Daron, "Public Policy in a Model of Long-Term Unemployment," Economica, 62 (1995), 161-178.

Addison, John T. and McKinley L. Blackburn, "The effects of unemployment insurance on postunemployment earnings," Labour Economics, 7 (1), (2000), 21-53.

- and Pedro Portugal, "Job Displacement, Relative Wage Changes, and Duration of Unemployment," Journal of Labor Economics, 7 (3), (1989), 281.

Angrist, Joshua D., Guido W. Imbens, and Donald Rubin, "Identification of Causal Effects Using Instrumental Variables," Journal of the American Statistical Association, 91 (1996), 444-472.

- , Kathryn Graddy, and Guido W. Imbens, "The Interpretation of Instrumental Variables Estimators in Simultaneous Equations Models with an Application to the Demand for Fish," Review of Economic Studies, 67 (2000), 499-527.

Ball, Laurence M., "Hysteresis in Unemployment: Old and New Evidence," NBER Working Papers No. 14818, (2009).

Bernanke, Ben S., "Recent Developments in the Labor Market," Speech at National Association for Business Economics Annual Conference (http://www.federalreserve.gov/newsevents/speech/bernanke20120326a.pdf), (2012).

Black, Dan A., Jeffrey A. Smith, Mark C. Berger, and Brett J. Noel, "Is the Threat of Reemployment Services More Effective than the Services Themselves? Evidence from Random Assignment in the UI," American Economic Review, 93 (4), (2003), 1313-1327.

Blau, David M and Philip K Robins, "Job search, wage offers, and unemployment insurance," Journal of Public Economics, 29 (2), (1986), 173-197.

Calonico, Sebastian, Matias D Cattaneo, and Rocio Titiunik, "Robust nonparametric confidence intervals for regression-discontinuity designs," Econometrica, (forthcoming).

Card, David, Raj Chetty, and Andrea Weber, "Cash-On-Hand and Competing Models of Intertemporal Behavior: New Evidence from the Labor Market," Quarterly Journal of Economics, 122 (4), (2007a), 1511-1560.

,-- , and - , "The spike at benefit exhaustion: Leaving the unemployment system or starting a new job?," American Economic Review Papers and Proceedings, 97 (2), (2007b), $113-118$. 
Centeno, Mario and Álvaro A. Novo, "Reemployment wages and UI liquidity effect: a regression discontinuity approach," Portuguese Economic Journal, 8 (1), (2009), 45-52.

Chetty, Raj, "Moral hazard versus liquidity and optimal unemployment insurance," Journal of political Economy, 116 (2), (2008), 173-234.

Degen, Kathrin and Rafael Lalive, "How Does a Reduction in Potential Benefit Duration Affect Medium-Run Earnings and Employment?," mimeo, (2013).

DellaVigna, Stefano and M. Daniele Paserman, "Job search and impatience," Journal of Labor Economics, 23 (3), (2005), 527.

Edin, Per-Andres and Magnus Gustavsson, "Time Out of Work and Skill Depreciation," Industrial Labor Relations Review, 61 (2), (2008), 163-180.

Farber, Henry S. and Robert G. Valletta, "Do Extended Unemployment Benefits Lengthen Unemployment Spells? Evidence from Recent Cycles in the U.S. Labor Market," NBER Working Paper No. 19048, (2013).

Feldstein, Martin and James Poterba, "Unemployment insurance and reservation wages," Journal of Public Economics, 23 (1-2), (1984), 141-167.

Hagedorn, Marcus, Fatih Karahan, Iourii Manovskii, and Kurt Mitman, "Unemployment benefits and unemployment in the great recession: the role of macro effects," Technical Report, National Bureau of Economic Research (2013).

Hornstein, Andreas, Per Krusell, and Giovanni L. Violante, "Frictional Wage Dispersion in Search Models: A Quantitative Assessment," American Economic Review, 101 (7), (2011), 2873-2898.

Imbens, Guido and Karthik Kalyanaraman, "Optimal Bandwidth Choice for the Regression Discontinuity Estimator," Review of Economic Studies, 79 (3), (2012), 933-959.

Katz, Lawrence F. and Bruce D. Meyer, "The Impact of Potential Duration of Unemployment Benefits on the Duration of Unemployment Outcomes," Journal of Public Economics, (1990), 45-71.

- , Kory Kroft, Fabian Lange, and Matt J. Notowidigdo, "Long-Term Unemployment and the Great Recession: The Role of Composition, Duration Dependence, and Non-Participation," mimeo, (2013).

Keane, Michael P. and Kenneth I. Wolpin, "The Career Decisions of Young Men," Journal of Political Economy, 105 (3), (1997), 473-522.

Kroft, Kory and Matt J. Notowidigdo, "Should Unemployment Insurance Vary With the Local Unemployment Rate? Theory and Evidence," mimeo, (2010).

- , Fabian Lange, and Matthew Notowidigdo, "Duration Dependence and Labor Market Conditions: Evidence from a Field Experiment," Quarterly Journal of Economics, 123 (3), (2013), 1123-1167.

Krueger, Alan B. and Andreas Mueller, "Job Search, Emotional Well-Being and Job Finding in a Period of Mass Unemployment: Evidence from High-Frequency Longitudinal Data," Brookings Papers on Economic Activity, Spring (2011), 1-81.

- and - , "A Contribution to the Empirics of Reservation Wages," NBER Working Paper 19870, (2014).

Lalive, Rafael, "Unemployment benefits, unemployment duration, and post-unemployment jobs: A regression discontinuity approach," American Economic Review, 97 (2), (2007), 108-112.

- , Camille Landais, and Josef Zweimueller, "Market Externalities of Large Unemployment 
Insurance Extension Programs," Mimeo, (2013).

Lee, David S. and Thomas Lemieux, "Regression discontinuity designs in economics," Journal of Economic Literature, 48 (2), (2010), 281-355.

Ljungqvist, Lars and Thomas J. Sargent, "Two Questions about European Unemployment," Econometrica, 76 (1), (2008), 1-29.

Machin, Stephen and Alan Manning, "The causes and consequences of longterm unemployment in Europe," Handbook of labor economics, 3 (1999), 3085-3139.

McCrary, Justin, "Manipulation of the running variable in the regression discontinuity design: A density test," Journal of Econometrics, 142 (2), (2008), 698-714.

Meyer, Bruce D., "Unemployment Duration and Unemployment Spells," Econometrica, 58 (1990), 757-82.

- , "Lessons from the US Unemployment Insurance Experiments," Journal of Economic Literature, 33 (1), (1995), 91-131.

Moffitt, Robert, "Unemployment Insurance and the Distribution of Unemployment Spells," Journal of Econometrics, 28 (1), (1985), 85-101.

Neal, Derek A., "Industry-Specific Human Capital: Evidence from Displaced Workers," Journal of Labor Economics, 13 (4), (1995), 653-677.

Nekoei, Arash and Andrea Weber, "Does Extending Unemployment Benefits Improve Job Quality?," Mimeo, (2013).

Pavoni, Nicola, "Optimal Unemployment Insurance, with Human Capital Depreciation, and Duration Dependence," International Economic Review, 50 (2), (2009), 323-362.

- and Giovanni L. Violante, "Optimal Welfare-to-Work Programs," Review of Economic Studies, 74 (1), (2007), 283-318.

- , Ofer Setty, and Giovanni L. Violante, "Search and Work in Optimal Welfare Programs," NBER Working Papers No. 18666, (2013).

Pissarides, Christopher A., "Loss of Skill During Unemployment and the Persistence of Employment Shocks," Quarterly Journal of Economics, $10^{77}$ (4), (1992), 1371-1391.

Rothstein, Jesse, "Unemployment Insurance and Job Search in the Great Recession,"

Brookings Papers on Economic Activity, Fall (2011), 143-210.

Schmieder, Johannes F., Till von Wachter, and Stefan Bender, "The Long-Term Impact of Job Displacement in Germany During the 1982 Recession on Earnings, Income, and Employment," Columbia University, Department of Economics Discussion Paper Series, DP0910-07 (2009).

Schmieder, Johannes F, Till Von Wachter, and Stefan Bender, "The Effects of Extended Unemployment Insurance over the Business Cycle: Evidence from Regression Discontinuity Estimates over 20 years," The Quarterly Journal of Economics, 127 (2), (2012a), 701-752.

- , Till von Wachter, and Stefan Bender, "The Long-Term Effects of UI Extensions on Employment," The American Economic Review, 102 (3), (2012b), 514-519.

Shimer, Robert and Ivan Werning, "On the Optimal Timing of Benefits with Heterogeneous

Workers and Human Capital Depreciation," NBER Working Paper No. 12230, (2006).

van den Berg, Gerard J., "Nonstationarity in job search theory," The Review of Economic Studies, 57 (1990), 255-277.

van Ours, Jan and Milan Vodopivec, "Does reducing unemployment insurance generosity reduce job match quality?," Journal of Public Economics, 92 (3-4), (2008), 684-695. 
Table 1: The Effect of Potential UI Durations on Non-employment Duration and the Post Unemployment Wage

\begin{tabular}{|c|c|c|c|c|c|}
\hline & $\begin{array}{l}(1) \\
\text { UI Benefit } \\
\text { Duration }\end{array}$ & $\begin{array}{c}(2) \\
\text { Non-Emp } \\
\text { Duration }\end{array}$ & $\begin{array}{l}(3) \\
\text { Ever emp. } \\
\text { again }\end{array}$ & $\begin{array}{c}(4) \\
\text { Log Post } \\
\text { Wage }\end{array}$ & $\begin{array}{l}\quad(5) \\
\text { Log Wage } \\
\text { Difference }\end{array}$ \\
\hline \multicolumn{6}{|c|}{ Increase in Potential UI Dur. from 12 to 18 Months } \\
\hline RD Estimate (Age $\geq$ cutoff) & $\begin{array}{c}1.77 \\
{[0.048]^{* *}}\end{array}$ & $\begin{array}{c}0.95 \\
{[0.19]^{* *}}\end{array}$ & $\begin{array}{c}-0.0094 \\
{[0.0033]^{* *}}\end{array}$ & $\begin{array}{c}-0.0078 \\
{[0.0036]^{*}}\end{array}$ & $\begin{array}{c}-0.0070 \\
{[0.0034]^{*}}\end{array}$ \\
\hline Marginal Effect $\frac{d y}{d P}$ & $\begin{array}{c}0.29 \\
{[0.0080]^{* *}}\end{array}$ & $\begin{array}{c}0.16 \\
{[0.032]^{* *}}\end{array}$ & $\begin{array}{c}-0.0016 \\
{[0.00046]^{* *}}\end{array}$ & $\begin{array}{c}-0.0013 \\
{[0.00060]^{*}}\end{array}$ & $\begin{array}{c}-0.0012 \\
{[0.00058]^{*}}\end{array}$ \\
\hline $\begin{array}{l}\text { Effect relative to mean } \\
\text { Observations } \\
\text { Mean of Dep. Var. }\end{array}$ & $\begin{array}{c}0.23 \\
510955 \\
7.57\end{array}$ & $\begin{array}{c}0.065 \\
437899 \\
14.7\end{array}$ & $\begin{array}{c}-0.011 \\
510955 \\
0.86\end{array}$ & $\begin{array}{c}-0.0019 \\
437182 \\
4.01\end{array}$ & $\begin{array}{c}0.050 \\
420311 \\
-0.14\end{array}$ \\
\hline \multicolumn{6}{|c|}{ Pooling both Thresholds (12 to 18 Months and 18 to 22 Months) } \\
\hline RD Estimate (Age $\geq$ cutoff) & $\begin{array}{c}1.44 \\
{[0.041]^{* *}}\end{array}$ & $\begin{array}{c}0.72 \\
{[0.14]^{* *}}\end{array}$ & $\begin{array}{c}-0.0082 \\
{[0.0021]^{* *}}\end{array}$ & $\begin{array}{c}-0.0051 \\
{[0.0024]^{*}}\end{array}$ & $\begin{array}{c}-0.0055 \\
{[0.0025]^{*}}\end{array}$ \\
\hline Marginal Effect $\frac{d y}{d P}$ & $\begin{array}{c}0.29 \\
{[0.0081]^{* *}}\end{array}$ & $\begin{array}{c}0.14 \\
{[0.029]^{* *}}\end{array}$ & $\begin{array}{c}-0.0042 \\
{[0.00030]^{* *}}\end{array}$ & $\begin{array}{c}-0.0010 \\
{[0.00048]^{*}}\end{array}$ & $\begin{array}{c}-0.0011 \\
{[0.00050]^{*}}\end{array}$ \\
\hline Effect relative to mean & 0.17 & 0.048 & -0.0097 & -0.0013 & 0.038 \\
\hline Observations & 947068 & 799105 & 947068 & 797752 & 767161 \\
\hline Mean of Dep. Var. & 8.33 & 15.8 & 0.84 & 4.00 & -0.15 \\
\hline
\end{tabular}

Notes: ${ }^{*} \mathrm{P}<.05,{ }^{* *} \mathrm{P}<.01$. Robust standard errors based on the method of Calonico et al. (forthcoming).

The sample are individuals who started receiving unemployment insurance between 1987 and 1999 within 2 years from the age thresholds. Each coefficient is from a separate regression discontinuity model with the dependent variable given in the column heading. The first panel shows the increase at the discontinuity at the age 42 threshold (where potential UI durations increase from 12 to 18 months). The second panel shows pooled estimates using the age 42 threshold as well as the increase at the age 44 threshold (where potential UI durations increase from 18 to 22 months). The models control for linear splines in age with different slopes on each side of the cutoff. The number of observations vary across specifications due to missing observations for right hand side variables: UI benefit durations (column 1) are defined for everyone in our sample (UI recipients) by definition, non-employment duration is the duration until reemployment, which is missing if individuals are never employed again within 9 years after UI entry, reemployment is defined for everyone, post wage and wage difference are slightly smaller than column 2 due to missing wage observations. 
Table 2: The Effect of Potential UI Durations on Other Match Quality Outcomes (First Age cutoff)

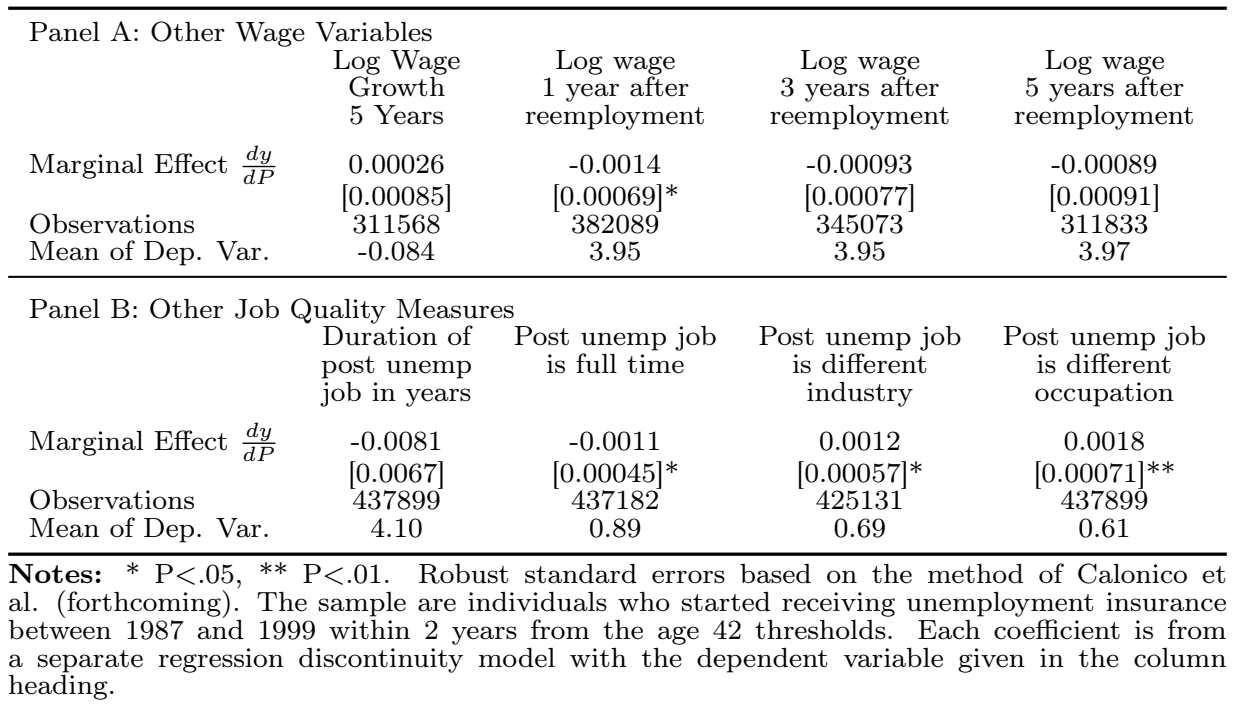

Table 3: The Effect of Potential UI Durations on Reemployment Wages Conditional on Nonemployment Duration

\begin{tabular}{|c|c|c|c|c|c|}
\hline & $\begin{array}{c}(1) \\
\log (w)\end{array}$ & $\begin{array}{c}(2) \\
\log (w)\end{array}$ & $\begin{array}{c}(3) \\
P(\log (w)>3.5)\end{array}$ & $\begin{array}{c}(4) \\
P(\log (w)>3.75)\end{array}$ & $\begin{array}{c}(5) \\
P(\log (w)>4)\end{array}$ \\
\hline \multicolumn{6}{|c|}{ Increase in Potential UI Dur. from 12 to 18 Months } \\
\hline Marginal Effect $\frac{d y}{d P}$ & $\begin{array}{l}0.000093 \\
{[0.00075]}\end{array}$ & $\begin{array}{c}-0.000042 \\
{[0.00068]}\end{array}$ & $\begin{array}{c}0.00027 \\
{[0.00049]}\end{array}$ & $\begin{array}{l}-0.00021 \\
{[0.00062]}\end{array}$ & $\begin{array}{l}-0.00030 \\
{[0.00073]}\end{array}$ \\
\hline $\begin{array}{l}\text { Observations } \\
\text { Mean of Dep. Var. }\end{array}$ & $\begin{array}{c}437182 \\
4.01\end{array}$ & $\begin{array}{c}437182 \\
4.01\end{array}$ & $\begin{array}{c}437182 \\
0.88\end{array}$ & $\begin{array}{c}437182 \\
0.75\end{array}$ & $\begin{array}{c}437182 \\
0.56\end{array}$ \\
\hline \multicolumn{6}{|c|}{ Pooling both Thresholds (12 to 18 Months and 18 to 22 Months) } \\
\hline Marginal Effect $\frac{d y}{d P}$ & $\begin{array}{c}0.00021 \\
{[0.00067]}\end{array}$ & $\begin{array}{c}0.00015 \\
{[0.00059]}\end{array}$ & $\begin{array}{c}0.00024 \\
{[0.00042]}\end{array}$ & $\begin{array}{c}0.00029 \\
{[0.00061]}\end{array}$ & $\begin{array}{l}-0.00022 \\
{[0.00069]}\end{array}$ \\
\hline $\begin{array}{l}\text { Observations } \\
\text { Mean of Dep. Var. }\end{array}$ & $\begin{array}{c}797752 \\
4.02\end{array}$ & $\begin{array}{c}797752 \\
4.02\end{array}$ & $\begin{array}{c}797752 \\
0.86\end{array}$ & $\begin{array}{l}797752 \\
0.76\end{array}$ & $\begin{array}{c}797752 \\
0.56\end{array}$ \\
\hline $\begin{array}{l}\text { Controlling for Nonemp. Duration: } \\
\text { Cubic polynomial: } \\
\text { Full set of dummies: }\end{array}$ & $\begin{array}{l}\text { Yes } \\
\text { No }\end{array}$ & $\begin{array}{l}\text { No } \\
\text { Yes }\end{array}$ & $\begin{array}{l}\text { No } \\
\text { Yes }\end{array}$ & $\begin{array}{l}\text { No } \\
\text { Yes }\end{array}$ & $\begin{array}{l}\text { No } \\
\text { Yes }\end{array}$ \\
\hline
\end{tabular}

Notes: ${ }^{*} \mathrm{P}<.05,{ }^{*} \mathrm{P}<.01$. Robust standard errors based on the method of Calonico et al. (forthcoming).

Coefficients from RD regressions. Local linear regressions (different slopes) on each side of cutoff. We report the estimated marginal effect of a one month increase in potential UI durations controlling for actual UI duration. 
Table 4: The Effect of Time Out of Work on Log Reemployment Wages, OLS and IV Estimates

\begin{tabular}{|c|c|c|c|c|c|}
\hline & Main Sample & $\begin{array}{c}\text { OLS } \\
\text { Nonemp Dur } \\
\leq 18 \text { months }\end{array}$ & $\begin{array}{c}(3) \\
\text { OLS } \\
\text { Nonemp Dur } \\
\leq 18 \text { months } \\
\text { No Exp. Restr. }\end{array}$ & Main Sample & $\begin{array}{c}(5) \\
\text { 2SLS } \\
\text { Reemp Wage } \\
\text { No Experience } \\
\text { Restrictions }\end{array}$ \\
\hline \multicolumn{6}{|c|}{ Increase in Potential UI Dur. from 12 to 18 Months } \\
\hline $\begin{array}{l}\text { Observations } \\
\text { Mean of Dep. Var. }\end{array}$ & $\begin{array}{c}-0.0067 \\
{[0.000053]^{* *}} \\
437182 \\
4.01\end{array}$ & $\begin{array}{c}-0.017 \\
{[0.00018]^{* *}} \\
332063 \\
4.08\end{array}$ & $\begin{array}{c}-0.020 \\
{[0.000092]^{* *}} \\
1392502 \\
3.96\end{array}$ & $\begin{array}{c}-0.0078 \\
{[0.0033]^{*}} \\
437182 \\
4.01\end{array}$ & $\begin{array}{c}-0.013 \\
{[0.0026]^{* *}} \\
1717597 \\
3.91\end{array}$ \\
\hline \multicolumn{6}{|c|}{ Pooling both Thresholds (12 to 18 Months and 18 to 22 Months) } \\
\hline $\begin{array}{l}\text { Observations } \\
\text { Mean of Dep. Var. }\end{array}$ & $\begin{array}{c}-0.0069 \\
{[0.000039]^{* *}} \\
797752 \\
4.02\end{array}$ & $\begin{array}{c}-0.016 \\
{[0.00013]^{* *}} \\
599408 \\
4.09\end{array}$ & $\begin{array}{c}-0.020 \\
{[0.000064]^{* *}} \\
2680474 \\
3.96\end{array}$ & $\begin{array}{c}-0.0064 \\
{[0.0031]^{*}} \\
797752 \\
4.02\end{array}$ & $\begin{array}{c}-0.015 \\
{[0.0025]^{* *}} \\
3321622 \\
3.91\end{array}$ \\
\hline \multicolumn{6}{|c|}{$\begin{array}{l}\text { Notes: }{ }^{*} \mathrm{P}<.05,{ }^{*} \mathrm{P}<.01 \text { Standard errors clustered on day level. Columns } 1-3 \text { show the slope coefficient } \\
\text { of a regression of log reemployment wages on nonemployment durations. Column } 1 \text { for the main RD sample } \\
\text { of individuals eligible to the maximum potential UI durations from Table } 1 \text {, Column } 2 \text { for the same sample } \\
\text { but with the restriction that nonemployment duration is less than } 18 \text { months, and Column } 3 \text { for the full } \\
\text { sample without experience restrictions. Columns } 4 \text { and } 5 \text { show the two-stage least squares estimator of the } \\
\text { effect of nonemployment duration on wages using UI extensions as instrument variable. Column } 4 \text { shows } \\
\text { the main RD sample, while Column } 5 \text { the full sample without experience restrictions. }\end{array}$} \\
\hline
\end{tabular}

Table 5: Slope of Mean Wage Offers as Function of $\frac{d V u / d t}{d V u / d P}$ and the effect of UI extensions conditional on duration of nonemployment $d E[w \mid t] / d P$

\begin{tabular}{lccccc}
\hline & \multicolumn{5}{c}{$\frac{d V u / d t}{d V u / d P}$} \\
$\delta=E[d E[w \mid t] / d P]$ in percent & -1 & -3 & -5 & -7 & -8 \\
\hline 0 & -0.008 & -0.008 & -0.008 & -0.008 & -0.008 \\
0.095 & -0.014 & -0.012 & -0.010 & -0.008 & -0.007 \\
0.1 & -0.014 & -0.012 & -0.010 & -0.008 & -0.007 \\
0.2 & -0.020 & -0.016 & -0.012 & -0.008 & -0.006 \\
0.4 & -0.032 & -0.024 & -0.016 & -0.008 & -0.004 \\
0.6 & -0.045 & -0.033 & -0.021 & -0.009 & -0.003 \\
0.8 & -0.057 & -0.041 & -0.025 & -0.009 & -0.001 \\
1.0 & -0.069 & -0.049 & -0.029 & -0.009 & 0.001 \\
\hline
\end{tabular}

Notes: The table shows the implied slope of the mean wage offer distribution if the effect of potential UI durations on reemployment wages conditional on nonemployment durations is not equal to zero $d E[w \mid t] / d P$. Rows show the implied slope for different values of $d E[w \mid t] / d P$ and columns for different values of $\frac{d V u / d t}{d V u / d P}$. The preferred point Estimate for $d E[w \mid t] / d P$ is $0.015 \%$ (from Table 3, column (2), bottom panel).

The upper bound of the $95 \%$ confidence interval for $d E[w \mid t] / d P$ is $0.095 \%$. 
Table 6: Sensitivity Analysis

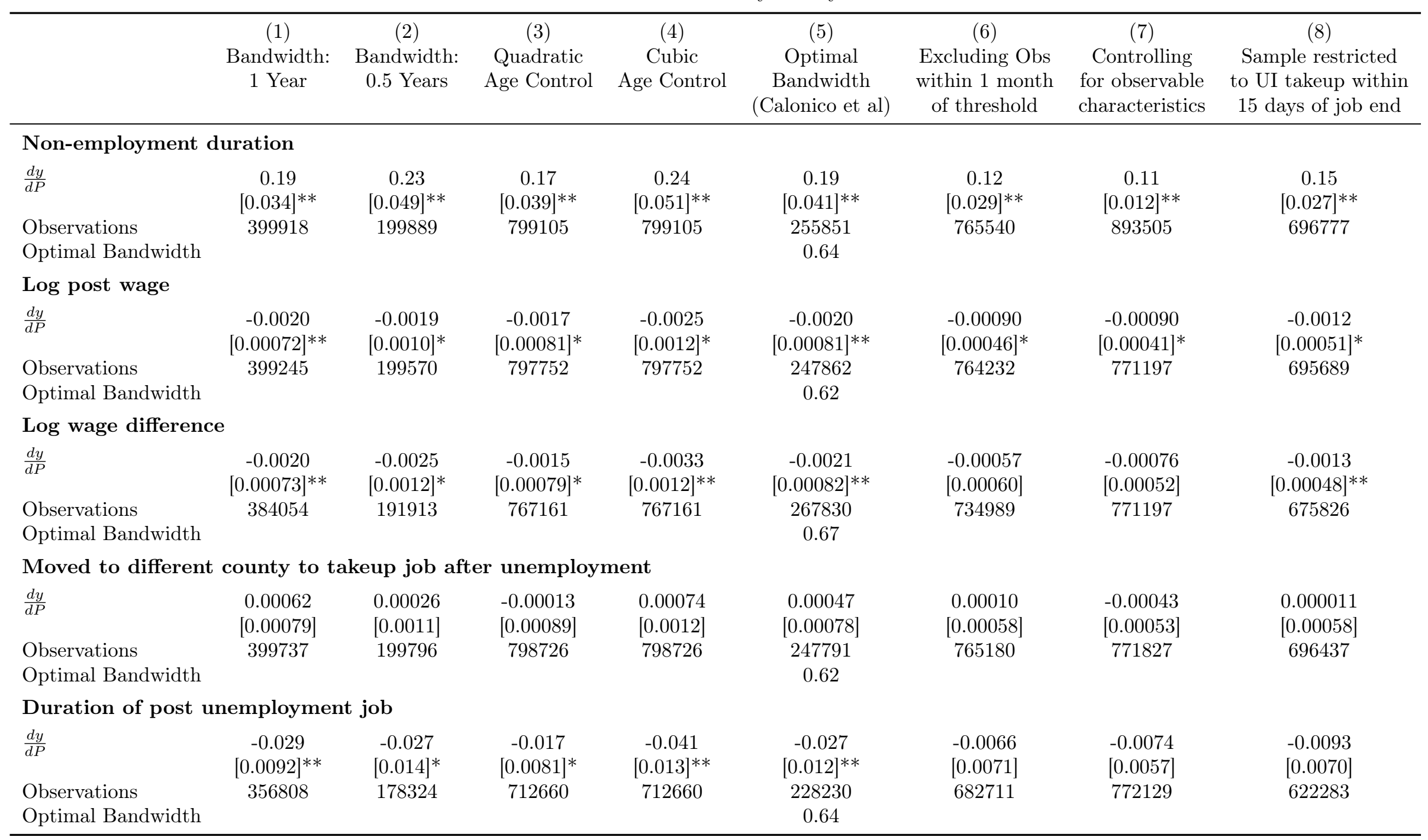

Notes: ${ }^{*} \mathrm{P}<.05,{ }^{* *} \mathrm{P}<.01$. Robust standard errors based on the method of Calonico et al. (forthcoming). The optimal bandwidth in column (5) is also calculated using the Calonico et al. algorithm.

The sample are individuals who started receiving unemployment insurance between 1987 and 1999. Each panel shows the increase at the age threshold of the dependent variable (given in the panel title) rescaled by the average increase in potential UI durations at the thresholds. The columns refer to different estimating the RD model with different bandwidths and controlling for different polynomials in age. 
Figure 1: Validity of Regression Discontinuity Design - Continuity of Density and Baseline Wages

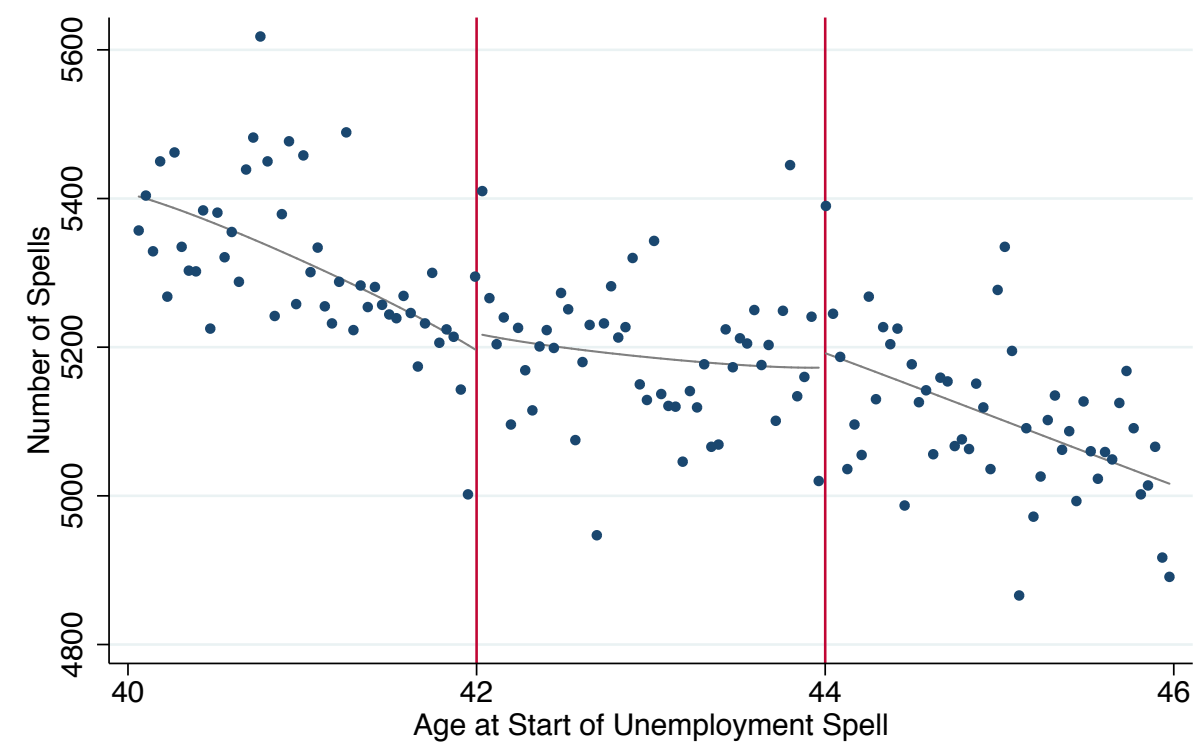

(a) Frequency of Observations Around Age Cutoffs

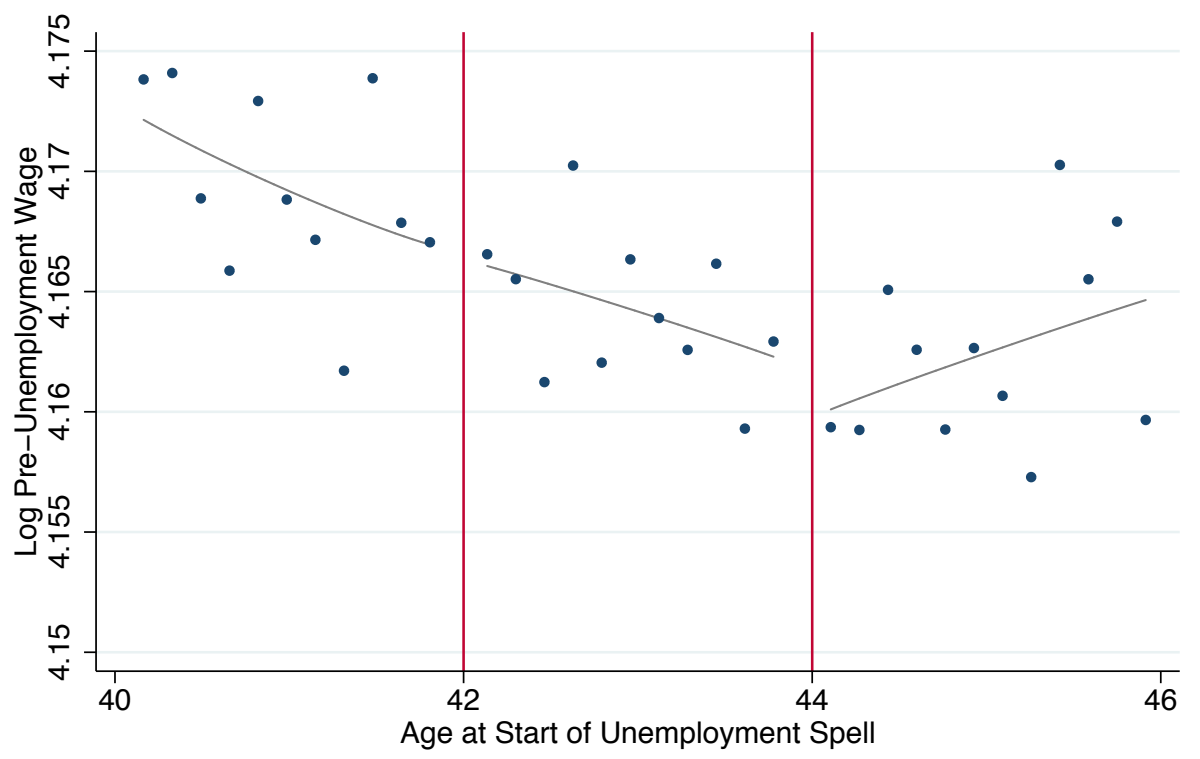

(b) Log Pre-Unemployment Wage

Notes: The top figure shows density of spells by age at the start of receiving unemployment insurance (i.e. the number of spells in 2 week interval age bins). The bottom figure shows the log pre-unemployment wage of individuals in 2 month age bins. The vertical lines mark age cutoffs for increases in potential UI durations at age 42 (12 to 18 months) and age 44 (18 to 22 months). The sample are unemployed worker claiming UI between July 1987 and March 1999 who had worked for at least 44 months in the last 7 years without intermittent UI spell. 
Figure 2: The Effect of Extended Potential UI Durations on Benefit and Nonempoyment Durations

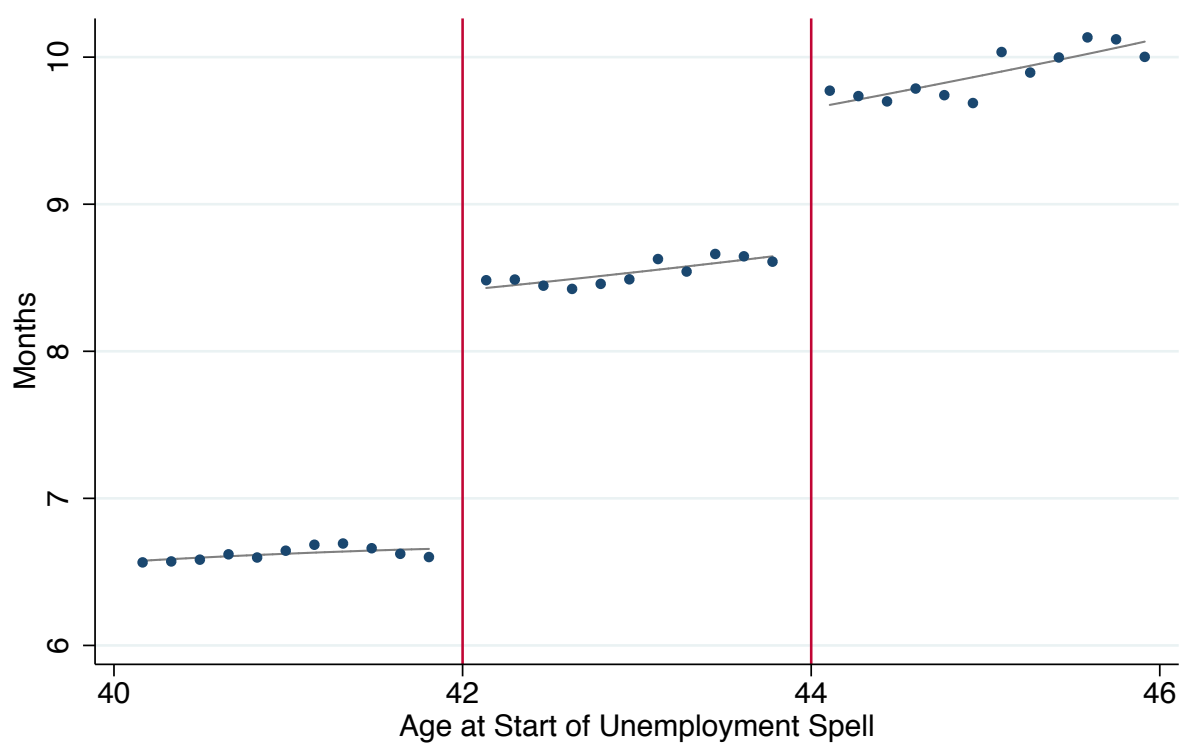

(a) Months of receiving UI benefits

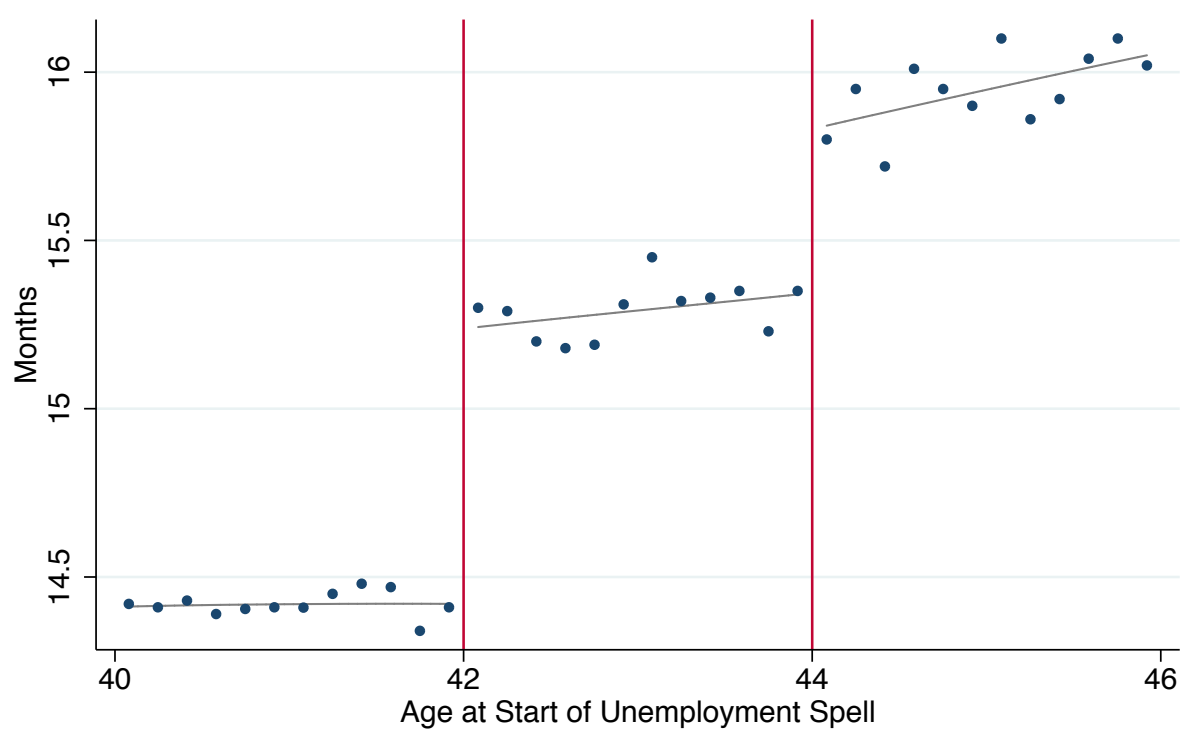

(b) Months of Nonemployment

Notes: The top figure shows average durations of receiving UI benefits by age at the start of unemployment insurance receipt. The bottom figure shows average nonemployment durations for these workers, where nonemployment duration is measured as the time until return to a job and is capped at 36 months. Each dot corresponds to an average over 60 days. The continuous lines represent quadratic polynomials fitted separately within the respective age range. The vertical lines mark age cutoffs for increases in potential UI durations at age 42 (12 to 18 months), 44 (18 to 22 months). 
Figure 3: The Effect of Extended Potential UI Durations on Post Unemployment Wages

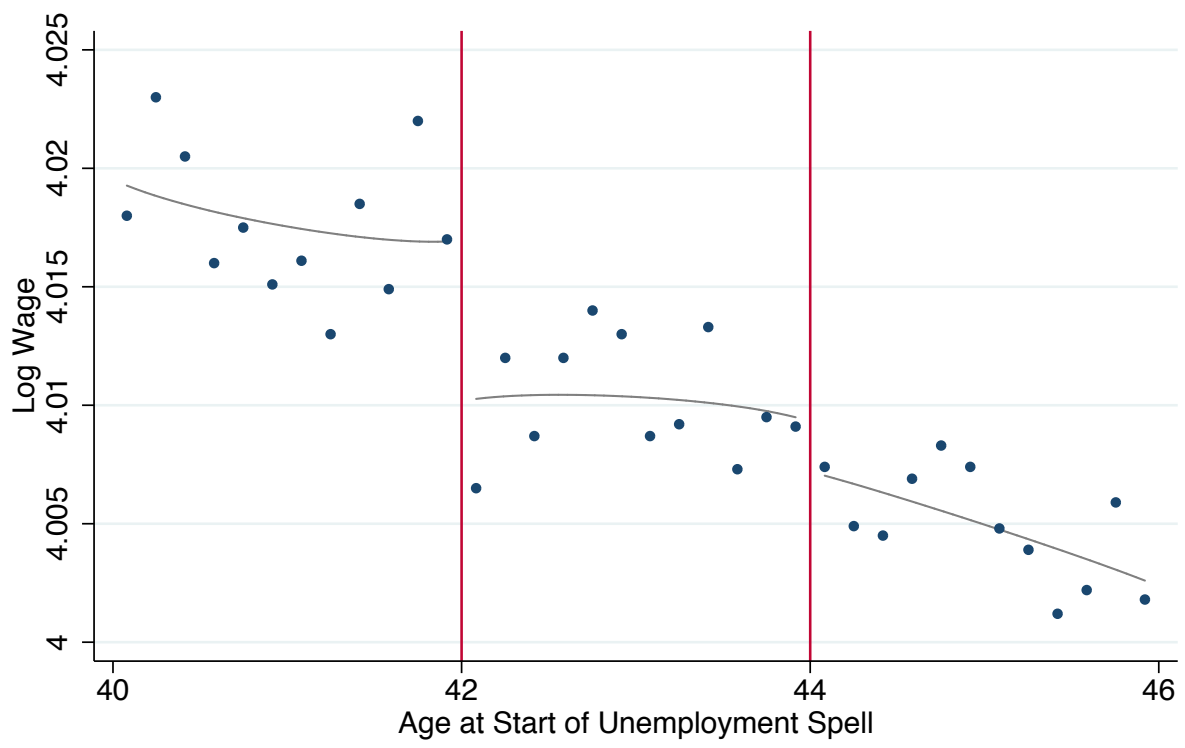

(a) Log post unemployment wage

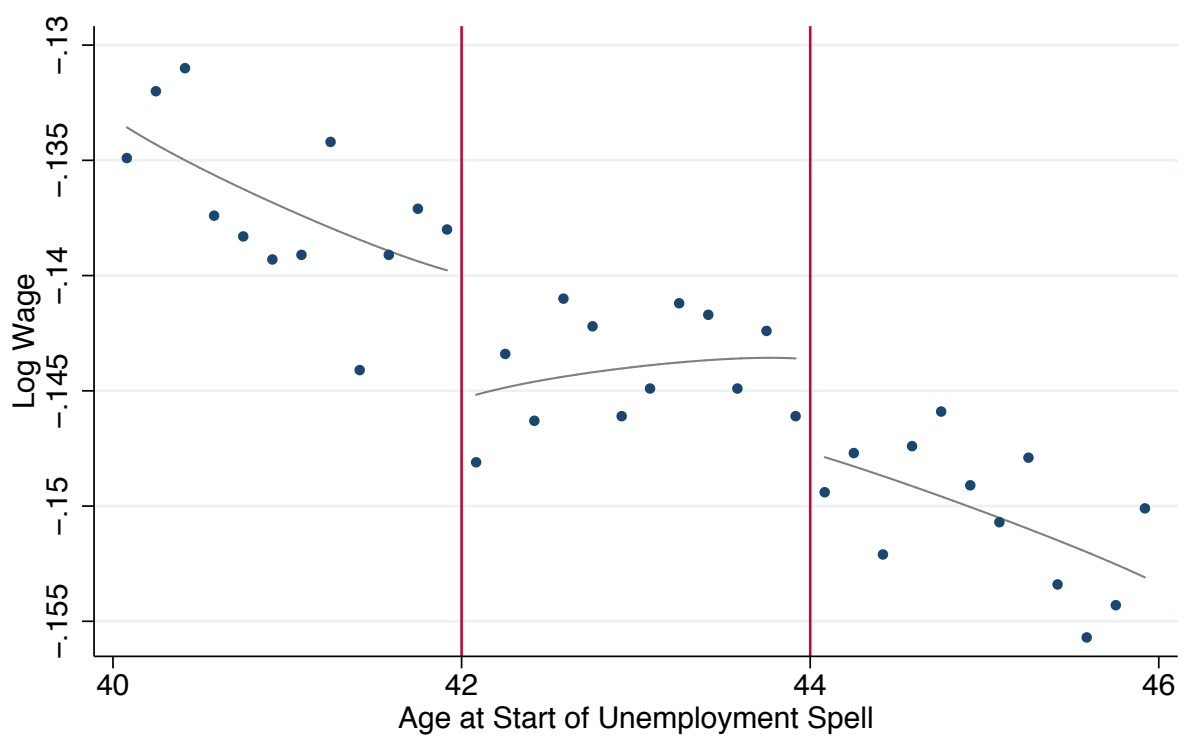

(b) Log wage difference (pre unemployment minus post unemployment)

Notes: The top figure shows average post unemployment log wages by age at the start of unemployment insurance receipt. The bottom figure shows average difference in the pre and post unemployment $\log$ wage for these workers. Each dot corresponds to an average over 60 days. The continuous lines represent quadratic polynomials fitted separately within the respective age range. The vertical lines mark age cutoffs for increases in potential UI durations at age 42 (12 to 18 months), 44 (18 to 22 months). 
Figure 4: The Effects of Extended Potential UI Durations on Selection throughout the Spell of Non-employment

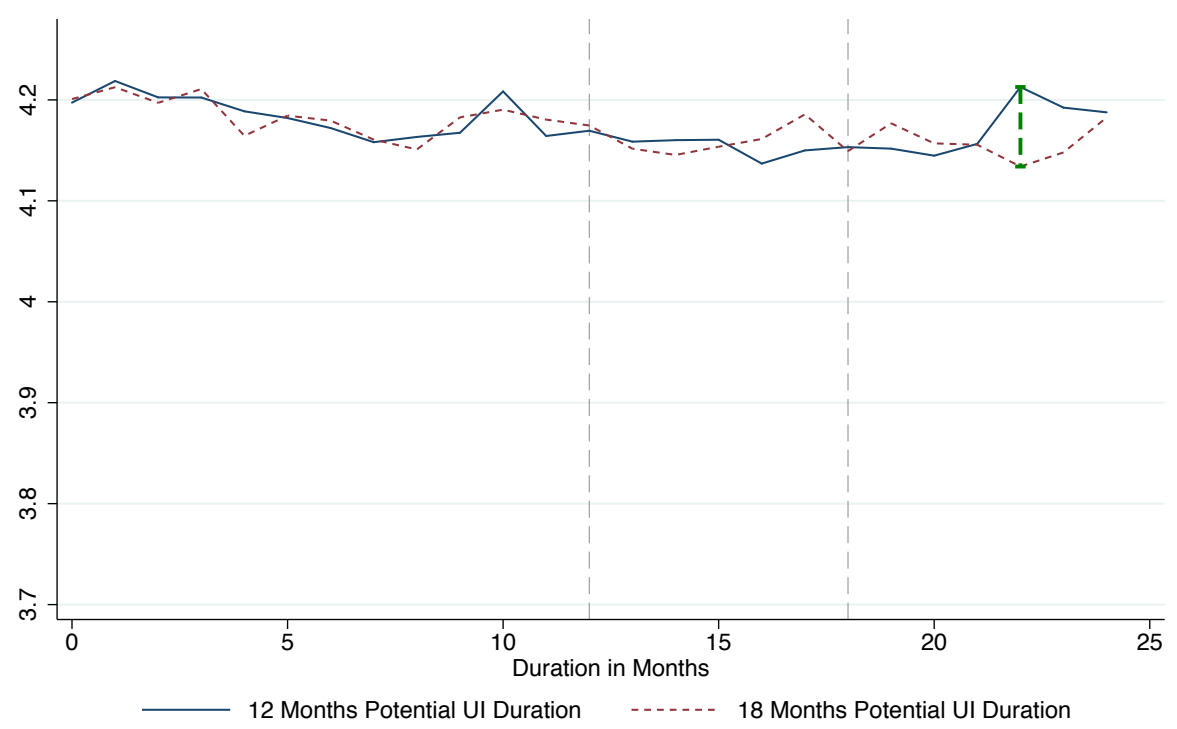

(a) Pre-unemployment log wage by time of non-emp exit

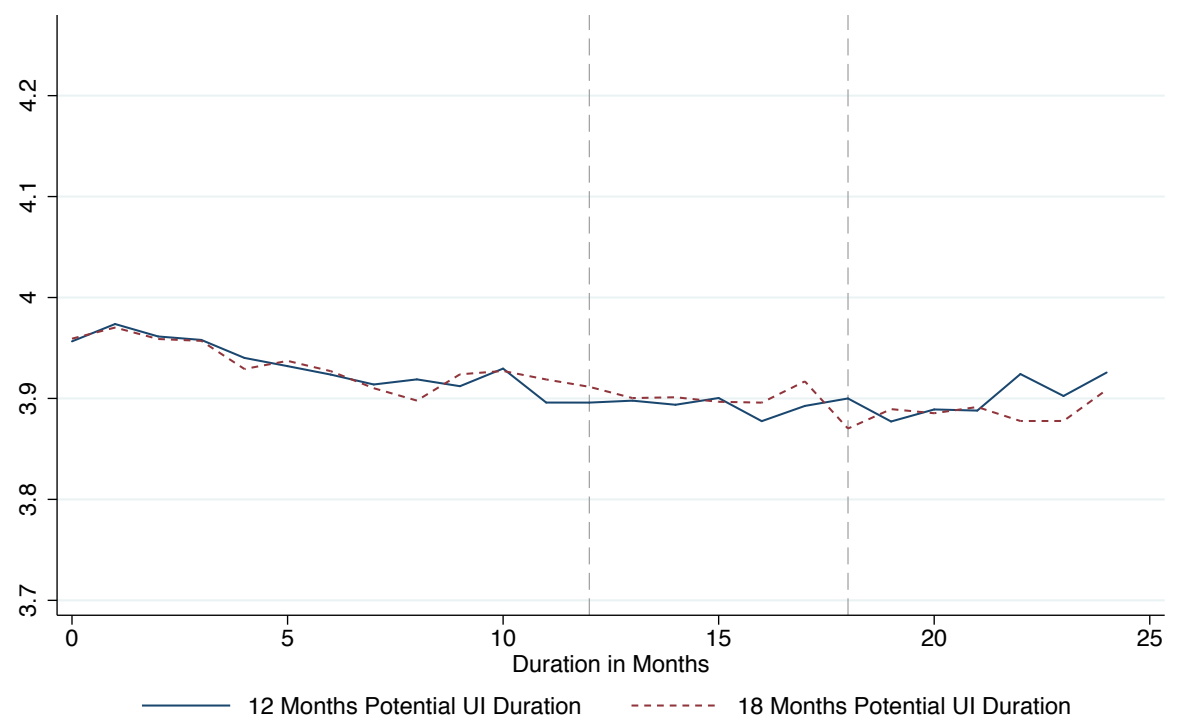

(b) Predicted reemployment log wage by time of non-emp exit

Notes: The difference between the lines is estimated pointwise at each point of support using regression discontinuity estimation. Vertical bars indicate that the differences are statistically significant from each other at the five percent level. The sample are unemployed worker claiming UI between July 1987 and March 1999 who had worked for at least 36 months in the last 7 years without intermittent UI spell. For details see text. 
Figure 5: Effect of Increasing Potential Unemployment Insurance (UI) Durations from 12 to 18 Months on the Hazard and Survival Functions - Regression Discontinuity Estimate at Age 42 Discontinuity

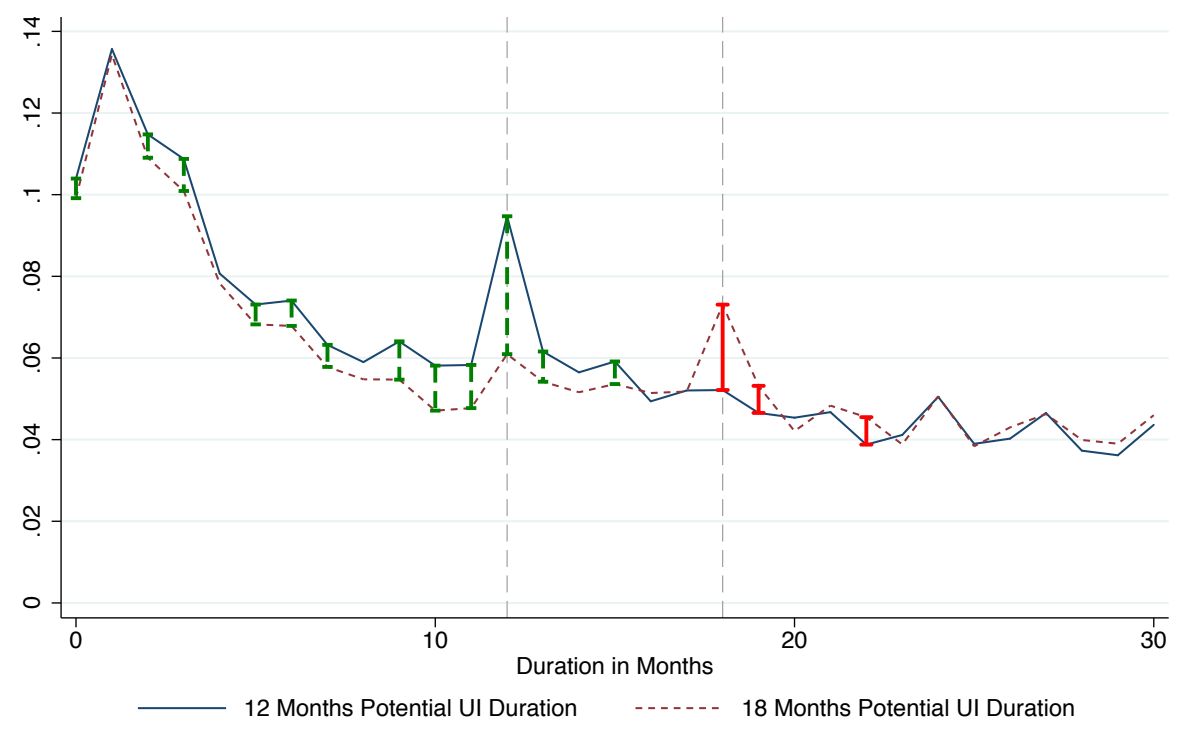

(a) Unemployment Exit Hazard

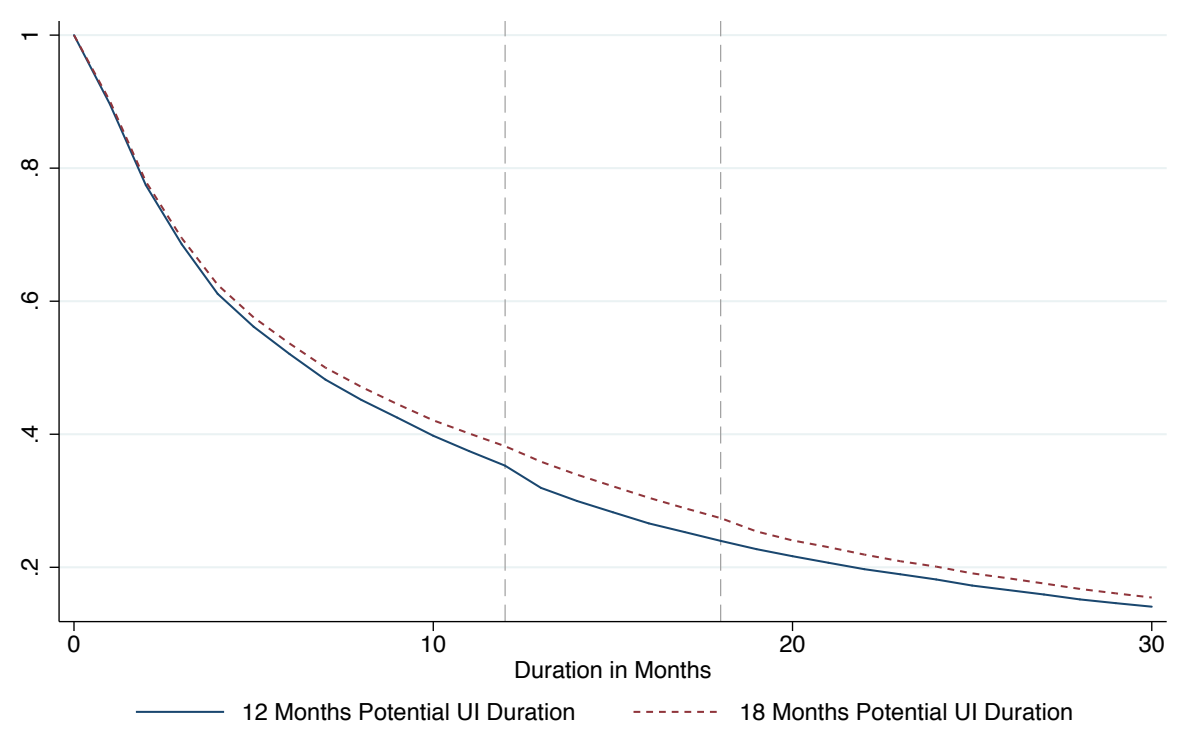

(b) Survival Functions

Notes: The difference between the hazard functions is estimated pointwise at each point of support using regression discontinuity estimation. Vertical bars indicate that the hazard rates are statistically significant from each other at the five percent level. The sample are unemployed worker claiming UI between July 1987 and March 1999 who had worked for at least 36 months in the last 7 years without intermittent UI spell. For details see text. 
Figure 6: The Effects of Extended Potential UI Durations on Reemployment Wages throughout the Spell of Non-employment

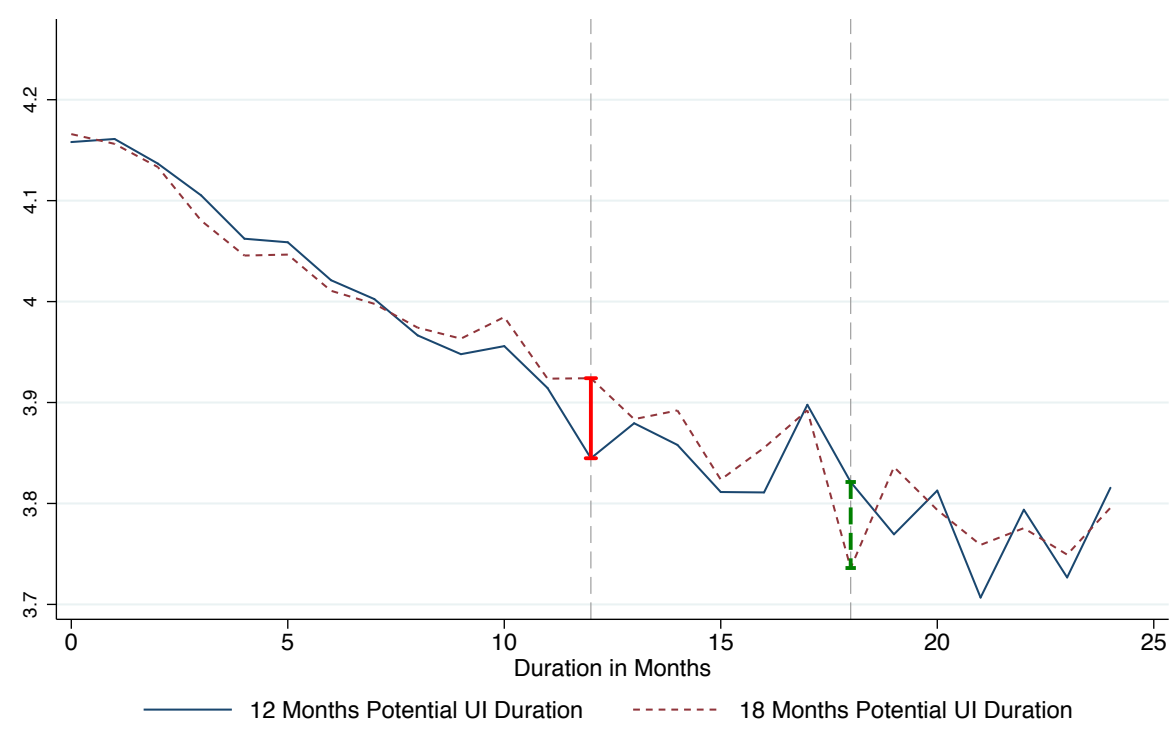

(a) Post-unemployment log wage

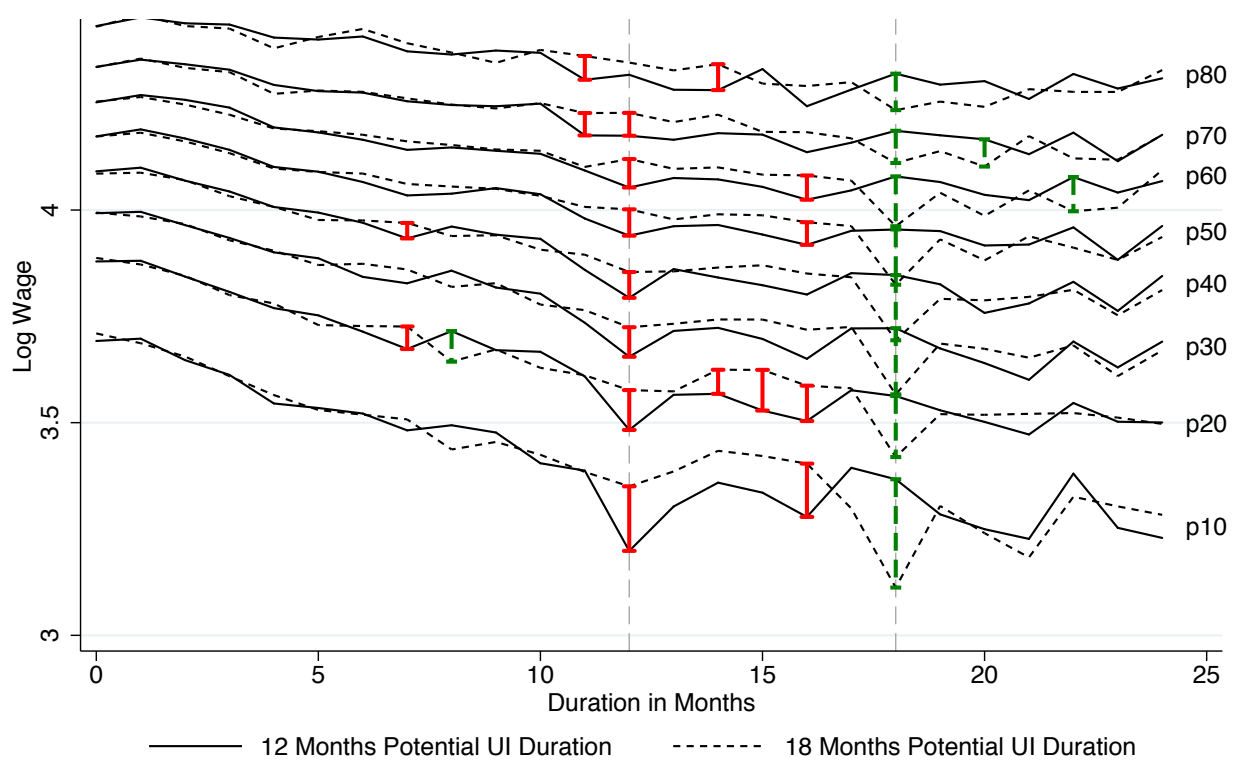

(b) Post-unemployment log wage

Notes: The difference between the reemployment wage paths is estimated pointwise at each point of support using regression discontinuity estimation. Vertical bars indicate that the differences in the reemployment wages are statistically significant from each other at the five percent level. The sample are unemployed worker claiming UI between July 1987 and March 1999 who had worked for at least 36 months in the last 7 years without intermittent UI spell. For details see text. 


\section{Web Appendix}

\section{Contents}

1 Model Details $\quad 2$

1.1 Optimal Reservation Wage and Search Intensity Paths . . . . . . . . . . . . . 2

1.2 Derivation of Equation (7) in main text . . . . . . . . . . . . . 4

1.3 Proof of Proposition 1 . . . . . . . . . . . . . . . 6

1.4 The Causal Effect of Nonemployment Duration on Wages with Binding Reservation Wage . . . . . . . . . . . . . . . . . . . . . 6

2 Empirical Implementation $\quad 6$

2.1 Upward Bias in Wage Regression . . . . . . . . . . . . . . . . . 6

\section{List of Tables}

1 Smoothness of Predetermined Variables around Age Thresholds . . . . . . . . 8

2 The Effect of Potential UI Durations on Non-employment Durations and Wages by Sub-groups . . . . . . . . . . . . . . . . . . . . . . . 9

3 Slope of Mean Wage Offers as Function of $\frac{d V u / d t}{d V u / d P}$ and the effect of UI extensions conditional on duration of nonemployment $d E[w \mid t] / d P \ldots \ldots \ldots$

4 The Effect of UI Extensions by Different States of the Business Cycle . . . . . . 11

5 Investigating Different Channels of Wage Losses . . . . . . . . . . . . . . 12

\section{List of Figures}

1 The Effects of Extended Potential UI Durations on Selection throughout the Spell of Non-employment . . . . . . . . . . . . . . . . . . . . . . . . 13

2 The Effects of Extended Potential UI Durations on Selection throughout the Spell of Non-employment . . . . . . . . . . . . . . . . . . . . . . 14

3 Quantile Regressions of the Effects of Extended Potential UI Durations on Reemployment Wages throughout the Spell of Non-employment . . . . . . . . . . 15 


\section{Model Details}

\subsection{Optimal Reservation Wage and Search Intensity Paths}

In the following we omit individual $i$ subscripts from the model parameters to simplify notations.

Employment is an absorbing state, i.e. once employed a worker does not get laid off or move to better jobs. Since workers discount the future at the common subjective discount rate $\rho$, the value of being employed $V^{e}$ satisfies:

$$
V^{e}\left(w^{*}\right)=\frac{1}{\rho} w^{*}
$$

The Bellman equation for an unemployed worker is given as:

$$
\begin{aligned}
V^{u}(t)=b_{t}+ & \max _{\lambda_{t}}\left[-\psi\left(\lambda_{t}\right)+\left(1-\lambda_{t}\right) \frac{1}{1+\rho} V^{u}(t+1)\right. \\
& \left.+\lambda_{t} \frac{1}{1+\rho} \int_{w} \max _{\text {accept }, \text { reject }}\left[V^{e}\left(w^{*}\right), V^{u}(t+1)\right] d F_{t}\left(w^{*}\right)\right]
\end{aligned}
$$

Since $V^{e}\left(w^{*}\right)$ is increasing in $w^{*}$, the optimal search behavior of the worker is described by a reservation wage $\phi_{t}$, so that all wage offers $w^{*} \geq \phi_{t}$ are accepted. This allows for writing the Bellman equation as:

$$
V^{u}(t)=b_{t}+\max _{\lambda_{t}}\left[-\psi\left(\lambda_{t}\right)+\frac{1}{1+\rho}\left(V^{u}(t+1)+\lambda_{t} \int_{\phi_{t}}^{\infty} V^{e}\left(w^{*}\right)-V^{u}(t+1) d F_{t}\left(w^{*}\right)\right)\right]
$$

Suppose that the environment becomes stationary for some $t \geq T$. In particular UI benefits and the wage offer distribution become constant after $T: b_{t}=b, F_{t}\left(w^{*}\right)=F_{T}\left(w^{*}\right)$. This implies that the optimal search strategy is a constant: reservation wage $\phi_{T}$. Using the fact that $V^{u}(t)=V^{u}(t+1)$ in the stationary environment, it follows that the stationary reservation wage and the optimal search intensity are given by the follwowing system of equations:

$$
\begin{gathered}
\phi_{T}=(1+\rho)\left(b_{T}-\psi\left(\lambda_{T}\right)\right)+\frac{\lambda_{T}}{\rho} \int_{\phi_{T}}^{\infty} w^{*}-\phi_{T} d F_{T}\left(w^{*}\right) \\
(1+\rho) \rho \psi^{\prime}\left(\lambda_{T}\right)-\int_{\phi_{T}}^{\infty} w^{*}-\phi_{T} d F_{T}\left(w^{*}\right)=0
\end{gathered}
$$

An optimal search strategy in this model is described by a reservation wage $\phi_{t}$ and search intensity $\lambda_{t}$ in each period. In the appendix we show that the optimal reservation wage and search intensity paths are described by the following pair of difference equations, where the reservation wage and search intensity in period $t-1$ can be derived from the reservatoin wage in period $t$. 
In the nonstationary environment, $t<T$, we use the fact that: $\frac{1}{\rho} \phi_{t}=V^{u}(t+1)$. Therefore knowledge about the reservation wage $\phi_{t}$ and the optimal search intensity $\lambda_{t}$ in period $t$ will allow us to find the reservation wage in period $t-1$ using this equation:

$$
(1+\rho) \phi_{t-1}=(1+\rho) \rho\left(b_{t-1}-\psi\left(\lambda_{t}\right)\right)+\phi_{t}+\lambda_{t} \int_{\phi_{t}}^{\infty} w^{*}-\phi_{t} d F_{t}\left(w^{*}\right)
$$

Once we have found the reservation wage $\phi_{t-1}$ in period $t-1$ we can directly solve for the optimal search intensity in the same period:

$$
(1+\rho) \rho \psi^{\prime}\left(\lambda_{t-1}\right)-\int_{\phi_{t-1}}^{\infty} w^{*}-\phi_{t-1} d F_{t}\left(w^{*}\right)=0
$$

In our empirical application we consider a system where UI benefits are at a constant level $b$ up to the maximum potential duration of receiving UI benefits $P$. After benefit exhaustion, indivduals receive a second tier of payments indefinitely. We therefore have that $b_{t}=b$ for all $t \leq P$ and $b_{t}=\underline{b}$ for all $t>P$. Consider how the reservation wage path and the search intensity path is affected by a change in potential UI durations $P$. Using the first order conditions we get that:

$$
\frac{d \phi_{t}}{d P}=\frac{d V_{t+1}^{u}}{d P} \rho
$$

and

$$
\frac{d \lambda_{t}}{d P}=-\frac{d V_{t+1}^{u}}{d P} \frac{1-F_{t}\left(\phi_{t}\right)}{(1+\rho) \psi^{\prime \prime}\left(\lambda_{t}\right)}
$$

If there is at least a small chance that individuals might not find a job until UI exhaustion at $t=P$, then increasing $P$ will increase the value of remaining unemployed for all $t \leq P$, so that $\frac{d V_{t+1}^{u}}{d P}>0$. Therefore increasing $P$ will increase the reservation wage $\phi_{t}$ and lower search intensity $\lambda_{t}$.

Since the hazard of leaving unemployment is given as $h_{t}=\lambda_{t}\left(1-F_{t}\left(\phi_{t}\right)\right)$, we get that

$$
\frac{d h_{t}}{d P}=-\frac{d V_{t+1}^{u}}{d P}\left[\frac{\left(1-F_{t}\left(\phi_{t}\right)\right)^{2}}{(1+\rho) \psi^{\prime \prime}\left(\lambda_{t}\right)}+\rho \lambda_{t} f\left(\phi_{t}\right)\right]
$$

Therefore if the extension in UI benefits affects the value of being unemployed in period $t$, then it will lower the probability of leaving unemployment in that period. 


\subsection{Derivation of Equation (7) in main text}

The expected reemployment wage of individual $i$ conditional on $t$ is given as:

$$
w_{i}^{e}(t, P)=E\left[w\left(t_{i}, P, \zeta_{i}, u\right) \mid t_{i}, \zeta_{i}\right]=\frac{\int_{\phi_{t}}^{\infty} w^{*} d F_{t}\left(w^{*}\right)}{1-F_{t}\left(\phi_{t}\right)}
$$

Individual unemployment duration $t_{i}=t\left(P, \zeta_{i}, \varepsilon\right)$ is equal to the first period when a job offer arrives with a wage above the reservation wage. Thus $\varepsilon$ is a vector of indicators signifying whether for each period there is a job offer with a wage above the reservation wage: $\varepsilon=\left\{I\left[j_{o b} \_\right.\right.$offer $\left.r_{t}\right] \times$ $\left.I\left[w * \geq \phi_{t}\right]\right\}$ for $t=0,1, \ldots$ Note that the realized $\varepsilon$ does not contain information about the value realized of realized wage offers conditional on being above the reservation wage.

We denote the distribution of $\varepsilon$ for an individual with parameters $\zeta_{i}$ as $d H\left(\varepsilon ; \zeta_{i}\right)$ and therefore the expected unemployment duration of an individual is: $t_{i}^{e}\left(P, \zeta_{i}\right)=\int t\left(P, \zeta_{i}, \varepsilon\right) d H\left(\varepsilon ; \zeta_{i}\right)$

The expected reemployment wage of individual $i$ (not conditioning on unemployment duration) $w_{i}^{e}(P)=E\left[w_{i}^{e}(t, P) \mid \zeta_{i}\right]$ can be obtained by integrating over $H\left(t ; \zeta_{i}\right)$ :

$$
w_{i}^{e}(P)=E\left[w\left(t_{i}, P, \zeta_{i}, u\right) \mid \zeta_{i}\right]=\int w_{i}^{e}(t, P) d H\left(\varepsilon ; \zeta_{i}\right)
$$

The expected reemployment wage in population conditional on $t, w^{e}(t, P)=E\left[w_{i}^{e}(t, P) \mid t\right]$ is obtained by integrating over the distribution of $\zeta_{i}$ :

$$
w^{e}(t, P)=E\left[w\left(t_{i}, P, \zeta_{i}, u\right) \mid t\right]=\int w_{i}^{e}(t, P) d G\left(\zeta_{i}\right)
$$

The expected unconditional reemployment wage $w^{e}(P)=E\left[w_{i}^{e}(t, P)\right]=E\left[w_{i}^{e}(P)\right]=E\left[w^{e}(t, P)\right]$ can then be obtained by integrating over durations $t$ and parameters $\zeta_{i}$

$$
w^{e}(P)=E\left[w\left(t_{i}, P, \zeta_{i}, u\right)\right]=\iint w_{i}^{e}(t, P) d H\left(\varepsilon ; \zeta_{i}\right) d G\left(\zeta_{i}\right)
$$

Now we have that:

$$
\begin{aligned}
w^{e}(P+h)-w^{e}(P) & =E\left[w_{i}^{e}(t(P+h), P+h)-w_{i}^{e}(t(P), P)\right] \\
& =E\left[w_{i}^{e}(t(P+h), P+h)-w_{i}^{e}(t(P+h), P)+w_{i}^{e}(t(P+h), P)-w_{i}^{e}(t(P), P)\right] \\
& =E\left[w_{i}^{e}(t(P+h), P+h)-w_{i}^{e}(t(P+h), P)\right]+E\left[w_{i}^{e}(t(P+h), P)-w_{i}^{e}(t(P), P)\right]
\end{aligned}
$$

Consider the second part of this expression: 


$$
\begin{aligned}
E\left[w_{i}^{e}\left(t_{i}(P+h), P\right)-w_{i}^{e}\left(t_{i}(P), P\right)\right] & =E\left[\int_{t_{i}(P, \varepsilon)}^{t_{i}(P+h, \varepsilon)} \frac{\partial w_{i}^{e}}{\partial t}(t) d t\right] \\
& =E\left[\int_{0}^{\infty} \frac{\partial w_{i}^{e}}{\partial t}(t) \times I\left(t_{i}(P, \varepsilon)<t<t_{i}(P+h, \varepsilon)\right) d t\right] \\
& =\iiint_{0}^{\infty} \frac{\partial w_{i}^{e}}{\partial t}(t) \times I\left(t_{i}(P, \varepsilon)<t<t_{i}(P+h, \varepsilon)\right) d t d H\left(\varepsilon ; \zeta_{i}\right) d G\left(\zeta_{i}\right) \\
& =\int_{0}^{\infty} \iint \frac{\partial w_{i}^{e}}{\partial t}(t) \times I\left(t_{i}(P, \varepsilon)<t<t_{i}(P+h, \varepsilon)\right) d H\left(\varepsilon ; \zeta_{i}\right) d G\left(\zeta_{i}\right) d t \\
& =\int_{0}^{\infty} \int \frac{\partial w_{i}^{e}}{\partial t}(t) \times \int I\left(t_{i}(P, \varepsilon)<t<t_{i}(P+h, \varepsilon)\right) d H\left(\varepsilon ; \zeta_{i}\right) d G\left(\zeta_{i}\right) d t \\
& =\int_{0}^{\infty} \int \frac{\partial w_{i}^{e}}{\partial t}(t) \times I\left(t_{i}^{e}(P)<t<t_{i}^{e}(P+h)\right) d G\left(\zeta_{i}\right) d t \\
& =\int_{0}^{\infty} E_{\zeta}\left[\frac{\partial w_{i}^{e}(t)}{\partial t} \times I\left(t_{i}^{e}(P)<t<t_{i}^{e}(P+h)\right)\right] d t \\
& =\int_{0}^{\infty} E_{\zeta}\left[\frac{\partial w_{i}^{e}(t)}{\partial t} \mid t, t_{i}^{e}(P)<t<t_{i}^{e}(P+h)\right] \operatorname{Pr}\left(t_{i}^{e}(P)<t<t_{i}^{e}(P+h)\right) d t(9)
\end{aligned}
$$

Note that

$$
\begin{aligned}
\operatorname{Pr}\left(t_{i}^{e}(P)<t<t_{i}^{e}(P+h)\right) & =\operatorname{Pr}\left(t<t_{i}^{e}(P+h)\right)-\operatorname{Pr}\left(t<t_{i}^{e}(P)\right) \\
& =S(t ; P+h))-S(t ; P))
\end{aligned}
$$

Taking the limit of equation (9) for $h \rightarrow 0$, we get that:

$$
\begin{aligned}
\lim _{h \rightarrow 0} \frac{E\left[w_{i}\left(t_{i}(P+h), P\right)-w_{i}\left(t_{i}(P)\right), P\right]}{h} & =\lim _{h \rightarrow 0} \frac{\int_{0}^{\infty} E_{\zeta}\left[\frac{\partial w_{i}^{e}(t)}{\partial t} \mid t_{i}^{e}(P)<t<t_{i}^{e}(P+h)\right] \operatorname{Pr}\left(t_{i}^{e}(P)<t<t_{i}^{e}(P+h)\right) d t}{h} \\
& =\int_{0}^{\infty} \lim _{h \rightarrow 0} \frac{E_{\zeta}\left[\frac{\partial w_{i}^{e}(t)}{\partial t} \mid t_{i}^{e}(P)<t<t_{i}^{e}(P+h)\right] \operatorname{Pr}\left(t_{i}^{e}(P)<t<t_{i}^{e}(P+h)\right)}{h} d t \\
& =\int_{0}^{\infty} \lim _{h \rightarrow 0} \frac{E_{\zeta}\left[\frac{\partial w_{i}^{e}(t)}{\partial t} \mid t_{i}^{e}(P)<t<t_{i}^{e}(P+h)\right]}{h} \times \lim _{h \rightarrow 0} \frac{\operatorname{Pr}\left(t_{i}^{e}(P)<t<t_{i}^{e}(P+h)\right)}{h} d t \\
& =\int_{0}^{\infty} E_{\zeta}\left[\frac{\partial w_{i}^{e}(t)}{\partial t} \mid \frac{\partial S_{i}(t)}{\partial P}>0\right] \frac{\partial S(t)}{\partial P} d t
\end{aligned}
$$

Now we take the limit of equation (8) for $h \rightarrow 0$, to obtain the derivative

$$
\begin{aligned}
\frac{d E\left[w_{i}^{e}\left(t_{i}, P, \zeta_{i}, u\right)\right]}{d P} & =\lim _{h \rightarrow 0} \frac{w^{e}(P+h)-w^{e}(P)}{h} \\
& =E\left[\frac{\partial w_{i}^{e}(t, P)}{\partial P}\right]+\int_{0}^{\infty} E_{\zeta}\left[\frac{\partial w_{i}^{e}(t)}{\partial t} \mid \frac{\partial S_{i}(t)}{\partial P}>0\right] \frac{\partial S(t)}{\partial P} d t
\end{aligned}
$$

q.e.d. 


\subsection{Proof of Proposition 1}

Suppose $\frac{\partial w_{i}^{e}(t, P)}{\partial \phi_{i t}}=0$ for all individuals who respond to changes in UI durations. It then follows that $E\left[\frac{\partial w_{i}^{e}(t, P)}{\partial P}\right]=0$ or equivalently that the first term in equation (8) in this appendix is equal to zero. Furthermore $\frac{\partial w_{i}^{e}(t, P)}{\partial \phi_{i t}}=0$ implies that $\frac{\partial w_{i}^{e}(t)}{\partial t}=\frac{\partial w_{i}^{e}\left(\phi_{i t}, \mu_{i t}\right)}{\partial \mu_{i t}} \frac{\partial \mu_{i t}}{\partial t}$. Plugging this into equation (9) above, directly yields the result in Proposition 1.

\subsection{The Causal Effect of Nonemployment Duration on Wages with Binding Reservation Wage}

Here we show how the causal effect of nonemployment durations on wages can be calculated for the homogenous-linear case. We have that $\frac{\partial w^{e}(t, P)}{\partial P}=\frac{\partial w^{e}(t, P)}{\partial \phi_{t}} \frac{\partial \phi_{t}}{\partial P}=\frac{\partial w^{e}(t, P)}{\partial \phi_{t}} \frac{d V_{t}^{u}}{d P} \rho$ and therefore: $\frac{\partial w^{e}(t, P)}{\partial \phi_{t}}=\frac{\frac{\partial w^{e}(t, P)}{\partial P}}{\frac{d V_{t}^{u}}{d P} \rho}$. To simplify notation denote: $\delta=E\left[\frac{\partial w^{e}(t, P)}{\partial P}\right]$ and note that in the linear case: $E\left[\frac{\partial w^{e}(t, P)}{\partial P}\right]=\frac{\partial w^{e}(t, P)}{\partial P}$. Plugging this into equation (5) in the main text we get:

$$
\begin{aligned}
\frac{d E\left[w^{e}(t ; P)\right]}{d P} & =\delta+\left[\delta\left(\frac{d V_{t}^{u}}{d P} \rho\right)^{-1} \frac{\partial \phi_{t}}{\partial t}+\frac{\partial w^{e}(t ; P)}{\partial \mu_{t}} \frac{\partial \mu_{t}}{\partial t}\right] \frac{d D}{d P} \\
& =\delta+\left[\delta \frac{\frac{d V_{t}^{u}}{d t}}{\frac{d V_{t}^{u}}{d P}}+\frac{\partial w^{e}(t ; P)}{\partial \mu_{t}} \frac{\partial \mu_{t}}{\partial t}\right] \frac{d D}{d P}
\end{aligned}
$$

where we use that the change in the reservation wage from one period to the next is proportional to the change in the value of unemployment: $\frac{\partial \phi_{t}}{\partial t}=\frac{d V_{t}^{u}}{d t} \rho$. Some rearranging yields the slope of the wage offer distribution as a function of the IV estimator from above plus a term that depends on $\delta$ and the ratio of the change in the value of unemployment over time, relative to the change in the value of unemployment when potential UI benefits are extended by one month:

$$
\frac{\partial w^{e}(t ; P)}{\partial \mu_{t}} \frac{\partial \mu_{t}}{\partial t}=\frac{\frac{d E\left[w^{e}(t ; P)\right]}{d P}}{\frac{d D}{d P}}-\delta\left[\frac{1}{\frac{d D}{d P}}+\frac{\frac{d V_{t}^{u}}{d t}}{\frac{d V_{t}^{u}}{d P}}\right]
$$

\section{Empirical Implementation}

\subsection{Upward Bias in Wage Regression}

Consider first the case in which the effect of potential UI durations on wages is the same at all nonemployment durations, and which the effect of nonemployment durations on wages is linear. 
We are interested in an estimate of the coefficient $\delta$ in the linear model

$$
w_{i}^{*}=\alpha+\delta P_{i}+\theta t_{i}+u_{i}
$$

where $w=$ wage, $P=$ potential UI durations, $t=$ actual nonemployment durations. This is a linear version of equation (9) in the main text, where we have dropped the low-order polynomial in age for simplicity. Instead, we assume directly that we have that $\operatorname{cov}(P, u)=0$ and $E[u]=0$. Moreover, we know that $\operatorname{cov}(P, t) \neq 0$ and suspect that $\operatorname{cov}(t, u) \neq 0$. In matrix notation, the OLS coefficient for $\delta$ from the short regression is

$$
\hat{\delta}=\frac{P^{\prime} M_{t} w}{P^{\prime} M_{t} P}=\frac{\left(M_{t} P\right)^{\prime} M_{t} w}{P^{\prime} M_{t} P}
$$

where $M_{x} \equiv 1-P_{x}=1-x\left(x^{\prime} x\right)^{-1} x^{\prime}$ is the orthogonal projector onto the space orthogonal to $x$, and $P_{x}$ is the orthogonal projector onto the space of $x$.

The numerator of the expression for the OLS estimator for $\delta$ is what is important. Since we have $M_{t} w=\delta M_{t} P+M_{t} u$, we have that

$$
\left(M_{t} P\right)^{\prime} M_{t} w=\delta P^{\prime} M_{t} P+P^{\prime} M_{t} u
$$

where the omitted variable bias term can be rewritten as $P^{\prime} M_{t} u=P^{\prime} u-P^{\prime} P_{t} u=-P^{\prime} P_{t} u=-\left(P_{t} P\right)^{\prime} P_{t} u$, where we used the fact that $\operatorname{cov}(P, u)=E[P u] \approx P^{\prime} u / N=0$ given that $E[u]=0$. As a result we get

$$
\hat{\delta}=\frac{P^{\prime} M_{t} w}{P^{\prime} M_{t} P}=\delta+\frac{-P^{\prime} P_{t} u}{P^{\prime} M_{t} P}
$$

Since $P$ is uncorrelated with $u$, the second term in this expression can only be zero if there is no endogeneity, i.e., if $\operatorname{cov}(u, t)=0$. (This is the intution behind the test for endogeneity by Davidson and McKinnon, which tests the null hypothesis that the coefficient on the instrument when directly included in the 'structural' regression is zero, where $\delta$ would be equal to zero in a standard IV setting). This implies that if nonemployment durations are endogenous, we cannot directly estimate the average shift of the reemployment wage path from our data.

However, it turns out that with reasonable assumptions we can bound the true $\delta$. To see this, note that $P^{\prime} P_{t} u=\left(P^{\prime} t\right)\left(t^{\prime} t\right)^{-1}\left(t^{\prime} u\right)$. The first product is simply the sum of nonemployment durations for those above the age cutoff, and hence strictly greater zero. The middle term is also strictly greater zero. In contrast, we have that $\operatorname{cov}(u, t)=E(u t)=t^{\prime} u / N$. Hence, under the reasonable assumption that $t^{\prime} u \leq 0$, i.e., on average workers with lower earnings potential have longer nonemployment spells, we obtain that that $\hat{\delta}$ is an upper bound for the true $\delta$. Since from the theory, we expect that $\delta \geq 0$, a finding that $\hat{\delta} \approx 0$ implies that both $\delta \approx 0$ and $P^{\prime} P_{t} u \approx 0$. 
Table 1: Smoothness of Predetermined Variables around Age Thresholds

\begin{tabular}{|c|c|c|c|c|c|c|c|c|}
\hline & $\begin{array}{c}(1) \\
\text { Years of } \\
\text { Education }\end{array}$ & $\begin{array}{l}(2) \\
\text { Female }\end{array}$ & $\begin{array}{l}(3) \\
\text { Foreign } \\
\text { Citizen }\end{array}$ & $\begin{array}{c}(4) \\
\text { Tenure } \\
\text { Last Job }\end{array}$ & $\begin{array}{c}(5) \\
\text { Experience } \\
\text { Last Job }\end{array}$ & $\begin{array}{c}(6) \\
\text { Pre } \\
\text { Wage }\end{array}$ & $\begin{array}{c}\text { (7) } \\
\text { UR at start } \\
\text { of unemp }\end{array}$ & $\begin{array}{c}(8) \\
\text { County UR at } \\
\text { start of unemp }\end{array}$ \\
\hline \multicolumn{9}{|c|}{ Increase in Potential UI Dur. from 12 to 18 Months } \\
\hline D(Age above Cutoff) & $\begin{array}{c}0.030 \\
{[0.014]^{*}}\end{array}$ & $\begin{array}{c}0.0086 \\
{[0.0028]^{* *}}\end{array}$ & $\begin{array}{c}0.0038 \\
{[0.0020]}\end{array}$ & $\begin{array}{c}0.044 \\
{[0.028]}\end{array}$ & $\begin{array}{c}-0.046 \\
{[0.031]}\end{array}$ & $\begin{array}{c}0.12 \\
{[0.18]}\end{array}$ & $\begin{array}{c}0.0016 \\
{[0.0087]}\end{array}$ & $\begin{array}{c}0.035 \\
{[0.025]}\end{array}$ \\
\hline Effect relative to mean & 0.0027 & 0.024 & 0.037 & 0.0082 & -0.0041 & 0.0017 & 0.00017 & 0.0033 \\
\hline Observations & 510955 & 510955 & 510955 & 510955 & 510955 & 480724 & 510955 & 441907 \\
\hline Mean of Dep. Var. & 11.0 & 0.36 & 0.10 & 5.35 & 11.1 & 70.8 & 9.29 & 10.4 \\
\hline \multicolumn{9}{|c|}{ Pooling both Thresholds ( 12 to 18 Months and 18 to 22 Months) } \\
\hline D(Age above Cutoff) & $\begin{array}{c}0.015 \\
{[0.0094]}\end{array}$ & $\begin{array}{c}0.0054 \\
{[0.0020]^{* *}}\end{array}$ & $\begin{array}{c}0.0017 \\
{[0.0017]}\end{array}$ & $\begin{array}{c}0.041 \\
{[0.023]}\end{array}$ & $\begin{array}{c}-0.034 \\
{[0.024]}\end{array}$ & $\begin{array}{c}0.12 \\
{[0.13]}\end{array}$ & $\begin{array}{c}-0.0095 \\
{[0.0066]}\end{array}$ & $\begin{array}{c}0.017 \\
{[0.019]}\end{array}$ \\
\hline Effect relative to mean & 0.0014 & 0.015 & 0.016 & 0.0072 & -0.0030 & 0.0016 & -0.0010 & 0.0016 \\
\hline Observations & 947068 & 947068 & 947068 & 947068 & 947068 & 888293 & 947068 & 829669 \\
\hline Mean of Dep. Var. & 10.9 & 0.36 & 0.11 & 5.69 & 11.6 & 71.6 & 9.31 & 10.4 \\
\hline
\end{tabular}

Notes: Standard errors clustered on day relative to cutoff level $(* \mathrm{P}<.05$, ** $\mathrm{P}<.01))$.

The sample are individuals who started receiving unemployment insurance between 1987 and 1999 within 2 years from the age thresholds. Each coefficient is from a separate regression discontinuity model with the dependent variable given in the column heading. The first panel shows the increase at the discontinuity at the age 42 threshold (where potential UI durations increase from 12 to 18 months). The second panel shows the increase at the age 44 threshold (where potential UI durations increase from 18 to 22 months). The third panel pools both thresholds. The models control for linear splines in age with different slopes on each side of the cutoff. 
Table 2: The Effect of Potential UI Durations on Non-employment Durations and Wages by Sub-groups

\begin{tabular}{|c|c|c|c|c|}
\hline & $\begin{array}{c}\text { (1) } \\
\text { UI Ben. } \\
\text { Duration }\end{array}$ & $\begin{array}{c}\text { (2) } \\
\text { Non-Emp } \\
\text { Duration }\end{array}$ & $\begin{array}{c}\text { (3) } \\
\text { Log Post } \\
\text { Wage }\end{array}$ & $\begin{array}{c}\text { (4) } \\
\text { Log Wage } \\
\text { Difference }\end{array}$ \\
\hline \multicolumn{5}{|l|}{ Men Only } \\
\hline$\frac{d y}{d P}$ & $\begin{array}{c}0.22 \\
{[0.0068]^{* *}}\end{array}$ & $\begin{array}{c}0.097 \\
{[0.014]^{* *}}\end{array}$ & $\begin{array}{c}-0.00084 \\
{[0.00048]}\end{array}$ & $\begin{array}{c}-0.00094 \\
{[0.00048]^{*}}\end{array}$ \\
\hline Effect relative to mean & 0.15 & 0.036 & -0.0010 & 0.037 \\
\hline Observations & 602852 & 602852 & 517473 & 498508 \\
\hline Mean of Dep. Var. & 7.40 & 13.7 & 4.15 & -0.13 \\
\hline \multicolumn{5}{|l|}{ Women Only } \\
\hline$\frac{d y}{d P}$ & $\begin{array}{c}0.40 \\
{[0.010]^{* *}}\end{array}$ & $\begin{array}{c}0.19 \\
{[0.020]^{* *}}\end{array}$ & $\begin{array}{c}-0.00048 \\
{[0.00078]}\end{array}$ & $\begin{array}{c}-0.0013 \\
{[0.00084]}\end{array}$ \\
\hline Effect relative to mean & 0.20 & 0.053 & -0.00062 & 0.036 \\
\hline Observations & 344216 & 344216 & 280279 & 268653 \\
\hline Mean of Dep. Var. & 9.94 & 17.9 & 3.78 & -0.18 \\
\hline \multicolumn{5}{|c|}{ Education: Abitur (University qual. exam) or higher } \\
\hline$\frac{d y}{d P}$ & $\begin{array}{c}0.24 \\
{[0.014]^{* *}}\end{array}$ & $\begin{array}{c}0.077 \\
{[0.028]^{* *}}\end{array}$ & $\begin{array}{c}-0.0013 \\
{[0.0011]}\end{array}$ & $\begin{array}{l}-0.00076 \\
{[0.0010]}\end{array}$ \\
\hline Effect relative to mean & 0.15 & 0.024 & -0.0015 & 0.023 \\
\hline Observations & 157595 & 157595 & 136822 & 134099 \\
\hline Mean of Dep. Var. & 8.29 & 16.1 & 4.26 & -0.16 \\
\hline \multicolumn{5}{|c|}{ Education: Less than Abitur (University qual. exam) } \\
\hline$\frac{d y}{d P}$ & $\begin{array}{c}0.30 \\
{[0.0064]^{* *}}\end{array}$ & $\begin{array}{c}0.15 \\
{[0.013]^{* *}}\end{array}$ & $\begin{array}{c}-0.0012 \\
{[0.00044]^{* *}}\end{array}$ & $\begin{array}{c}-0.0012 \\
{[0.00047]^{*}}\end{array}$ \\
\hline Effect relative to mean & 0.18 & 0.049 & -0.0015 & 0.040 \\
\hline Observations & 789473 & 789473 & 660930 & 633062 \\
\hline Mean of Dep. Var. & 8.33 & 15.1 & 3.97 & -0.14 \\
\hline
\end{tabular}

Notes: Coefficients from RD regressions. Local linear regressions (different slopes) on each side of cutoff. Standard errors clustered on day level $(* \mathrm{P}<.05$, ** $\mathrm{P}<.01)$ ). 
Table 3: Slope of Mean Wage Offers as Function of $\frac{d V u / d t}{d V u / d P}$ and the effect of UI extensions conditional on duration of nonemployment $d E[w \mid t] / d P$

\begin{tabular}{lccccccccc}
\hline & \multicolumn{7}{c}{$\frac{d V u / d t}{d V u / d P}$} \\
$\delta=E[d E[w \mid t] / d P]$ in percent & -1 & -2 & -3 & -4 & -5 & -6 & -7 & -8 & -9 \\
\hline 0 & -0.008 & -0.008 & -0.008 & -0.008 & -0.008 & -0.008 & -0.008 & -0.008 & -0.008 \\
0.095 & -0.014 & -0.013 & -0.012 & -0.011 & -0.010 & -0.009 & -0.008 & -0.007 & -0.006 \\
0.1 & -0.014 & -0.013 & -0.012 & -0.011 & -0.010 & -0.009 & -0.008 & -0.007 & -0.006 \\
0.2 & -0.020 & -0.018 & -0.016 & -0.014 & -0.012 & -0.010 & -0.008 & -0.006 & -0.004 \\
0.3 & -0.026 & -0.023 & -0.020 & -0.017 & -0.014 & -0.011 & -0.008 & -0.005 & -0.002 \\
0.4 & -0.032 & -0.028 & -0.024 & -0.020 & -0.016 & -0.012 & -0.008 & -0.004 & 0.000 \\
0.5 & -0.039 & -0.034 & -0.029 & -0.024 & -0.019 & -0.014 & -0.009 & -0.004 & 0.001 \\
0.6 & -0.045 & -0.039 & -0.033 & -0.027 & -0.021 & -0.015 & -0.009 & -0.003 & 0.003 \\
0.7 & -0.051 & -0.044 & -0.037 & -0.030 & -0.023 & -0.016 & -0.009 & -0.002 & 0.005 \\
0.8 & -0.057 & -0.049 & -0.041 & -0.033 & -0.025 & -0.017 & -0.009 & -0.001 & 0.007 \\
0.9 & -0.063 & -0.054 & -0.045 & -0.036 & -0.027 & -0.018 & -0.009 & 0.000 & 0.009 \\
1.0 & -0.069 & -0.059 & -0.049 & -0.039 & -0.029 & -0.019 & -0.009 & 0.001 & 0.011 \\
\hline
\end{tabular}

Notes: The table shows the implied slope of the mean wage offer distribution if the effect of potential UI durations on reemployment wages conditional on nonemployment durations is not equal to zero $d E[w \mid t] / d P$. Rows show the implied slope for different values of $d E[w \mid t] / d P$ and columns for different values of $\frac{d V u / d t}{d V u / d P}$. The preferred point Estimate for $d E[w \mid t] / d P$ is $0.015 \%$ (from last column and bottom panel of Table 10).

The upper bound of the $95 \%$ confidence interval for $d E[w \mid t] / d P$ is $0.095 \%$. 
Table 4: The Effect of UI Extensions by Different States of the Business Cycle

\begin{tabular}{|c|c|c|c|c|c|c|}
\hline & \multicolumn{3}{|c|}{ Unemployment Rate Decreasing } & \multicolumn{3}{|c|}{ Unemployment Rate Increasing } \\
\hline & Non-Emp & Log Post & Log Wage & Non-Emp & Log Post & Log Wage \\
\hline & Duration & Wage & Difference & Duration & Wage & Difference \\
\hline \multirow{2}{*}{\multicolumn{7}{|c|}{$\begin{array}{l}\text { Increase in Potential UI } \\
\text { Dur. from } 12 \text { to } 18 \text { Months }\end{array}$}} \\
\hline & & & & & & \\
\hline \multirow{2}{*}{ D(Age above Cutoff) } & 0.97 & -0.0072 & -0.0017 & 0.90 & -0.0081 & -0.0092 \\
\hline & {$[0.22]^{* *}$} & {$[0.0049]$} & {$[0.0046]$} & {$[0.17]^{* *}$} & {$[0.0037]^{*}$} & {$[0.0036]^{*}$} \\
\hline \multirow{2}{*}{$\frac{d y}{d P}$} & 0.16 & -0.0012 & -0.00028 & 0.15 & -0.0013 & -0.0015 \\
\hline & {$[0.037]^{* *}$} & {$[0.00082]$} & [0.00077] & {$[0.029]^{* *}$} & {$[0.00062]^{*}$} & {$[0.00061]^{*}$} \\
\hline Effect relative to mean & 0.071 & -0.0018 & 0.015 & 0.059 & -0.0020 & 0.059 \\
\hline Observations & 168936 & 168637 & 161534 & 268963 & 268545 & 258777 \\
\hline \multicolumn{7}{|l|}{ Pooling both Thresholds } \\
\hline \multirow[t]{2}{*}{ D(Age above Cutoff) } & 0.62 & -0.0041 & -0.0049 & 0.75 & -0.0056 & -0.0052 \\
\hline & {$[0.16]^{* *}$} & {$[0.0037]$} & {$[0.0035]$} & {$[0.13]^{* *}$} & {$[0.0026]^{*}$} & {$[0.0027]$} \\
\hline \multirow{2}{*}{$\frac{d y}{d P}$} & 0.12 & -0.00082 & -0.00097 & 0.15 & -0.0011 & -0.0010 \\
\hline & {$[0.032]^{* *}$} & {$[0.00073]$} & [0.00069] & {$[0.026]^{* *}$} & {$[0.00053]^{*}$} & {$[0.00055]$} \\
\hline Effect relative to mean & 0.045 & -0.0010 & 0.040 & 0.049 & -0.0014 & 0.032 \\
\hline Observations & 302786 & 302225 & 289473 & 496319 & 495527 & 477688 \\
\hline
\end{tabular}

Notes: Coefficients from RD regressions. Local linear regressions (different slopes) on each side of cutoff. Standard errors clustered on day level $(* \mathrm{P}<.05$, ** $\mathrm{P}<.01))$. 
Table 5: Investigating Different Channels of Wage Losses

\begin{tabular}{|c|c|c|c|c|c|c|}
\hline & $\begin{array}{c}(1) \\
\text { Log Wage } \\
\text { Baseline }\end{array}$ & $\begin{array}{c}(2) \\
\text { Log Wage } \\
\text { Ctrls Obs }\end{array}$ & $\begin{array}{c}(3) \\
\text { Log Wage } \\
\text { Ctrls Obs }\end{array}$ & $\begin{array}{c}(4) \\
\text { Log Wage } \\
\text { Ctrls Obs }\end{array}$ & $\begin{array}{c}(5) \\
\text { Log Wage } \\
\text { Ctrls Obs }\end{array}$ & $\begin{array}{c}(6) \\
\text { Log Wage } \\
\text { Ctrls Obs }\end{array}$ \\
\hline \multicolumn{7}{|c|}{ Increase in Potential UI Dur. from 12 to 18 Months } \\
\hline $\mathrm{D}$ (Age above Cutoff) & $\begin{array}{c}-0.0066 \\
{[0.0029]^{*}}\end{array}$ & -0.0060 & $\begin{array}{c}-0.0074 \\
{[0.0030] *}\end{array}$ & -0.0083 & -0.0057 & -0.0046 \\
\hline Switch 3 digit Industry after UE & -0.082 & -0.035 & & & & \\
\hline Switch Occupation after UE & {$[0.0015]^{* *}$} & $\begin{array}{c}{[0.0018]^{* *}} \\
-0.091 \\
{[0.0017]^{* *}}\end{array}$ & & & & \\
\hline UR at start of unemployment spell & & & $\begin{array}{c}-0.015 \\
{[0.00077]^{* *}}\end{array}$ & & & \\
\hline UR at end of unemployment spell & & & {$[0.00081]^{-0.0066}$} & & & \\
\hline Log Establishment Size of Post-UE Job & & & & $\begin{array}{c}0.036 \\
{[0.00043]^{* *}}\end{array}$ & & \\
\hline Post UE Spell: Fulltime Emp & & & & & $\begin{array}{c}0.61 \\
{[0.0024]^{* *}}\end{array}$ & \\
\hline Tenure at next job after UE & & & & & & $\begin{array}{c}0.012 \\
{[0.00012]^{* *}}\end{array}$ \\
\hline$\frac{d y}{d P}$ & -0.0011 & -0.0010 & -0.0012 & -0.0014 & -0.00061 & -0.00053 \\
\hline & {$[0.00049]^{*}$} & {$[0.00049]^{*}$} & {$[0.00049]^{*}$} & {$[0.00049]^{* *}$} & {$[0.00044]$} & {$[0.00044]$} \\
\hline Observations & 437182 & 437182 & 437182 & 437182 & 437182 & 437182 \\
\hline Mean of Dep. Var. & 4.01 & 4.01 & 4.01 & 4.01 & 4.01 & 4.01 \\
\hline \multicolumn{7}{|c|}{ Pooling both Thresholds ( 12 to 18 Months and 18 to 22 Months) } \\
\hline $\mathrm{D}$ (Age above Cutoff) & $\begin{array}{l}-0.0039 \\
{[0.0021]}\end{array}$ & $\begin{array}{l}-0.0034 \\
{[0.0021]}\end{array}$ & $\begin{array}{c}-0.0050 \\
{[0.0021]^{*}}\end{array}$ & $\begin{array}{c}-0.0051 \\
{[0.0021] *}\end{array}$ & -0.0044 & $\begin{array}{l}-0.0028 \\
{[0.0019]}\end{array}$ \\
\hline Switch 3 digit Industry after UE & -0.085 & -0.037 & & & & \\
\hline Switch Occupation after UE & {$[0.0012]^{* *}$} & $\begin{array}{c}-0.093 \\
{[0.0012]^{* *}}\end{array}$ & & & & \\
\hline UR at start of spell & & & $\begin{array}{c}-0.018 \\
{[0.00059]^{* *}}\end{array}$ & & & \\
\hline UR at end of unemployment spell & & & $\begin{array}{c}-0.0028 \\
{[0.00062]^{* *}}\end{array}$ & & & \\
\hline Log Establishment Size of Post-UE Job & & & & $\begin{array}{c}0.035 \\
{[0.00032]^{* *}}\end{array}$ & & \\
\hline Post UE Spell: Fulltime Emp & & & & & $\begin{array}{c}0.62 \\
{[0.0018]^{* *}}\end{array}$ & \\
\hline Tenure at next job after UE & & & & & & $\begin{array}{c}0.012 \\
{[0.000089]^{* *}}\end{array}$ \\
\hline$\frac{d y}{d P}$ & -0.00079 & -0.00069 & -0.0010 & -0.0010 & -0.00047 & -0.00037 \\
\hline & {$[0.00042]$} & [0.00042] & {$[0.00042]^{*}$} & {$[0.00042]^{*}$} & {$[0.00038]$} & {$[0.00038]$} \\
\hline Mean of Dep. Var. & $\begin{array}{l}197152 \\
4.02\end{array}$ & $\begin{array}{l}191 / 52 \\
402\end{array}$ & $\begin{array}{l}191 / 52 \\
402\end{array}$ & $\begin{array}{l}191 / 52 \\
402\end{array}$ & $191 / 52$ & $19 / 752$ \\
\hline
\end{tabular}


Figure 1: The Effects of Extended Potential UI Durations on Selection throughout the Spell of Non-employment

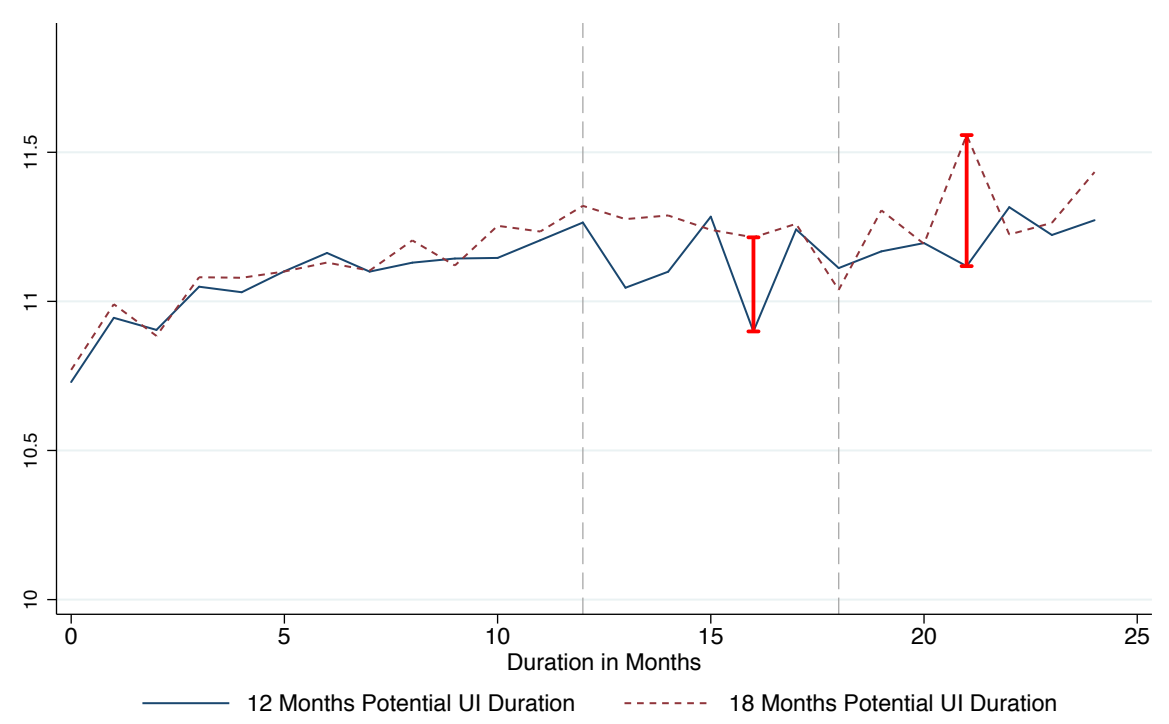

(a) Years of Schooling

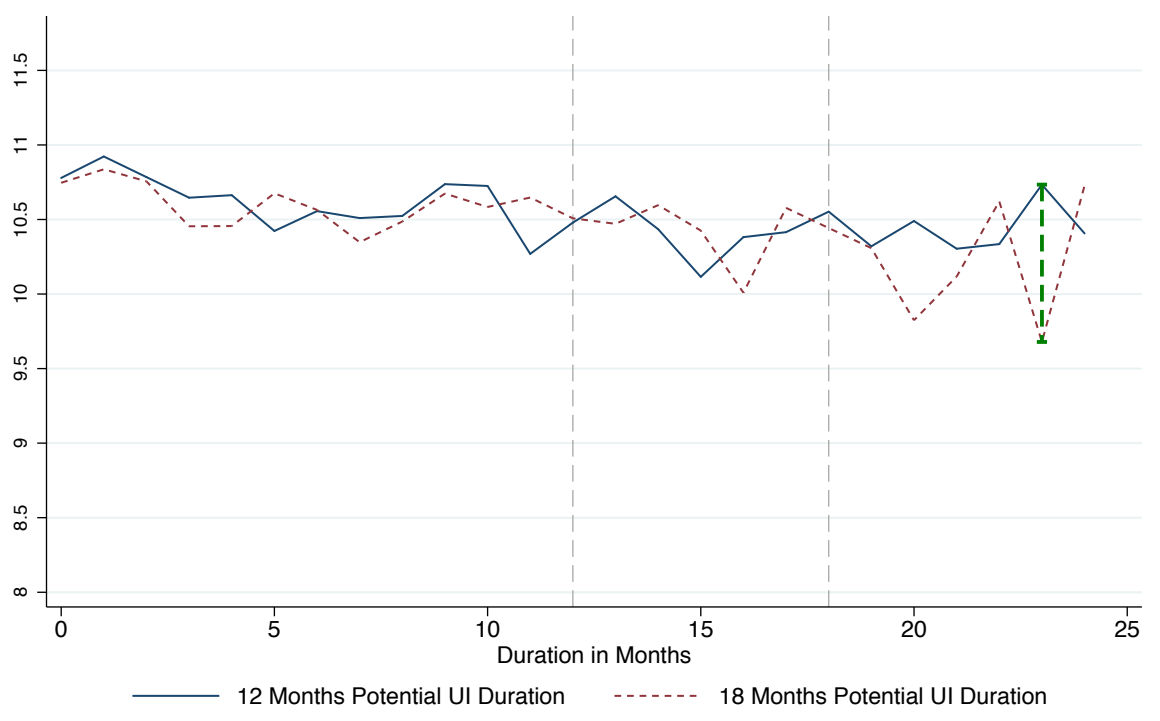

(b) Pre-unemployment Experience

Notes: The difference between the lines is estimated pointwise at each point of support using regression discontinuity estimation. Vertical bars indicate that the differences are statistically significant from each other at the five percent level. The sample are unemployed worker claiming UI between July 1987 and March 1999 who had worked for at least 36 months in the last 7 years without intermittent UI spell. For details see text. 
Figure 2: The Effects of Extended Potential UI Durations on Selection throughout the Spell of Non-employment

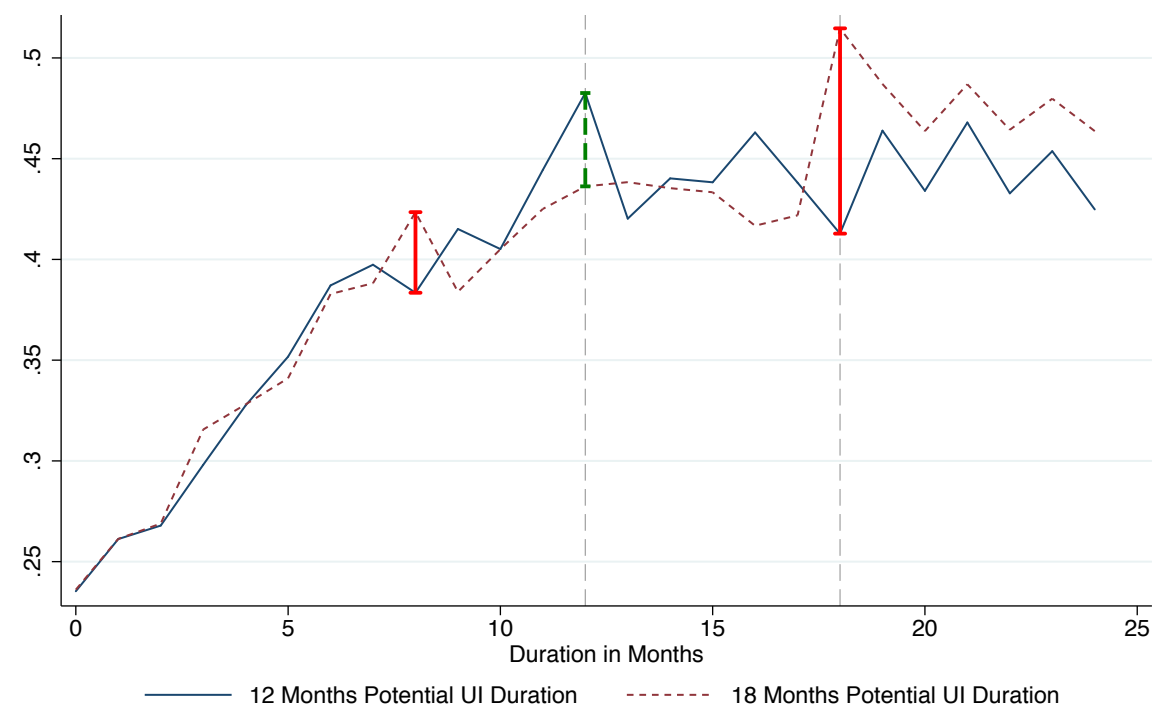

(a) Female

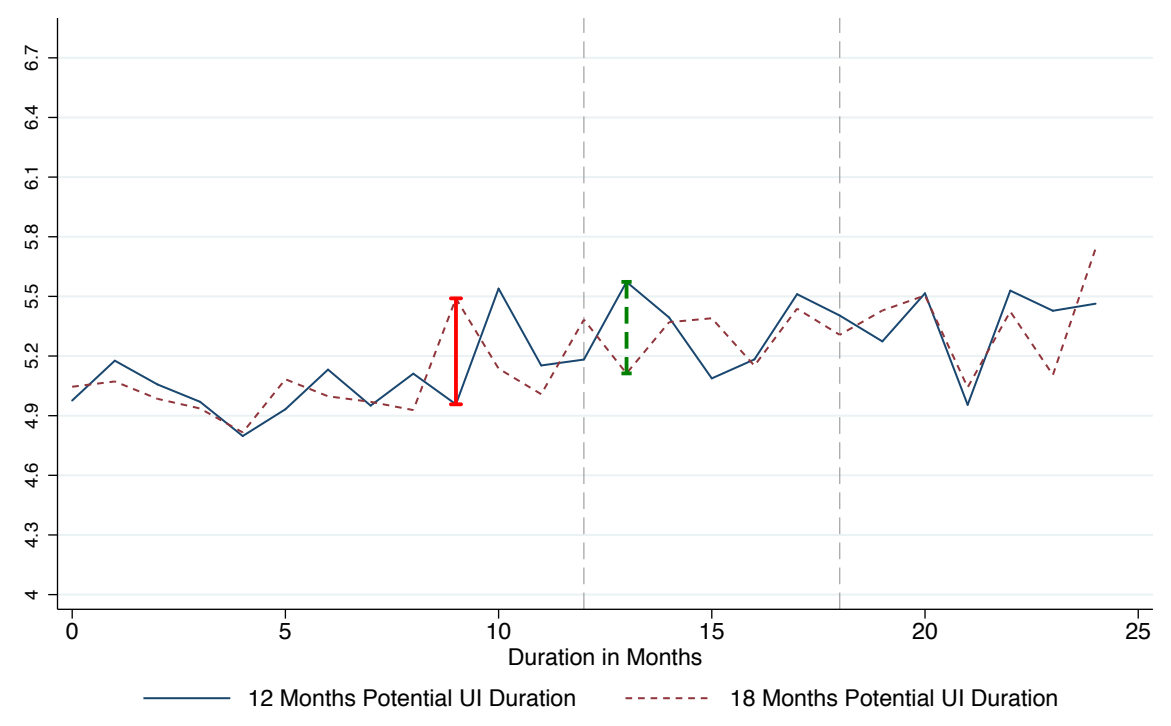

(b) Pre-unemployment Tenure

Notes: The difference between the lines is estimated pointwise at each point of support using regression discontinuity estimation. Vertical bars indicate that the differences are statistically significant from each other at the five percent level. The sample are unemployed worker claiming UI between July 1987 and March 1999 who had worked for at least 36 months in the last 7 years without intermittent UI spell. For details see text. 
Figure 3: Quantile Regressions of the Effects of Extended Potential UI Durations on Reemployment Wages throughout the Spell of Non-employment

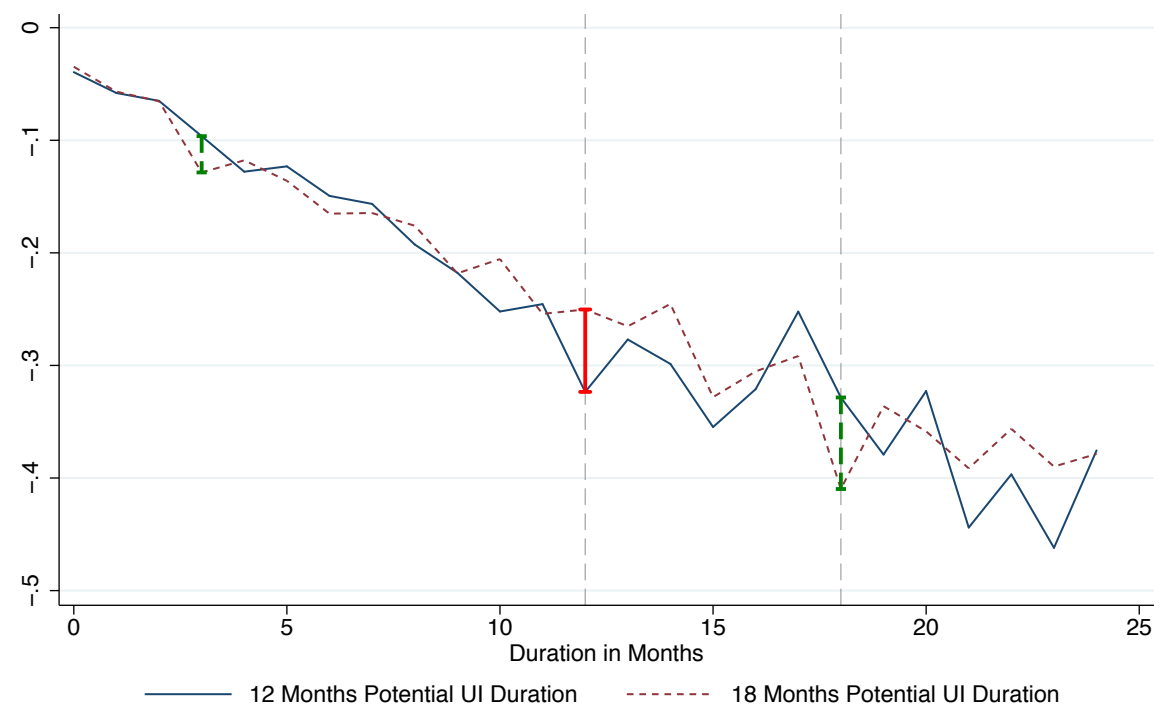

(a) Log wage difference (post - pre unemployment)

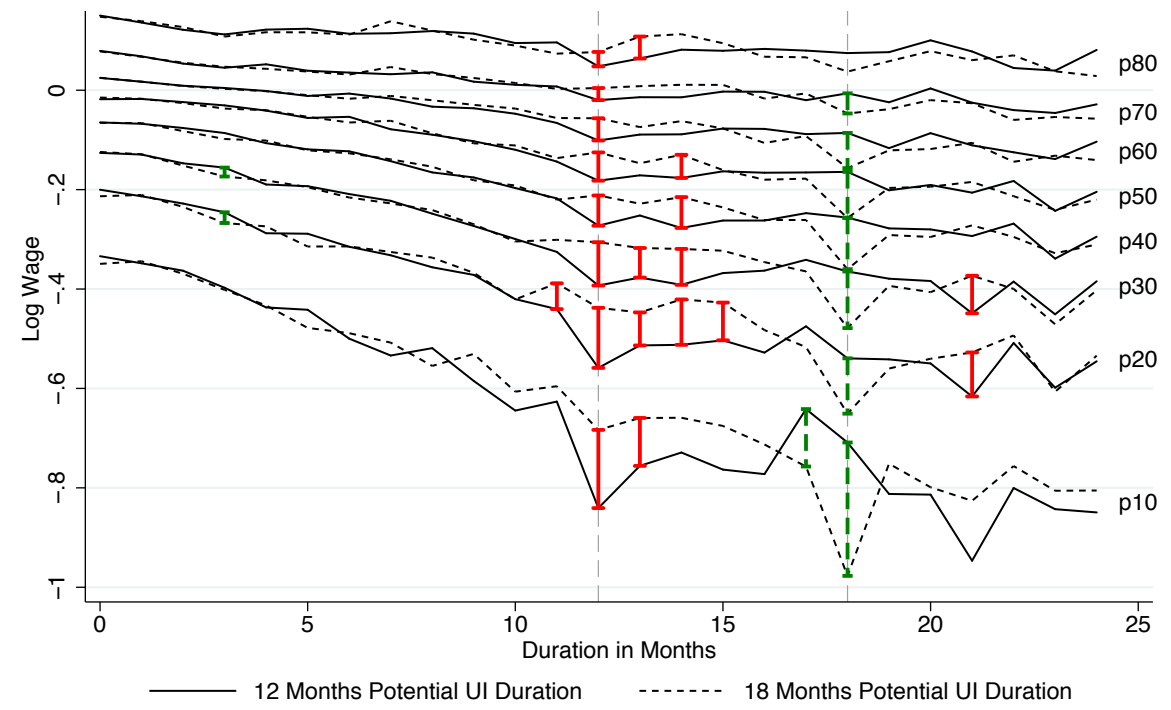

(b) Log wage difference (post - pre unemployment)

Notes: The difference between the lines is estimated point wise at each point of support using regression discontinuity estimation. Vertical bars indicate that the differences are statistically significant from each other at the five percent level. The sample are unemployed worker claiming UI between July 1987 and March 1999 who had worked for at least 36 months in the last 7 years without intermittent UI spell. The labels on the right indicate the percentiles at which the differences are estimated. For details see text. 


\section{Web Appendix}

\section{Contents}

1 Model Details $\quad 2$

1.1 Optimal Reservation Wage and Search Intensity Paths . . . . . . . . . . . . . 2

1.2 Derivation of Equation (7) in main text . . . . . . . . . . . . . 4

1.3 Proof of Proposition 1 . . . . . . . . . . . . . . . 6

1.4 The Causal Effect of Nonemployment Duration on Wages with Binding Reservation Wage . . . . . . . . . . . . . . . . . . . . . 6

2 Empirical Implementation $\quad 6$

2.1 Upward Bias in Wage Regression . . . . . . . . . . . . . . . . . 6

\section{List of Tables}

1 Smoothness of Predetermined Variables around Age Thresholds . . . . . . . . 8

2 The Effect of Potential UI Durations on Non-employment Durations and Wages by Sub-groups . . . . . . . . . . . . . . . . . . . . . . . 9

3 Slope of Mean Wage Offers as Function of $\frac{d V u / d t}{d V u / d P}$ and the effect of UI extensions conditional on duration of nonemployment $d E[w \mid t] / d P \ldots \ldots \ldots$

4 The Effect of UI Extensions by Different States of the Business Cycle . . . . . . 11

5 Investigating Different Channels of Wage Losses . . . . . . . . . . . . . . 12

\section{List of Figures}

1 The Effects of Extended Potential UI Durations on Selection throughout the Spell of Non-employment . . . . . . . . . . . . . . . . . . . . . . . . 13

2 The Effects of Extended Potential UI Durations on Selection throughout the Spell of Non-employment . . . . . . . . . . . . . . . . . . . . . . 14

3 Quantile Regressions of the Effects of Extended Potential UI Durations on Reemployment Wages throughout the Spell of Non-employment . . . . . . . . . . 15 


\section{Model Details}

\subsection{Optimal Reservation Wage and Search Intensity Paths}

In the following we omit individual $i$ subscripts from the model parameters to simplify notations.

Employment is an absorbing state, i.e. once employed a worker does not get laid off or move to better jobs. Since workers discount the future at the common subjective discount rate $\rho$, the value of being employed $V^{e}$ satisfies:

$$
V^{e}\left(w^{*}\right)=\frac{1}{\rho} w^{*}
$$

The Bellman equation for an unemployed worker is given as:

$$
\begin{aligned}
V^{u}(t)=b_{t}+ & \max _{\lambda_{t}}\left[-\psi\left(\lambda_{t}\right)+\left(1-\lambda_{t}\right) \frac{1}{1+\rho} V^{u}(t+1)\right. \\
& \left.+\lambda_{t} \frac{1}{1+\rho} \int_{w} \max _{\text {accept }, \text { reject }}\left[V^{e}\left(w^{*}\right), V^{u}(t+1)\right] d F_{t}\left(w^{*}\right)\right]
\end{aligned}
$$

Since $V^{e}\left(w^{*}\right)$ is increasing in $w^{*}$, the optimal search behavior of the worker is described by a reservation wage $\phi_{t}$, so that all wage offers $w^{*} \geq \phi_{t}$ are accepted. This allows for writing the Bellman equation as:

$$
V^{u}(t)=b_{t}+\max _{\lambda_{t}}\left[-\psi\left(\lambda_{t}\right)+\frac{1}{1+\rho}\left(V^{u}(t+1)+\lambda_{t} \int_{\phi_{t}}^{\infty} V^{e}\left(w^{*}\right)-V^{u}(t+1) d F_{t}\left(w^{*}\right)\right)\right]
$$

Suppose that the environment becomes stationary for some $t \geq T$. In particular UI benefits and the wage offer distribution become constant after $T: b_{t}=b, F_{t}\left(w^{*}\right)=F_{T}\left(w^{*}\right)$. This implies that the optimal search strategy is a constant: reservation wage $\phi_{T}$. Using the fact that $V^{u}(t)=V^{u}(t+1)$ in the stationary environment, it follows that the stationary reservation wage and the optimal search intensity are given by the follwowing system of equations:

$$
\begin{gathered}
\phi_{T}=(1+\rho)\left(b_{T}-\psi\left(\lambda_{T}\right)\right)+\frac{\lambda_{T}}{\rho} \int_{\phi_{T}}^{\infty} w^{*}-\phi_{T} d F_{T}\left(w^{*}\right) \\
(1+\rho) \rho \psi^{\prime}\left(\lambda_{T}\right)-\int_{\phi_{T}}^{\infty} w^{*}-\phi_{T} d F_{T}\left(w^{*}\right)=0
\end{gathered}
$$

An optimal search strategy in this model is described by a reservation wage $\phi_{t}$ and search intensity $\lambda_{t}$ in each period. In the appendix we show that the optimal reservation wage and search intensity paths are described by the following pair of difference equations, where the reservation wage and search intensity in period $t-1$ can be derived from the reservatoin wage in period $t$. 
In the nonstationary environment, $t<T$, we use the fact that: $\frac{1}{\rho} \phi_{t}=V^{u}(t+1)$. Therefore knowledge about the reservation wage $\phi_{t}$ and the optimal search intensity $\lambda_{t}$ in period $t$ will allow us to find the reservation wage in period $t-1$ using this equation:

$$
(1+\rho) \phi_{t-1}=(1+\rho) \rho\left(b_{t-1}-\psi\left(\lambda_{t}\right)\right)+\phi_{t}+\lambda_{t} \int_{\phi_{t}}^{\infty} w^{*}-\phi_{t} d F_{t}\left(w^{*}\right)
$$

Once we have found the reservation wage $\phi_{t-1}$ in period $t-1$ we can directly solve for the optimal search intensity in the same period:

$$
(1+\rho) \rho \psi^{\prime}\left(\lambda_{t-1}\right)-\int_{\phi_{t-1}}^{\infty} w^{*}-\phi_{t-1} d F_{t}\left(w^{*}\right)=0
$$

In our empirical application we consider a system where UI benefits are at a constant level $b$ up to the maximum potential duration of receiving UI benefits $P$. After benefit exhaustion, indivduals receive a second tier of payments indefinitely. We therefore have that $b_{t}=b$ for all $t \leq P$ and $b_{t}=\underline{b}$ for all $t>P$. Consider how the reservation wage path and the search intensity path is affected by a change in potential UI durations $P$. Using the first order conditions we get that:

$$
\frac{d \phi_{t}}{d P}=\frac{d V_{t+1}^{u}}{d P} \rho
$$

and

$$
\frac{d \lambda_{t}}{d P}=-\frac{d V_{t+1}^{u}}{d P} \frac{1-F_{t}\left(\phi_{t}\right)}{(1+\rho) \psi^{\prime \prime}\left(\lambda_{t}\right)}
$$

If there is at least a small chance that individuals might not find a job until UI exhaustion at $t=P$, then increasing $P$ will increase the value of remaining unemployed for all $t \leq P$, so that $\frac{d V_{t+1}^{u}}{d P}>0$. Therefore increasing $P$ will increase the reservation wage $\phi_{t}$ and lower search intensity $\lambda_{t}$.

Since the hazard of leaving unemployment is given as $h_{t}=\lambda_{t}\left(1-F_{t}\left(\phi_{t}\right)\right)$, we get that

$$
\frac{d h_{t}}{d P}=-\frac{d V_{t+1}^{u}}{d P}\left[\frac{\left(1-F_{t}\left(\phi_{t}\right)\right)^{2}}{(1+\rho) \psi^{\prime \prime}\left(\lambda_{t}\right)}+\rho \lambda_{t} f\left(\phi_{t}\right)\right]
$$

Therefore if the extension in UI benefits affects the value of being unemployed in period $t$, then it will lower the probability of leaving unemployment in that period. 


\subsection{Derivation of Equation (7) in main text}

The expected reemployment wage of individual $i$ conditional on $t$ is given as:

$$
w_{i}^{e}(t, P)=E\left[w\left(t_{i}, P, \zeta_{i}, u\right) \mid t_{i}, \zeta_{i}\right]=\frac{\int_{\phi_{t}}^{\infty} w^{*} d F_{t}\left(w^{*}\right)}{1-F_{t}\left(\phi_{t}\right)}
$$

Individual unemployment duration $t_{i}=t\left(P, \zeta_{i}, \varepsilon\right)$ is equal to the first period when a job offer arrives with a wage above the reservation wage. Thus $\varepsilon$ is a vector of indicators signifying whether for each period there is a job offer with a wage above the reservation wage: $\varepsilon=\left\{I\left[j_{o b} \_\right.\right.$offer $\left.r_{t}\right] \times$ $\left.I\left[w * \geq \phi_{t}\right]\right\}$ for $t=0,1, \ldots$ Note that the realized $\varepsilon$ does not contain information about the value realized of realized wage offers conditional on being above the reservation wage.

We denote the distribution of $\varepsilon$ for an individual with parameters $\zeta_{i}$ as $d H\left(\varepsilon ; \zeta_{i}\right)$ and therefore the expected unemployment duration of an individual is: $t_{i}^{e}\left(P, \zeta_{i}\right)=\int t\left(P, \zeta_{i}, \varepsilon\right) d H\left(\varepsilon ; \zeta_{i}\right)$

The expected reemployment wage of individual $i$ (not conditioning on unemployment duration) $w_{i}^{e}(P)=E\left[w_{i}^{e}(t, P) \mid \zeta_{i}\right]$ can be obtained by integrating over $H\left(t ; \zeta_{i}\right)$ :

$$
w_{i}^{e}(P)=E\left[w\left(t_{i}, P, \zeta_{i}, u\right) \mid \zeta_{i}\right]=\int w_{i}^{e}(t, P) d H\left(\varepsilon ; \zeta_{i}\right)
$$

The expected reemployment wage in population conditional on $t, w^{e}(t, P)=E\left[w_{i}^{e}(t, P) \mid t\right]$ is obtained by integrating over the distribution of $\zeta_{i}$ :

$$
w^{e}(t, P)=E\left[w\left(t_{i}, P, \zeta_{i}, u\right) \mid t\right]=\int w_{i}^{e}(t, P) d G\left(\zeta_{i}\right)
$$

The expected unconditional reemployment wage $w^{e}(P)=E\left[w_{i}^{e}(t, P)\right]=E\left[w_{i}^{e}(P)\right]=E\left[w^{e}(t, P)\right]$ can then be obtained by integrating over durations $t$ and parameters $\zeta_{i}$

$$
w^{e}(P)=E\left[w\left(t_{i}, P, \zeta_{i}, u\right)\right]=\iint w_{i}^{e}(t, P) d H\left(\varepsilon ; \zeta_{i}\right) d G\left(\zeta_{i}\right)
$$

Now we have that:

$$
\begin{aligned}
w^{e}(P+h)-w^{e}(P) & =E\left[w_{i}^{e}(t(P+h), P+h)-w_{i}^{e}(t(P), P)\right] \\
& =E\left[w_{i}^{e}(t(P+h), P+h)-w_{i}^{e}(t(P+h), P)+w_{i}^{e}(t(P+h), P)-w_{i}^{e}(t(P), P)\right] \\
& =E\left[w_{i}^{e}(t(P+h), P+h)-w_{i}^{e}(t(P+h), P)\right]+E\left[w_{i}^{e}(t(P+h), P)-w_{i}^{e}(t(P), P)\right]
\end{aligned}
$$

Consider the second part of this expression: 


$$
\begin{aligned}
E\left[w_{i}^{e}\left(t_{i}(P+h), P\right)-w_{i}^{e}\left(t_{i}(P), P\right)\right] & =E\left[\int_{t_{i}(P, \varepsilon)}^{t_{i}(P+h, \varepsilon)} \frac{\partial w_{i}^{e}}{\partial t}(t) d t\right] \\
& =E\left[\int_{0}^{\infty} \frac{\partial w_{i}^{e}}{\partial t}(t) \times I\left(t_{i}(P, \varepsilon)<t<t_{i}(P+h, \varepsilon)\right) d t\right] \\
& =\iiint_{0}^{\infty} \frac{\partial w_{i}^{e}}{\partial t}(t) \times I\left(t_{i}(P, \varepsilon)<t<t_{i}(P+h, \varepsilon)\right) d t d H\left(\varepsilon ; \zeta_{i}\right) d G\left(\zeta_{i}\right) \\
& =\int_{0}^{\infty} \iint \frac{\partial w_{i}^{e}}{\partial t}(t) \times I\left(t_{i}(P, \varepsilon)<t<t_{i}(P+h, \varepsilon)\right) d H\left(\varepsilon ; \zeta_{i}\right) d G\left(\zeta_{i}\right) d t \\
& =\int_{0}^{\infty} \int \frac{\partial w_{i}^{e}}{\partial t}(t) \times \int I\left(t_{i}(P, \varepsilon)<t<t_{i}(P+h, \varepsilon)\right) d H\left(\varepsilon ; \zeta_{i}\right) d G\left(\zeta_{i}\right) d t \\
& =\int_{0}^{\infty} \int \frac{\partial w_{i}^{e}}{\partial t}(t) \times I\left(t_{i}^{e}(P)<t<t_{i}^{e}(P+h)\right) d G\left(\zeta_{i}\right) d t \\
& =\int_{0}^{\infty} E_{\zeta}\left[\frac{\partial w_{i}^{e}(t)}{\partial t} \times I\left(t_{i}^{e}(P)<t<t_{i}^{e}(P+h)\right)\right] d t \\
& =\int_{0}^{\infty} E_{\zeta}\left[\frac{\partial w_{i}^{e}(t)}{\partial t} \mid t, t_{i}^{e}(P)<t<t_{i}^{e}(P+h)\right] \operatorname{Pr}\left(t_{i}^{e}(P)<t<t_{i}^{e}(P+h)\right) d t(9)
\end{aligned}
$$

Note that

$$
\begin{aligned}
\operatorname{Pr}\left(t_{i}^{e}(P)<t<t_{i}^{e}(P+h)\right) & =\operatorname{Pr}\left(t<t_{i}^{e}(P+h)\right)-\operatorname{Pr}\left(t<t_{i}^{e}(P)\right) \\
& =S(t ; P+h))-S(t ; P))
\end{aligned}
$$

Taking the limit of equation (9) for $h \rightarrow 0$, we get that:

$$
\begin{aligned}
\lim _{h \rightarrow 0} \frac{E\left[w_{i}\left(t_{i}(P+h), P\right)-w_{i}\left(t_{i}(P)\right), P\right]}{h} & =\lim _{h \rightarrow 0} \frac{\int_{0}^{\infty} E_{\zeta}\left[\frac{\partial w_{i}^{e}(t)}{\partial t} \mid t_{i}^{e}(P)<t<t_{i}^{e}(P+h)\right] \operatorname{Pr}\left(t_{i}^{e}(P)<t<t_{i}^{e}(P+h)\right) d t}{h} \\
& =\int_{0}^{\infty} \lim _{h \rightarrow 0} \frac{E_{\zeta}\left[\frac{\partial w_{i}^{e}(t)}{\partial t} \mid t_{i}^{e}(P)<t<t_{i}^{e}(P+h)\right] \operatorname{Pr}\left(t_{i}^{e}(P)<t<t_{i}^{e}(P+h)\right)}{h} d t \\
& =\int_{0}^{\infty} \lim _{h \rightarrow 0} \frac{E_{\zeta}\left[\frac{\partial w_{i}^{e}(t)}{\partial t} \mid t_{i}^{e}(P)<t<t_{i}^{e}(P+h)\right]}{h} \times \lim _{h \rightarrow 0} \frac{\operatorname{Pr}\left(t_{i}^{e}(P)<t<t_{i}^{e}(P+h)\right)}{h} d t \\
& =\int_{0}^{\infty} E_{\zeta}\left[\frac{\partial w_{i}^{e}(t)}{\partial t} \mid \frac{\partial S_{i}(t)}{\partial P}>0\right] \frac{\partial S(t)}{\partial P} d t
\end{aligned}
$$

Now we take the limit of equation (8) for $h \rightarrow 0$, to obtain the derivative

$$
\begin{aligned}
\frac{d E\left[w_{i}^{e}\left(t_{i}, P, \zeta_{i}, u\right)\right]}{d P} & =\lim _{h \rightarrow 0} \frac{w^{e}(P+h)-w^{e}(P)}{h} \\
& =E\left[\frac{\partial w_{i}^{e}(t, P)}{\partial P}\right]+\int_{0}^{\infty} E_{\zeta}\left[\frac{\partial w_{i}^{e}(t)}{\partial t} \mid \frac{\partial S_{i}(t)}{\partial P}>0\right] \frac{\partial S(t)}{\partial P} d t
\end{aligned}
$$

q.e.d. 


\subsection{Proof of Proposition 1}

Suppose $\frac{\partial w_{i}^{e}(t, P)}{\partial \phi_{i t}}=0$ for all individuals who respond to changes in UI durations. It then follows that $E\left[\frac{\partial w_{i}^{e}(t, P)}{\partial P}\right]=0$ or equivalently that the first term in equation (8) in this appendix is equal to zero. Furthermore $\frac{\partial w_{i}^{e}(t, P)}{\partial \phi_{i t}}=0$ implies that $\frac{\partial w_{i}^{e}(t)}{\partial t}=\frac{\partial w_{i}^{e}\left(\phi_{i t}, \mu_{i t}\right)}{\partial \mu_{i t}} \frac{\partial \mu_{i t}}{\partial t}$. Plugging this into equation (9) above, directly yields the result in Proposition 1.

\subsection{The Causal Effect of Nonemployment Duration on Wages with Binding Reservation Wage}

Here we show how the causal effect of nonemployment durations on wages can be calculated for the homogenous-linear case. We have that $\frac{\partial w^{e}(t, P)}{\partial P}=\frac{\partial w^{e}(t, P)}{\partial \phi_{t}} \frac{\partial \phi_{t}}{\partial P}=\frac{\partial w^{e}(t, P)}{\partial \phi_{t}} \frac{d V_{t}^{u}}{d P} \rho$ and therefore: $\frac{\partial w^{e}(t, P)}{\partial \phi_{t}}=\frac{\frac{\partial w^{e}(t, P)}{\partial P}}{\frac{d V_{t}^{u}}{d P} \rho}$. To simplify notation denote: $\delta=E\left[\frac{\partial w^{e}(t, P)}{\partial P}\right]$ and note that in the linear case: $E\left[\frac{\partial w^{e}(t, P)}{\partial P}\right]=\frac{\partial w^{e}(t, P)}{\partial P}$. Plugging this into equation (5) in the main text we get:

$$
\begin{aligned}
\frac{d E\left[w^{e}(t ; P)\right]}{d P} & =\delta+\left[\delta\left(\frac{d V_{t}^{u}}{d P} \rho\right)^{-1} \frac{\partial \phi_{t}}{\partial t}+\frac{\partial w^{e}(t ; P)}{\partial \mu_{t}} \frac{\partial \mu_{t}}{\partial t}\right] \frac{d D}{d P} \\
& =\delta+\left[\delta \frac{\frac{d V_{t}^{u}}{d t}}{\frac{d V_{t}^{u}}{d P}}+\frac{\partial w^{e}(t ; P)}{\partial \mu_{t}} \frac{\partial \mu_{t}}{\partial t}\right] \frac{d D}{d P}
\end{aligned}
$$

where we use that the change in the reservation wage from one period to the next is proportional to the change in the value of unemployment: $\frac{\partial \phi_{t}}{\partial t}=\frac{d V_{t}^{u}}{d t} \rho$. Some rearranging yields the slope of the wage offer distribution as a function of the IV estimator from above plus a term that depends on $\delta$ and the ratio of the change in the value of unemployment over time, relative to the change in the value of unemployment when potential UI benefits are extended by one month:

$$
\frac{\partial w^{e}(t ; P)}{\partial \mu_{t}} \frac{\partial \mu_{t}}{\partial t}=\frac{\frac{d E\left[w^{e}(t ; P)\right]}{d P}}{\frac{d D}{d P}}-\delta\left[\frac{1}{\frac{d D}{d P}}+\frac{\frac{d V_{t}^{u}}{d t}}{\frac{d V_{t}^{u}}{d P}}\right]
$$

\section{Empirical Implementation}

\subsection{Upward Bias in Wage Regression}

Consider first the case in which the effect of potential UI durations on wages is the same at all nonemployment durations, and which the effect of nonemployment durations on wages is linear. 
We are interested in an estimate of the coefficient $\delta$ in the linear model

$$
w_{i}^{*}=\alpha+\delta P_{i}+\theta t_{i}+u_{i}
$$

where $w=$ wage, $P=$ potential UI durations, $t=$ actual nonemployment durations. This is a linear version of equation (9) in the main text, where we have dropped the low-order polynomial in age for simplicity. Instead, we assume directly that we have that $\operatorname{cov}(P, u)=0$ and $E[u]=0$. Moreover, we know that $\operatorname{cov}(P, t) \neq 0$ and suspect that $\operatorname{cov}(t, u) \neq 0$. In matrix notation, the OLS coefficient for $\delta$ from the short regression is

$$
\hat{\delta}=\frac{P^{\prime} M_{t} w}{P^{\prime} M_{t} P}=\frac{\left(M_{t} P\right)^{\prime} M_{t} w}{P^{\prime} M_{t} P}
$$

where $M_{x} \equiv 1-P_{x}=1-x\left(x^{\prime} x\right)^{-1} x^{\prime}$ is the orthogonal projector onto the space orthogonal to $x$, and $P_{x}$ is the orthogonal projector onto the space of $x$.

The numerator of the expression for the OLS estimator for $\delta$ is what is important. Since we have $M_{t} w=\delta M_{t} P+M_{t} u$, we have that

$$
\left(M_{t} P\right)^{\prime} M_{t} w=\delta P^{\prime} M_{t} P+P^{\prime} M_{t} u
$$

where the omitted variable bias term can be rewritten as $P^{\prime} M_{t} u=P^{\prime} u-P^{\prime} P_{t} u=-P^{\prime} P_{t} u=-\left(P_{t} P\right)^{\prime} P_{t} u$, where we used the fact that $\operatorname{cov}(P, u)=E[P u] \approx P^{\prime} u / N=0$ given that $E[u]=0$. As a result we get

$$
\hat{\delta}=\frac{P^{\prime} M_{t} w}{P^{\prime} M_{t} P}=\delta+\frac{-P^{\prime} P_{t} u}{P^{\prime} M_{t} P}
$$

Since $P$ is uncorrelated with $u$, the second term in this expression can only be zero if there is no endogeneity, i.e., if $\operatorname{cov}(u, t)=0$. (This is the intution behind the test for endogeneity by Davidson and McKinnon, which tests the null hypothesis that the coefficient on the instrument when directly included in the 'structural' regression is zero, where $\delta$ would be equal to zero in a standard IV setting). This implies that if nonemployment durations are endogenous, we cannot directly estimate the average shift of the reemployment wage path from our data.

However, it turns out that with reasonable assumptions we can bound the true $\delta$. To see this, note that $P^{\prime} P_{t} u=\left(P^{\prime} t\right)\left(t^{\prime} t\right)^{-1}\left(t^{\prime} u\right)$. The first product is simply the sum of nonemployment durations for those above the age cutoff, and hence strictly greater zero. The middle term is also strictly greater zero. In contrast, we have that $\operatorname{cov}(u, t)=E(u t)=t^{\prime} u / N$. Hence, under the reasonable assumption that $t^{\prime} u \leq 0$, i.e., on average workers with lower earnings potential have longer nonemployment spells, we obtain that that $\hat{\delta}$ is an upper bound for the true $\delta$. Since from the theory, we expect that $\delta \geq 0$, a finding that $\hat{\delta} \approx 0$ implies that both $\delta \approx 0$ and $P^{\prime} P_{t} u \approx 0$. 
Table 1: Smoothness of Predetermined Variables around Age Thresholds

\begin{tabular}{|c|c|c|c|c|c|c|c|c|}
\hline & $\begin{array}{c}(1) \\
\text { Years of } \\
\text { Education }\end{array}$ & $\begin{array}{l}(2) \\
\text { Female }\end{array}$ & $\begin{array}{l}(3) \\
\text { Foreign } \\
\text { Citizen }\end{array}$ & $\begin{array}{c}(4) \\
\text { Tenure } \\
\text { Last Job }\end{array}$ & $\begin{array}{c}(5) \\
\text { Experience } \\
\text { Last Job }\end{array}$ & $\begin{array}{c}(6) \\
\text { Pre } \\
\text { Wage }\end{array}$ & $\begin{array}{c}\text { (7) } \\
\text { UR at start } \\
\text { of unemp }\end{array}$ & $\begin{array}{c}(8) \\
\text { County UR at } \\
\text { start of unemp }\end{array}$ \\
\hline \multicolumn{9}{|c|}{ Increase in Potential UI Dur. from 12 to 18 Months } \\
\hline D(Age above Cutoff) & $\begin{array}{c}0.030 \\
{[0.014]^{*}}\end{array}$ & $\begin{array}{c}0.0086 \\
{[0.0028]^{* *}}\end{array}$ & $\begin{array}{c}0.0038 \\
{[0.0020]}\end{array}$ & $\begin{array}{c}0.044 \\
{[0.028]}\end{array}$ & $\begin{array}{c}-0.046 \\
{[0.031]}\end{array}$ & $\begin{array}{c}0.12 \\
{[0.18]}\end{array}$ & $\begin{array}{c}0.0016 \\
{[0.0087]}\end{array}$ & $\begin{array}{c}0.035 \\
{[0.025]}\end{array}$ \\
\hline Effect relative to mean & 0.0027 & 0.024 & 0.037 & 0.0082 & -0.0041 & 0.0017 & 0.00017 & 0.0033 \\
\hline Observations & 510955 & 510955 & 510955 & 510955 & 510955 & 480724 & 510955 & 441907 \\
\hline Mean of Dep. Var. & 11.0 & 0.36 & 0.10 & 5.35 & 11.1 & 70.8 & 9.29 & 10.4 \\
\hline \multicolumn{9}{|c|}{ Pooling both Thresholds ( 12 to 18 Months and 18 to 22 Months) } \\
\hline D(Age above Cutoff) & $\begin{array}{c}0.015 \\
{[0.0094]}\end{array}$ & $\begin{array}{c}0.0054 \\
{[0.0020]^{* *}}\end{array}$ & $\begin{array}{c}0.0017 \\
{[0.0017]}\end{array}$ & $\begin{array}{c}0.041 \\
{[0.023]}\end{array}$ & $\begin{array}{c}-0.034 \\
{[0.024]}\end{array}$ & $\begin{array}{c}0.12 \\
{[0.13]}\end{array}$ & $\begin{array}{c}-0.0095 \\
{[0.0066]}\end{array}$ & $\begin{array}{c}0.017 \\
{[0.019]}\end{array}$ \\
\hline Effect relative to mean & 0.0014 & 0.015 & 0.016 & 0.0072 & -0.0030 & 0.0016 & -0.0010 & 0.0016 \\
\hline Observations & 947068 & 947068 & 947068 & 947068 & 947068 & 888293 & 947068 & 829669 \\
\hline Mean of Dep. Var. & 10.9 & 0.36 & 0.11 & 5.69 & 11.6 & 71.6 & 9.31 & 10.4 \\
\hline
\end{tabular}

Notes: Standard errors clustered on day relative to cutoff level $(* \mathrm{P}<.05$, ** $\mathrm{P}<.01))$.

The sample are individuals who started receiving unemployment insurance between 1987 and 1999 within 2 years from the age thresholds. Each coefficient is from a separate regression discontinuity model with the dependent variable given in the column heading. The first panel shows the increase at the discontinuity at the age 42 threshold (where potential UI durations increase from 12 to 18 months). The second panel shows the increase at the age 44 threshold (where potential UI durations increase from 18 to 22 months). The third panel pools both thresholds. The models control for linear splines in age with different slopes on each side of the cutoff. 
Table 2: The Effect of Potential UI Durations on Non-employment Durations and Wages by Sub-groups

\begin{tabular}{|c|c|c|c|c|}
\hline & $\begin{array}{c}\text { (1) } \\
\text { UI Ben. } \\
\text { Duration }\end{array}$ & $\begin{array}{c}\text { (2) } \\
\text { Non-Emp } \\
\text { Duration }\end{array}$ & $\begin{array}{c}\text { (3) } \\
\text { Log Post } \\
\text { Wage }\end{array}$ & $\begin{array}{c}\text { (4) } \\
\text { Log Wage } \\
\text { Difference }\end{array}$ \\
\hline \multicolumn{5}{|l|}{ Men Only } \\
\hline$\frac{d y}{d P}$ & $\begin{array}{c}0.22 \\
{[0.0068]^{* *}}\end{array}$ & $\begin{array}{c}0.097 \\
{[0.014]^{* *}}\end{array}$ & $\begin{array}{c}-0.00084 \\
{[0.00048]}\end{array}$ & $\begin{array}{c}-0.00094 \\
{[0.00048]^{*}}\end{array}$ \\
\hline Effect relative to mean & 0.15 & 0.036 & -0.0010 & 0.037 \\
\hline Observations & 602852 & 602852 & 517473 & 498508 \\
\hline Mean of Dep. Var. & 7.40 & 13.7 & 4.15 & -0.13 \\
\hline \multicolumn{5}{|l|}{ Women Only } \\
\hline$\frac{d y}{d P}$ & $\begin{array}{c}0.40 \\
{[0.010]^{* *}}\end{array}$ & $\begin{array}{c}0.19 \\
{[0.020]^{* *}}\end{array}$ & $\begin{array}{c}-0.00048 \\
{[0.00078]}\end{array}$ & $\begin{array}{c}-0.0013 \\
{[0.00084]}\end{array}$ \\
\hline Effect relative to mean & 0.20 & 0.053 & -0.00062 & 0.036 \\
\hline Observations & 344216 & 344216 & 280279 & 268653 \\
\hline Mean of Dep. Var. & 9.94 & 17.9 & 3.78 & -0.18 \\
\hline \multicolumn{5}{|c|}{ Education: Abitur (University qual. exam) or higher } \\
\hline$\frac{d y}{d P}$ & $\begin{array}{c}0.24 \\
{[0.014]^{* *}}\end{array}$ & $\begin{array}{c}0.077 \\
{[0.028]^{* *}}\end{array}$ & $\begin{array}{c}-0.0013 \\
{[0.0011]}\end{array}$ & $\begin{array}{l}-0.00076 \\
{[0.0010]}\end{array}$ \\
\hline Effect relative to mean & 0.15 & 0.024 & -0.0015 & 0.023 \\
\hline Observations & 157595 & 157595 & 136822 & 134099 \\
\hline Mean of Dep. Var. & 8.29 & 16.1 & 4.26 & -0.16 \\
\hline \multicolumn{5}{|c|}{ Education: Less than Abitur (University qual. exam) } \\
\hline$\frac{d y}{d P}$ & $\begin{array}{c}0.30 \\
{[0.0064]^{* *}}\end{array}$ & $\begin{array}{c}0.15 \\
{[0.013]^{* *}}\end{array}$ & $\begin{array}{c}-0.0012 \\
{[0.00044]^{* *}}\end{array}$ & $\begin{array}{c}-0.0012 \\
{[0.00047]^{*}}\end{array}$ \\
\hline Effect relative to mean & 0.18 & 0.049 & -0.0015 & 0.040 \\
\hline Observations & 789473 & 789473 & 660930 & 633062 \\
\hline Mean of Dep. Var. & 8.33 & 15.1 & 3.97 & -0.14 \\
\hline
\end{tabular}

Notes: Coefficients from RD regressions. Local linear regressions (different slopes) on each side of cutoff. Standard errors clustered on day level $(* \mathrm{P}<.05$, ** $\mathrm{P}<.01)$ ). 
Table 3: Slope of Mean Wage Offers as Function of $\frac{d V u / d t}{d V u / d P}$ and the effect of UI extensions conditional on duration of nonemployment $d E[w \mid t] / d P$

\begin{tabular}{lccccccccc}
\hline & \multicolumn{7}{c}{$\frac{d V u / d t}{d V u / d P}$} \\
$\delta=E[d E[w \mid t] / d P]$ in percent & -1 & -2 & -3 & -4 & -5 & -6 & -7 & -8 & -9 \\
\hline 0 & -0.008 & -0.008 & -0.008 & -0.008 & -0.008 & -0.008 & -0.008 & -0.008 & -0.008 \\
0.095 & -0.014 & -0.013 & -0.012 & -0.011 & -0.010 & -0.009 & -0.008 & -0.007 & -0.006 \\
0.1 & -0.014 & -0.013 & -0.012 & -0.011 & -0.010 & -0.009 & -0.008 & -0.007 & -0.006 \\
0.2 & -0.020 & -0.018 & -0.016 & -0.014 & -0.012 & -0.010 & -0.008 & -0.006 & -0.004 \\
0.3 & -0.026 & -0.023 & -0.020 & -0.017 & -0.014 & -0.011 & -0.008 & -0.005 & -0.002 \\
0.4 & -0.032 & -0.028 & -0.024 & -0.020 & -0.016 & -0.012 & -0.008 & -0.004 & 0.000 \\
0.5 & -0.039 & -0.034 & -0.029 & -0.024 & -0.019 & -0.014 & -0.009 & -0.004 & 0.001 \\
0.6 & -0.045 & -0.039 & -0.033 & -0.027 & -0.021 & -0.015 & -0.009 & -0.003 & 0.003 \\
0.7 & -0.051 & -0.044 & -0.037 & -0.030 & -0.023 & -0.016 & -0.009 & -0.002 & 0.005 \\
0.8 & -0.057 & -0.049 & -0.041 & -0.033 & -0.025 & -0.017 & -0.009 & -0.001 & 0.007 \\
0.9 & -0.063 & -0.054 & -0.045 & -0.036 & -0.027 & -0.018 & -0.009 & 0.000 & 0.009 \\
1.0 & -0.069 & -0.059 & -0.049 & -0.039 & -0.029 & -0.019 & -0.009 & 0.001 & 0.011 \\
\hline
\end{tabular}

Notes: The table shows the implied slope of the mean wage offer distribution if the effect of potential UI durations on reemployment wages conditional on nonemployment durations is not equal to zero $d E[w \mid t] / d P$. Rows show the implied slope for different values of $d E[w \mid t] / d P$ and columns for different values of $\frac{d V u / d t}{d V u / d P}$. The preferred point Estimate for $d E[w \mid t] / d P$ is $0.015 \%$ (from last column and bottom panel of Table 10).

The upper bound of the $95 \%$ confidence interval for $d E[w \mid t] / d P$ is $0.095 \%$. 
Table 4: The Effect of UI Extensions by Different States of the Business Cycle

\begin{tabular}{|c|c|c|c|c|c|c|}
\hline & \multicolumn{3}{|c|}{ Unemployment Rate Decreasing } & \multicolumn{3}{|c|}{ Unemployment Rate Increasing } \\
\hline & Non-Emp & Log Post & Log Wage & Non-Emp & Log Post & Log Wage \\
\hline & Duration & Wage & Difference & Duration & Wage & Difference \\
\hline \multirow{2}{*}{\multicolumn{7}{|c|}{$\begin{array}{l}\text { Increase in Potential UI } \\
\text { Dur. from } 12 \text { to } 18 \text { Months }\end{array}$}} \\
\hline & & & & & & \\
\hline \multirow{2}{*}{ D(Age above Cutoff) } & 0.97 & -0.0072 & -0.0017 & 0.90 & -0.0081 & -0.0092 \\
\hline & {$[0.22]^{* *}$} & {$[0.0049]$} & {$[0.0046]$} & {$[0.17]^{* *}$} & {$[0.0037]^{*}$} & {$[0.0036]^{*}$} \\
\hline \multirow{2}{*}{$\frac{d y}{d P}$} & 0.16 & -0.0012 & -0.00028 & 0.15 & -0.0013 & -0.0015 \\
\hline & {$[0.037]^{* *}$} & {$[0.00082]$} & [0.00077] & {$[0.029]^{* *}$} & {$[0.00062]^{*}$} & {$[0.00061]^{*}$} \\
\hline Effect relative to mean & 0.071 & -0.0018 & 0.015 & 0.059 & -0.0020 & 0.059 \\
\hline Observations & 168936 & 168637 & 161534 & 268963 & 268545 & 258777 \\
\hline \multicolumn{7}{|l|}{ Pooling both Thresholds } \\
\hline \multirow[t]{2}{*}{ D(Age above Cutoff) } & 0.62 & -0.0041 & -0.0049 & 0.75 & -0.0056 & -0.0052 \\
\hline & {$[0.16]^{* *}$} & {$[0.0037]$} & {$[0.0035]$} & {$[0.13]^{* *}$} & {$[0.0026]^{*}$} & {$[0.0027]$} \\
\hline \multirow{2}{*}{$\frac{d y}{d P}$} & 0.12 & -0.00082 & -0.00097 & 0.15 & -0.0011 & -0.0010 \\
\hline & {$[0.032]^{* *}$} & {$[0.00073]$} & [0.00069] & {$[0.026]^{* *}$} & {$[0.00053]^{*}$} & {$[0.00055]$} \\
\hline Effect relative to mean & 0.045 & -0.0010 & 0.040 & 0.049 & -0.0014 & 0.032 \\
\hline Observations & 302786 & 302225 & 289473 & 496319 & 495527 & 477688 \\
\hline
\end{tabular}

Notes: Coefficients from RD regressions. Local linear regressions (different slopes) on each side of cutoff. Standard errors clustered on day level $(* \mathrm{P}<.05$, ** $\mathrm{P}<.01))$. 
Table 5: Investigating Different Channels of Wage Losses

\begin{tabular}{|c|c|c|c|c|c|c|}
\hline & $\begin{array}{c}(1) \\
\text { Log Wage } \\
\text { Baseline }\end{array}$ & $\begin{array}{c}(2) \\
\text { Log Wage } \\
\text { Ctrls Obs }\end{array}$ & $\begin{array}{c}(3) \\
\text { Log Wage } \\
\text { Ctrls Obs }\end{array}$ & $\begin{array}{c}(4) \\
\text { Log Wage } \\
\text { Ctrls Obs }\end{array}$ & $\begin{array}{c}(5) \\
\text { Log Wage } \\
\text { Ctrls Obs }\end{array}$ & $\begin{array}{c}(6) \\
\text { Log Wage } \\
\text { Ctrls Obs }\end{array}$ \\
\hline \multicolumn{7}{|c|}{ Increase in Potential UI Dur. from 12 to 18 Months } \\
\hline $\mathrm{D}$ (Age above Cutoff) & $\begin{array}{c}-0.0066 \\
{[0.0029]^{*}}\end{array}$ & -0.0060 & $\begin{array}{c}-0.0074 \\
{[0.0030] *}\end{array}$ & -0.0083 & -0.0057 & -0.0046 \\
\hline Switch 3 digit Industry after UE & -0.082 & -0.035 & & & & \\
\hline Switch Occupation after UE & {$[0.0015]^{* *}$} & $\begin{array}{c}{[0.0018]^{* *}} \\
-0.091 \\
{[0.0017]^{* *}}\end{array}$ & & & & \\
\hline UR at start of unemployment spell & & & $\begin{array}{c}-0.015 \\
{[0.00077]^{* *}}\end{array}$ & & & \\
\hline UR at end of unemployment spell & & & {$[0.00081]^{-0.0066}$} & & & \\
\hline Log Establishment Size of Post-UE Job & & & & $\begin{array}{c}0.036 \\
{[0.00043]^{* *}}\end{array}$ & & \\
\hline Post UE Spell: Fulltime Emp & & & & & $\begin{array}{c}0.61 \\
{[0.0024]^{* *}}\end{array}$ & \\
\hline Tenure at next job after UE & & & & & & $\begin{array}{c}0.012 \\
{[0.00012]^{* *}}\end{array}$ \\
\hline$\frac{d y}{d P}$ & -0.0011 & -0.0010 & -0.0012 & -0.0014 & -0.00061 & -0.00053 \\
\hline & {$[0.00049]^{*}$} & {$[0.00049]^{*}$} & {$[0.00049]^{*}$} & {$[0.00049]^{* *}$} & {$[0.00044]$} & {$[0.00044]$} \\
\hline Observations & 437182 & 437182 & 437182 & 437182 & 437182 & 437182 \\
\hline Mean of Dep. Var. & 4.01 & 4.01 & 4.01 & 4.01 & 4.01 & 4.01 \\
\hline \multicolumn{7}{|c|}{ Pooling both Thresholds ( 12 to 18 Months and 18 to 22 Months) } \\
\hline $\mathrm{D}$ (Age above Cutoff) & $\begin{array}{l}-0.0039 \\
{[0.0021]}\end{array}$ & $\begin{array}{l}-0.0034 \\
{[0.0021]}\end{array}$ & $\begin{array}{c}-0.0050 \\
{[0.0021]^{*}}\end{array}$ & $\begin{array}{c}-0.0051 \\
{[0.0021] *}\end{array}$ & -0.0044 & $\begin{array}{l}-0.0028 \\
{[0.0019]}\end{array}$ \\
\hline Switch 3 digit Industry after UE & -0.085 & -0.037 & & & & \\
\hline Switch Occupation after UE & {$[0.0012]^{* *}$} & $\begin{array}{c}-0.093 \\
{[0.0012]^{* *}}\end{array}$ & & & & \\
\hline UR at start of spell & & & $\begin{array}{c}-0.018 \\
{[0.00059]^{* *}}\end{array}$ & & & \\
\hline UR at end of unemployment spell & & & $\begin{array}{c}-0.0028 \\
{[0.00062]^{* *}}\end{array}$ & & & \\
\hline Log Establishment Size of Post-UE Job & & & & $\begin{array}{c}0.035 \\
{[0.00032]^{* *}}\end{array}$ & & \\
\hline Post UE Spell: Fulltime Emp & & & & & $\begin{array}{c}0.62 \\
{[0.0018]^{* *}}\end{array}$ & \\
\hline Tenure at next job after UE & & & & & & $\begin{array}{c}0.012 \\
{[0.000089]^{* *}}\end{array}$ \\
\hline$\frac{d y}{d P}$ & -0.00079 & -0.00069 & -0.0010 & -0.0010 & -0.00047 & -0.00037 \\
\hline & {$[0.00042]$} & [0.00042] & {$[0.00042]^{*}$} & {$[0.00042]^{*}$} & {$[0.00038]$} & {$[0.00038]$} \\
\hline Mean of Dep. Var. & $\begin{array}{l}197152 \\
4.02\end{array}$ & $\begin{array}{l}191 / 52 \\
402\end{array}$ & $\begin{array}{l}191 / 52 \\
402\end{array}$ & $\begin{array}{l}191 / 52 \\
402\end{array}$ & $191 / 52$ & $19 / 752$ \\
\hline
\end{tabular}


Figure 1: The Effects of Extended Potential UI Durations on Selection throughout the Spell of Non-employment

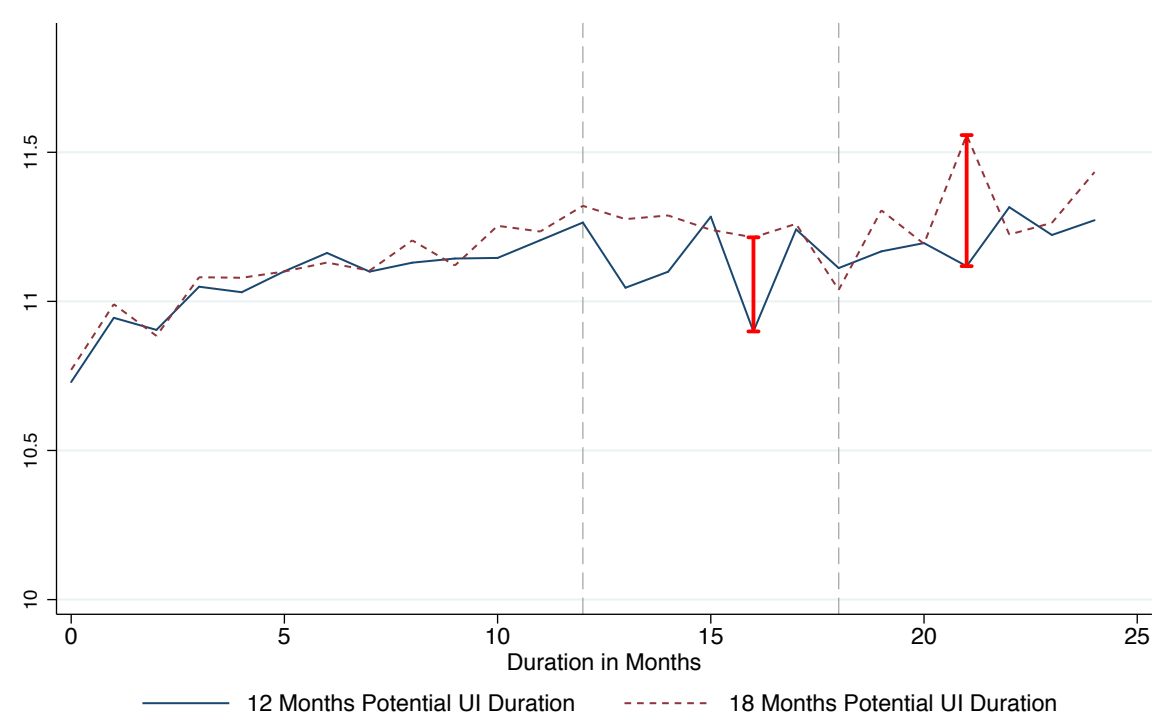

(a) Years of Schooling

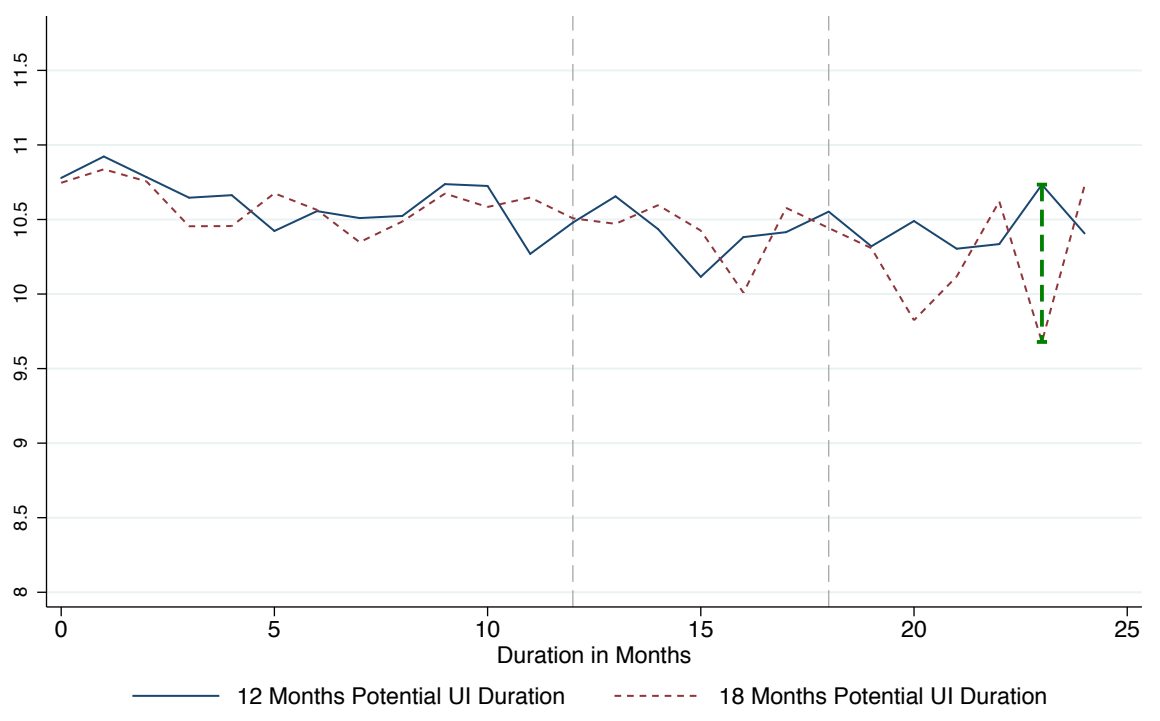

(b) Pre-unemployment Experience

Notes: The difference between the lines is estimated pointwise at each point of support using regression discontinuity estimation. Vertical bars indicate that the differences are statistically significant from each other at the five percent level. The sample are unemployed worker claiming UI between July 1987 and March 1999 who had worked for at least 36 months in the last 7 years without intermittent UI spell. For details see text. 
Figure 2: The Effects of Extended Potential UI Durations on Selection throughout the Spell of Non-employment

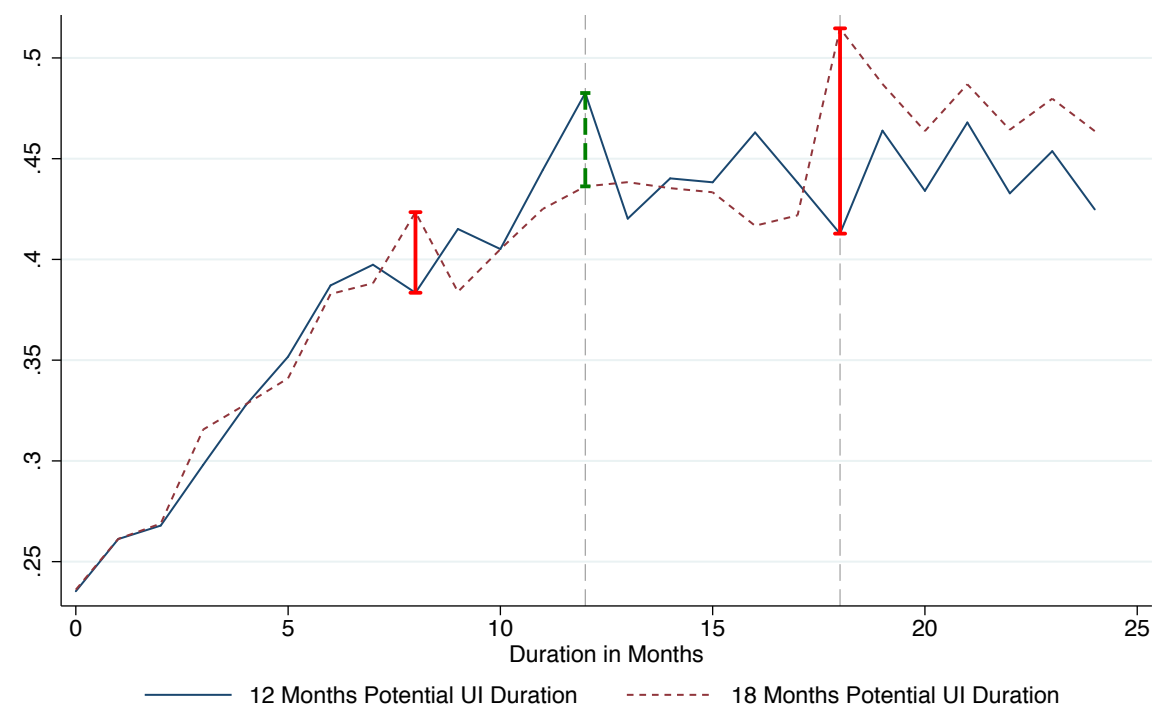

(a) Female

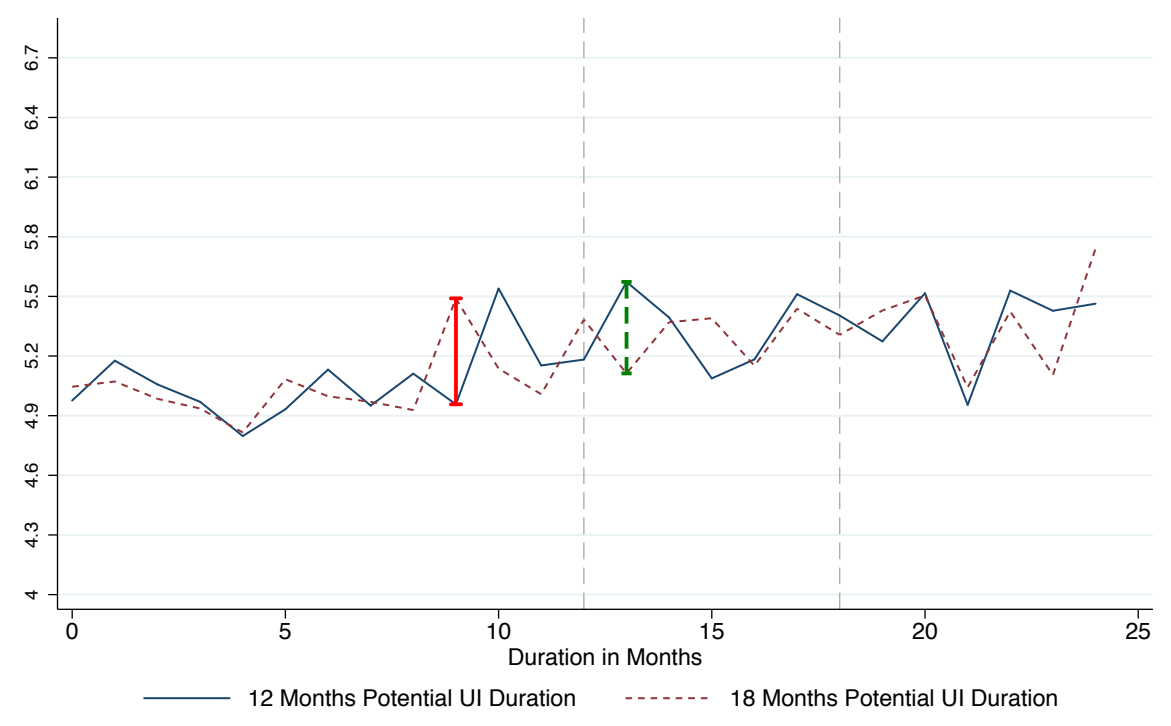

(b) Pre-unemployment Tenure

Notes: The difference between the lines is estimated pointwise at each point of support using regression discontinuity estimation. Vertical bars indicate that the differences are statistically significant from each other at the five percent level. The sample are unemployed worker claiming UI between July 1987 and March 1999 who had worked for at least 36 months in the last 7 years without intermittent UI spell. For details see text. 
Figure 3: Quantile Regressions of the Effects of Extended Potential UI Durations on Reemployment Wages throughout the Spell of Non-employment

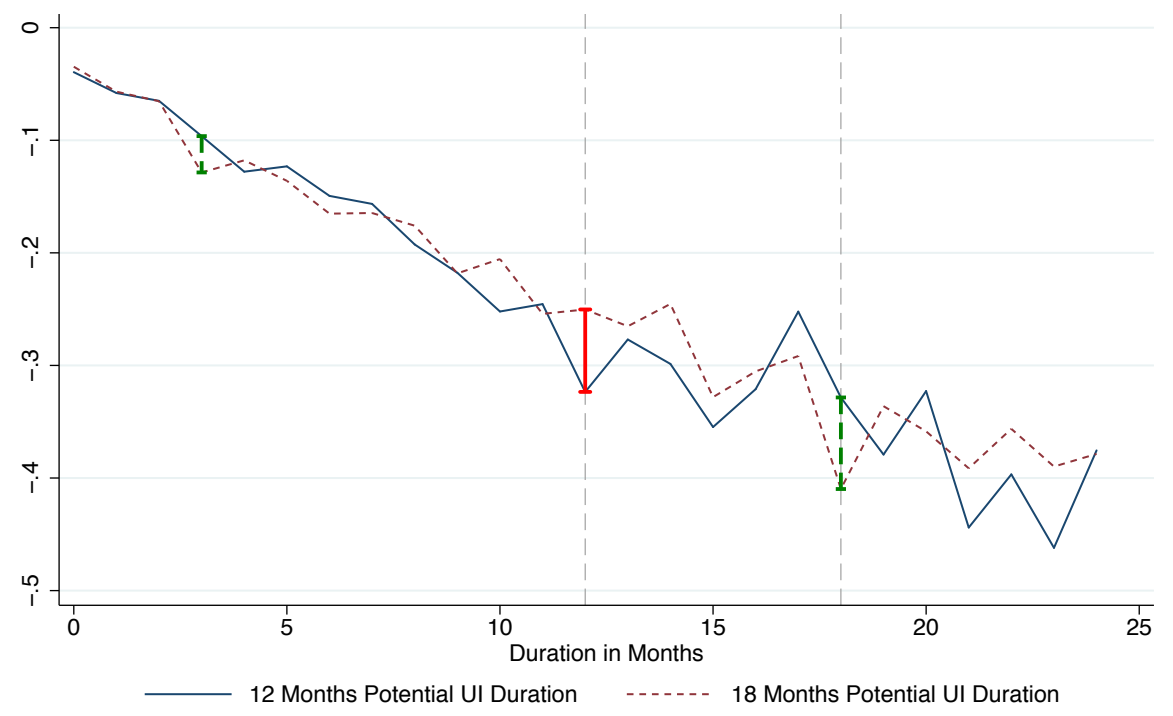

(a) Log wage difference (post - pre unemployment)

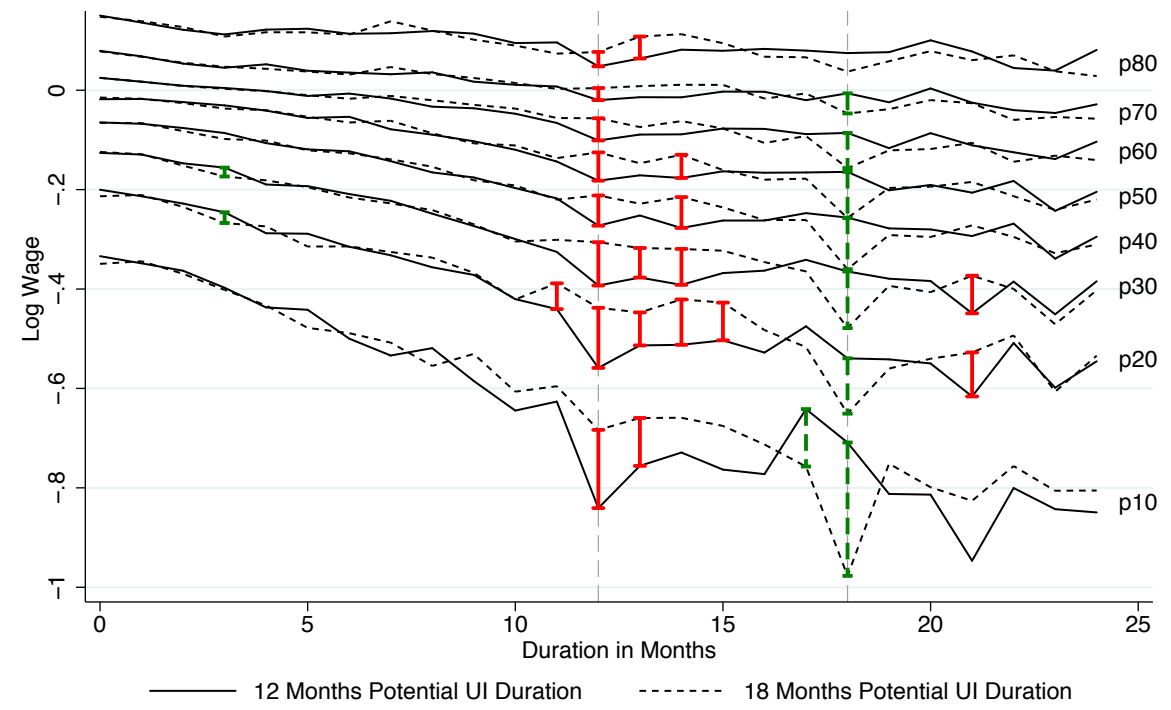

(b) Log wage difference (post - pre unemployment)

Notes: The difference between the lines is estimated point wise at each point of support using regression discontinuity estimation. Vertical bars indicate that the differences are statistically significant from each other at the five percent level. The sample are unemployed worker claiming UI between July 1987 and March 1999 who had worked for at least 36 months in the last 7 years without intermittent UI spell. The labels on the right indicate the percentiles at which the differences are estimated. For details see text. 